University of Louisville

ThinkIR: The University of Louisville's Institutional Repository

Electronic Theses and Dissertations

8-2007

\title{
A theory-based intervention to increase dental utilization by disadvantaged children.
}

Catherine J. Binkley

University of Louisville

Follow this and additional works at: https://ir.library.louisville.edu/etd

\section{Recommended Citation}

Binkley, Catherine J., "A theory-based intervention to increase dental utilization by disadvantaged children." (2007). Electronic Theses and Dissertations. Paper 111.

https://doi.org/10.18297/etd/111

This Doctoral Dissertation is brought to you for free and open access by ThinkIR: The University of Louisville's Institutional Repository. It has been accepted for inclusion in Electronic Theses and Dissertations by an authorized administrator of ThinkIR: The University of Louisville's Institutional Repository. This title appears here courtesy of the author, who has retained all other copyrights. For more information, please contact thinkir@louisville.edu. 


\title{
A THEORY-BASED INTERVENTION TO INCREASE DENTAL UTILIZATION BY DISADVANTAGED CHILDREN
}

\author{
By \\ Catherine J. Binkley \\ D.D.S., University of Maryland, 1980 \\ M.S.P.H., University of Louisville, 2001
}

\begin{abstract}
A Dissertation
Submitted to the Faculty of the

Graduate School of the University of Louisville

In Partial Fulfillment of the Requirements

for the Degree of
\end{abstract}

Doctor of Philosophy

Department of Epidemiology \& Population Health

University of Louisville

Louisville, Kentucky

August 2007 
Copyright 2007 by Catherine J. Binkley

All rights reserved. 
A Theory Based Intervention to Increase Dental Utilization by Disadvantaged Children

\section{By}

Catherine J. Binkley

D.D.S., University of Maryland, 1980

M.S.P.H., University of Louisville, 2001

A Dissertation Approved on

May 31, 2007

By the following Dissertation Committee:

$\overline{\text { Stephen W. Looney, PhD, Dissertation Director }}$

Kathy B. Baumgartner, Ph.D.

Knowlton W. Johnson, Ph.D.

Susan E. Kelly, Ph.D.

Susan B. Muldoon, Ph.D. 


\section{ACKNOWLEDGMENTS}

My foremost thanks are given to my principal advisor, Dr. Stephen Looney. Without him, this dissertation would still be a work in progress. I thank him for his time, encouragement, and patience that carried me through the process. I would also like to thank my mentors and friends, Drs. Knowlton Johnson, and Susan Kelly, for their guidance and patience over the past several years. I would also like to thank the other committee members, Drs. Kathy Baumgartner and Susan Muldoon, for their comments and advice in the preparation of this dissertation. I would also like to thank Dr. Brent Garrett for his advice and encouragement throughout this endeavor.

I wish to express my gratitude to the individuals at Pacific Institute for Research and Evaluation. The support of Chris Bayer, Terry Pan, Linda Young, and Jude Vanderhoff was invaluable. My deepest thanks are also given to all the staff at Passport Health Plan and Doral Dental who provided so much support for the study.

I also wish to express my deepest gratitude to Dr. Brian Alpert, my department chair and mentor, and Dr. John Williams, my former dean. Without their encouragement and support this dissertation would not have been possible.

This research was supported by the National Institute of Dental and Craniofacial Research with Grant R21 DE014967. 


\begin{abstract}
A THEORY-BASED INTERVENTION TO INCREASE DENTAL UTILIZATION BY DISADVANTAGED CHILDREN
\end{abstract}

Catherine J. Binkley

May 31, 2007

Oral disease is the greatest unmet healthcare need of disadvantaged children in the United States, with only $20 \%$ of disadvantaged Medicaid-eligible children receiving routine dental care. Peter Margolis proposed a theoretical model of access to healthcare services and reported the effectiveness of a case manager intervention in increasing medical care utilization by disadvantaged mothers and infants. This study was based on Margolis's theory and used a case manager to assist parents in obtaining dental care.

Methods: The study was based on secondary analyses of data from the "Parental Help Seeking for Dental Care" project. The randomized, controlled intervention study was conducted with 202 parents/caregivers of Medicaidinsured children in Louisville, Kentucky, from March 2004 to April 2005. The research questions were: 
1) What is the direct effect of the intervention on dental care utilization?

2) Do contextual factors moderate the intervention effects on utilization?

3) What is the effect of the intervention on barriers?

The primary dependent variable was dental care utilization and the primary independent variable was group assignment. Covariates included socioeconomic and psychosocial factors. Analyses were conducted using univariate, bivariate, and multivariate statistical techniques.

Results: One-fourth of the children enrolled were regular dental utilizers and the intervention did not have a direct effect on utilization for the entire sample of children. Subgroup analyses, however, indicated that younger children in the intervention group were three times more likely to visit the dentist than younger children in the control group. Additional subgroup analyses indicated that intervention families who did not routinely utilize dental care, who had a low family annual income, and/or who completed all study activities were almost three times more likely to see the dentist than similar families in the control group. The intervention did not have any obvious effect on perceived barriers.

Conclusions: The intervention was effective in increasing utilization only by younger children, those who had not previously received routine dental care, and those families in the lowest income brackets. Important information was gained from this study that could help develop effective interventions for disadvantaged families, thus reducing oral health disparities. 
TABLE OF CONTENTS

PAGE

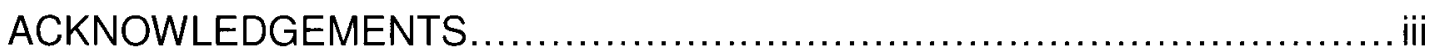

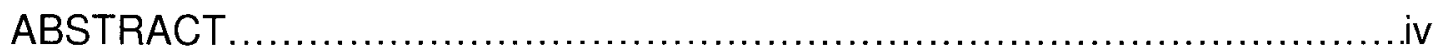

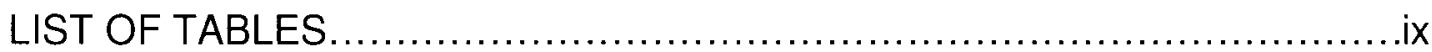

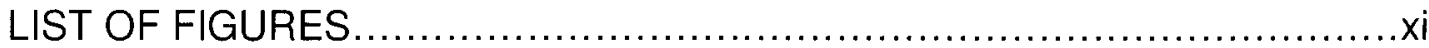

CHAPTER 1. INTRODUCTION

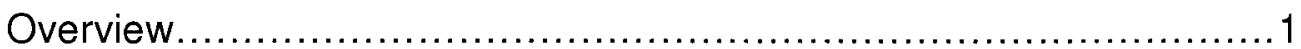

Disparities in Children's Oral Health.....................................

Consequences of Childhood Caries.................................... 5

Factors Associated with Low Dental Care Utilization......................6

Perceived Barriers to Dental Care Utilization...............................9

Interventions to Improve the General Health of Disadvantaged

Children

Interventions to Improve the Oral Health of Disadvantaged Children.....17

Potential Moderators of Intervention Effects............................. 18

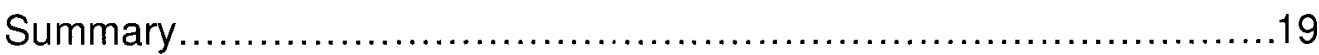

CHAPTER 2. THEORETICAL MODELS, CONCEPTUAL FRAMEWORK AND RESEARCH QUESTIONS

Parental Decision-Making Theories.....................................21

Theoretical-Based Intervention to Improve Preventive Medical Care.....25

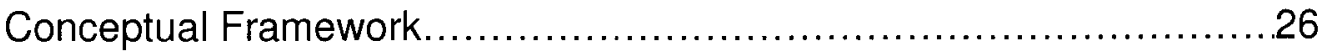

Study Research Questions...........................................28 
Summary.

CHAPTER 3. RESEARCH METHODS

Research Team Members.............................................30

Parental Help Seeking for Dental Care Research Design..................32

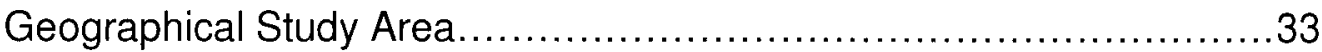

Parental Help Seeking for Dental Care Study Sample.....................33

Description of the Intervention....................................38

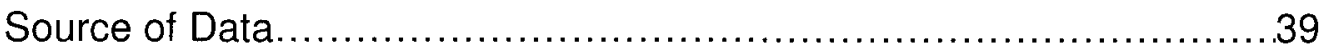

Study Variables............................................................ 40

Existing, Validated Measures/Scales Used in the Parental Help Seeking for Dental Care Study............................................. 45

New Scales Developed for the Parental Help Seeking for Dental Care Study.................................................................. 55

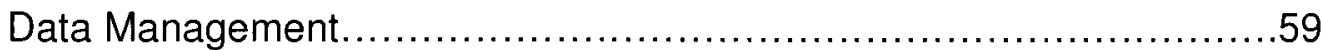

Results of Initial Parental Help Seeking for Dental Care Study Analyses.....................................................................60

Dissertation Study Analyses.......................................6 63

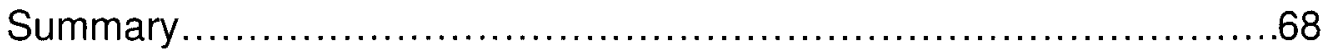

CHAPTER 4. RESULTS

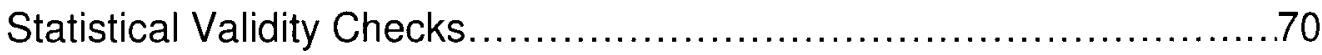

Profile of Utilizers and Non-Utilizers................................. 72

Group Comparison Tests - Utilizers vs. Non-Utilizers....................75

Attrition Analysis..................................................... 78

Research Question \#1 - Intent-to-Treat Analyses....................... 82 
Research Question \#1 - Completer Analyses

Research Question \#2 - Do contextual factors (individual and demographic) factors moderate the intervention effects on utilization?...90

Subgroup or Stratified Analysis for Potential Moderators of Entire Sample.

Subgroup or Stratified Analysis for Potential Moderators of Prior Non-Utilizers.

Research Question \#3 - What is the effect of the intervention on barriers? 94

Summary .95

\section{CHAPTER 5. DISCUSSION}

Summary of Findings of the Study Sample............................99

Research Question \#1 ..............................................102

Research Question \#2 ................................................104

Research Question \#3..................................................106

Limitations of the Study............................................... 108

Theoretical Implications.............................................. 117

Implications for Interventions to Improve Disadvantaged Children's Oral Health ...................................................................

Conclusions............................................................ 124

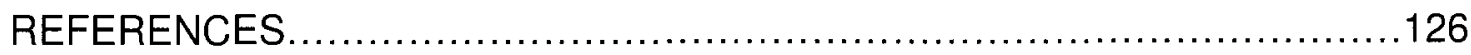

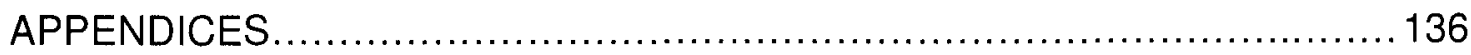

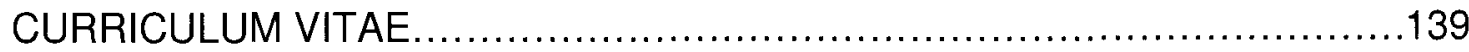




\section{LIST OF TABLES}

TABLE

PAGE

1. Baseline Subject Characteristics................................. 36

2. Summary of Study Variables........................................... 42

3. Oral Health Beliefs Scale................................................ 46

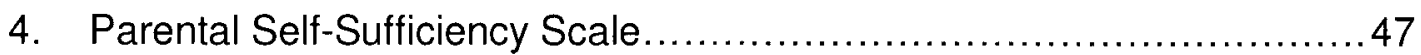

5. Child Fear Scale ........................................................... 49

6. Dental Satisfaction Questionnaire Scale ...............................50

7. Parental Dental Anxiety Scale .......................................52

8. Parental Social Support Scale ........................................ 53

9. Parental Perceived Stress Scale ..........................................54

10. Access to Dental Care Factor Analysis....................................56

11. Perceived Discrimination Factor Analysis..................................57

12. Pediatrician Role Factor Analysis.....................................58

13. Univariate Analysis of Skewness and Kurtosis for Baseline Survey

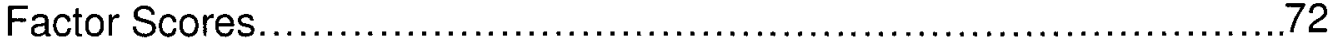

14. Bivariate Analyses of Utilizers and Non-Utilizers........................73

15. Baseline Scale Factor Scores for Utilizers and Non-Utilizers..............77

16. Bivariate Analyses of Completers and Droppers.........................78

17. Baseline Scale Factor Scores for Completers and Droppers..............81 
18. Logistic Regression Intent-To-Treat................................ 83

19. Logistic Regression of Potential Predictors of Utilization....................84

20. Logistic Regression Predictors of Utilization............................86

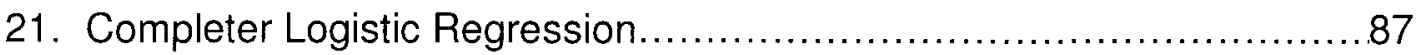

22. Univariate Regression of Intervention Completers with No Prior Utilization.................................................................... 87

23. Demographic and Individual Characteristics of Completer

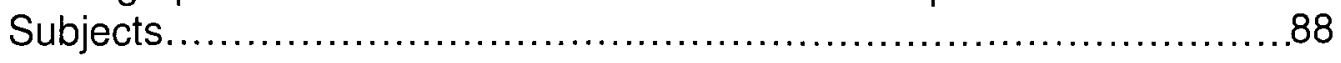

24. Regression Controlling for Covariate Completers with No Prior

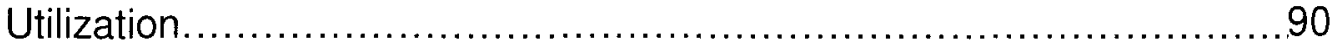

25. Potential Moderator Variables in Completers with No Prior Utilization.................................................................... 91

26. Logistic Regression of Entire Sample with Child Under Age 9 Years.......

27. Logistic Regression Prior Non-Utilizers with Income Less than $\$ 15,000$. 


\section{LIST OF FIGURES}

FIGURE

PAGE

1. Disparities in Carious Teeth by Socioeconomic Status.....................3

2. Pavuluri's Model of Levels and Filters for Service Utilization..............24

3. Margolis's Model of Access to Personal Healthcare Service...............25

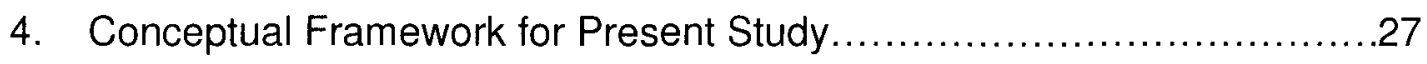

5. Subject Selection Process and Participation.............................35

6. Modification of Margolis's Model of Access to Service.....................119 


\section{CHAPTER 1}

\section{INTRODUCTION}

\section{Overview}

Oral disease is the most glaring health disparity among low-income children in the United States (Department of Health and Human Services (DHHS, 2000)). Children from poor families who qualify for Medicaid and those who come from low-income families without insurance are less likely to receive comprehensive dental care than children from middle and upper-income families (Mouradian et al., 2000). Medicaid is a federal and state supported program that provides free general dental care for eligible children in most states in the United States; however, only one in five Medicaid-insured children receive preventive dental care each year (National Institute for Dental \& Craniofacial Research (NIDCR, February 2002)).

Programs designed to provide dental care for children who are not eligible for Medicaid have reported similar patterns of under-utilization. The Colgate Kids program is a partnership between the University of Louisville and the ColgatePalmolive Corporation that provides free dental care and transportation to the dental clinic for uninsured children. Over the seven years of the program, only $50 \%$ of the parents of eligible children chose to take advantage of the program and consented to have their children receive dental care (Butters, 2000). 
The results from the Medicaid program and the Colgate Kids project suggest that there may be parental socioeconomic and psychosocial factors that significantly impact children's access to dental care. Despite national efforts to increase insurance coverage and dental providers, there may well continue to be a large disparity in oral health due to unaddressed barriers that parents may experience in obtaining dental care.

Determining the underlying factors in parental decision-making and developing effective interventions are essential to improving the oral health of our nation's disadvantaged children and reducing oral health disparities. This study was conducted to begin to fill the gap in knowledge about the effectiveness of a case manager intervention to reduce structural and personal barriers that parents may experience in obtaining dental care for their children. It was hoped that a case manager could provide the parents with education about oral health, and provide assistance and support in obtaining dental care (including scheduling appointments, transportation, appointment reminders, etc.), thus increasing dental care utilization among the disadvantaged children in the study.

\section{Disparities in Children's Oral Health}

Since the widespread implementation of water fluoridation in the United States (Banoczy \& Marthaler, 2004; Marthaler, 2004), it has been assumed that the oral health of our nation's children has improved. In the past 10 years, however, it has been demonstrated that dental care is the most prevalent unmet healthcare need among U.S. children (Edelstein \& Douglass, 1995). There are 
glaring disparities in children's oral health and access to dental services, especially among disadvantaged families (DHHS, 2000).

Poverty is a primary risk factor for oral health disparities. The Surgeon General's Report on Oral Health in America states that "individuals living below the poverty level experience more dental decay than those who are economically better off" (p. 63) and that the decay in these individuals is more likely to be untreated than decay in those living above the poverty level (DHHS, 2000). More than $33 \%$ of poor children aged 6 to 17 years in 1999 had untreated decay compared to only $13 \%$ of children the same age whose family income was $200 \%$ of the poverty level or greater (NCHS, 2004).

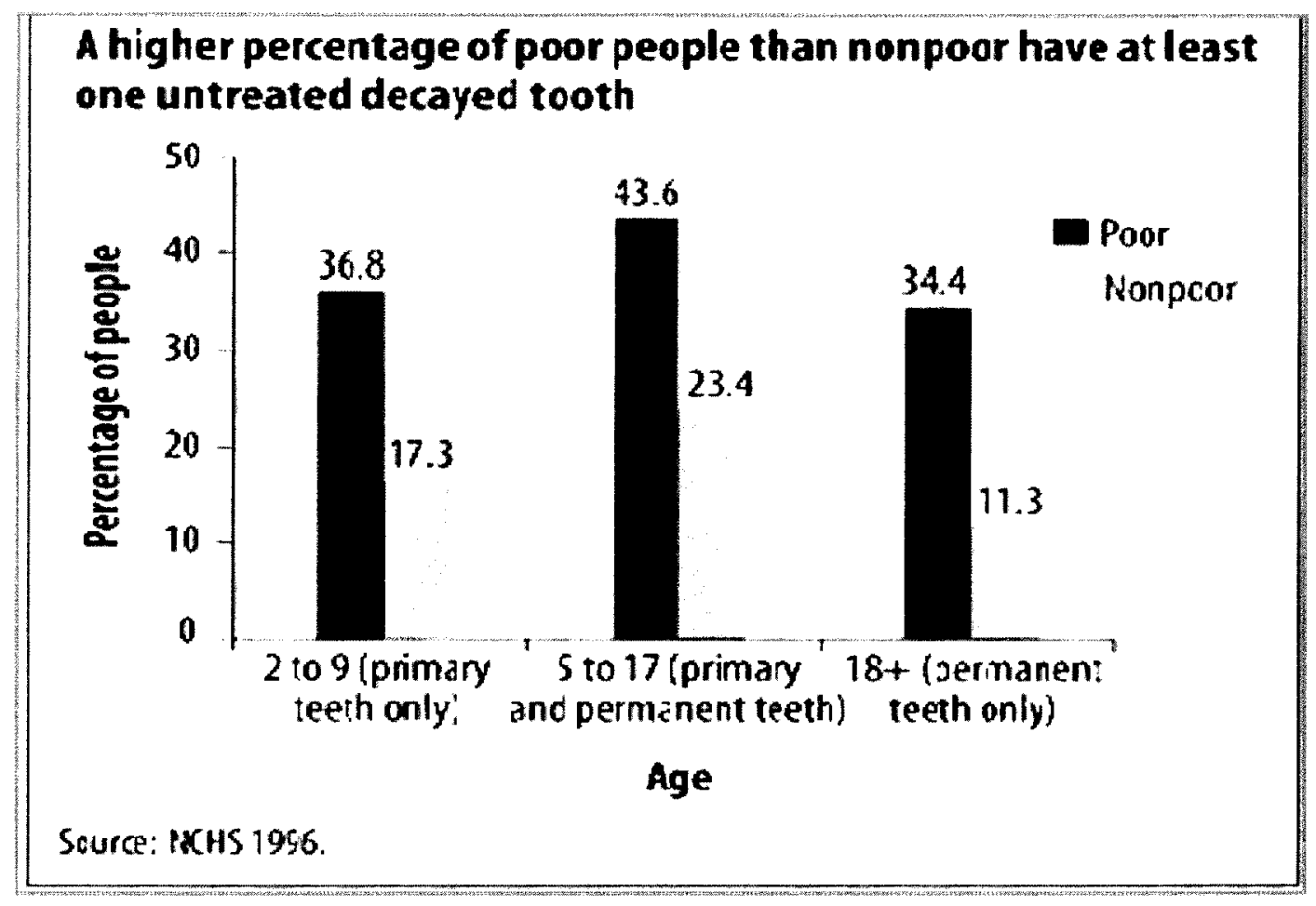

Figure 1. Disparities in Carious Teeth by Socioeconomic Status 
Race/ethnicity is also an important predictor of oral health disparities. National statistics on oral health are available from the annual National Health and Nutrition Examination Survey (NHANES) conducted by the Centers for Disease Control since 1999. NHANES provides estimates of the health status of the civilian, non-institutionalized population of the United States and includes a series of interviews, laboratory tests, and clinical examinations conducted in mobile examination clinics (MECs) by physicians and dentists.

In the 1999-2000 NHANES, untreated dental caries in children aged 6 to 17 years varied significantly by poverty status within race and Hispanic origin categories. Among non-Hispanic white children, $32 \%$ of the poor had untreated decay while only $16 \%$ of the non-poor had untreated dental caries. For African American children, $38 \%$ of the poor had untreated decay and $24 \%$ of near poor or non-poor had decay. Hispanic children had the highest percentage of untreated decay with $41 \%$ of the poor and $30 \%$ of the non-poor presenting untreated caries (NCHS, 2004).

Racial and ethnic oral health disparities were reaffirmed in the 2003 National Health Interview Survey. Hispanic children were almost twice as likely as non-Hispanic white children to have had no dental treatment for more than 2 years. Sixty-three percent of non-Hispanic white children were more likely to have had a dental visit in the past 6 months, compared with $48 \%$ of non-Hispanic black children and $47 \%$ of Hispanic children (Dey \& Bloom, 2005). 


\section{Consequences of Childhood Caries}

Early childhood caries (ECC) is defined as the presence of tooth decay in children with primary ("baby") teeth under the age of 71 months (Vargas \& Ronzio, 2006). Sequelae of ECC are primarily abscesses, pain, and systemic infections (Vargas et al., 2002). Children frequently endure dental pain due to ECC for weeks and it interferes with normal activities such as eating, sleeping, and playing (Edelstein et al., 2006; Vargas et al., 2002). When early childhood caries are not treated, the condition frequently progresses to the point that the child requires sedation or general anesthesia in the hospital with the concomitant increased cost $(\$ 2,000$ to $\$ 6,000)$ and risk (Tennant et al., 2000).

ECC frequently results in extraction of primary teeth that can affect the eruption of permanent teeth and ultimately causes malocclusion problems that require expensive orthodontic treatment. Children from low income homes are unlikely to receive orthodontic treatment and they are at a higher risk of having problems with their occlusion for the rest of their lives. Furthermore, ECC has been associated with caries in late childhood and poor oral health in adulthood (Thomson et al., 2004).

Decay that occurs in children's teeth after the age of 6 is also associated with further dental problems as the child becomes older (Haugejorden \& Birkeland, 2002; Litt et al., 1995). In addition, the presence of caries and subsequent poor oral health has a negative impact on growth and cognitive development because it interferes with eating, communication, and participation in school activities (Olivan, 2003; Thomas \& Primosch, 2002). Poor oral health 
in children can affect their self-esteem as a result of poor aesthetics, speech production owing to malocclusion, and social functioning (Mouradian, 2001).

The consequences of poor oral health in childhood frequently have major impacts on infants, children, and adults. ECC is the most powerful predictor of future experience with caries and poor oral health. Poor oral health at any age is a significant health burden but especially for disadvantaged children who already face difficulties in achieving parity with more privileged children in many areas of life (Vargas \& Ronzio, 2006).

Jonathan Kozol, a non-fiction writer, educator, and activist, best known for his books on public education in the United States, reported:

Bleeding gums, impacted teeth and rotting teeth are routine matters for children I have interviewed in the South Bronx. Children get used to feeling constant pain. They go to sleep with it. They go to school with it... Children live for months with pain that grown-ups would find unendurable. (Kozol, 1991), pp. 20-21)

Poor oral health is a significant problem for disadvantaged children but unless we can determine interventions that will affect parents' decisions to take their children to the dentist, there will continue to be low dental care utilization and oral health disparities.

\section{Factors Associated with Low Dental Care Utilization}

Perceived need for dental care has been found to be a strong predictor of dental care utilization in an explanatory model among disadvantaged families (Milgrom et al., 1998). Caregivers who believed in the efficacy of dental care and 
who were satisfied with their own oral health were more likely to utilize dental care for their children. Lower rates of dental utilization were associated with child dental fear and absences from school for family problems.

Parenting stress was found to be strongly associated with early childhood caries while controlling for psychosocial and biological factors in a high-risk population (Quinonez et al., 2001). The cross-sectional study of 151 healthy children aged 18-36 months indicated that a combination of psychosocial, behavioral, temporal, and biological variables predicted early childhood caries.

Poor social support also has been associated with low dental utilization by disadvantaged children (LaValle et al., 2000). In addition, children of racial and ethnic minorities and children whose parents have low educational attainment experience disparities in oral health status and poorer access to dental care than white children and children of parents with higher educational attainment (Edelstein, 2002).

A primary dental provider or usual source of dental care (USDC) is a strong predictor of dental care utilization. Individuals without a USDC were significantly less likely to access care (Nowak \& Casamassimo, 2002). Having a USDC or "dental home" was found by Davidson and colleagues to be a strong predictor of dental care utilization by diverse populations (Davidson et al., 1999).

Bias and stereotyping also contributes to low care utilization. Provider contributions to disparities in healthcare have only recently been recognized and studied in medicine (Ashton et al., 2003; Burgess et al., 2004; Nakazono et al., 1997; Nazroo, 2003; Pettigrew \& Meertens, 1995; van Ryn, 2002; van Ryn \& 
Burke, 2000; van Ryn \& Fu, 2003). Bias and stereotyping by physicians have been shown to contribute to racial, ethnic, and socioeconomic disparities in medical care (van Ryn, 2002).

In mental healthcare, perceived bias/discrimination has been studied and perceptions of discrimination have been consistently associated with poorer mental health status (Williams et al., 2003). Perceived discrimination also has been studied in other fields, including self-reported health (Karlsen \& Nazroo, 2002; Karlsen et al., 2002; Schulz et al., 2000), blood pressure and cardiovascular disease (Guyll et al., 2001), and smoking and alcohol abuse (Guthrie et al., 2002; Landrine \& Klonoff, 2000; Landrine et al., 1996; Yen et al., 1999a, 1999b). Many of these studies have focused on racial/ethnic discrimination, but a growing body of research is accumulating on discrimination based on socioeconomic status (Karlamangla et al., 2005; Lantz et al., 2001; Schulz et al., 2000).

Perceived discrimination in dentistry based on socioeconomic status or health insurance has only recently been studied. In the United Kingdom, barriers to the use of dental services by individuals from minority ethnic communities were identified through focus groups. The type of barriers differed among ethnic groups but the perceived negative attitudes on the part of dental staff and subsequent mistrust of dentists were common to all groups (Newton et al., 2001). Another study conducted in the United States by Mofidi and colleagues examined what type of problems parents/caregivers had encountered in accessing dental care for their Medicaid-insured children. They conducted 11 focus groups with 
77 caregivers of diverse racial and ethnic backgrounds who had sought dental care. The caregivers reported structural barriers such as finding providers, arranging appointments, and transportation. In addition, the caregivers reported negative attitudes on the part of dental staff, long waiting times, and discriminatory behavior from staff and providers (Mofidi et al., 2002).

A lack of knowledge of parents and physicians about the consequences of oral disease for children also has been associated with poor utilization (Allukian, 2000). The Surgeon General's Report on Oral Health in America calls for a plan of action to change perceptions among the public and professions regarding oral health and disease. Oral health needs to become an accepted component of general health. The report states that changes need to be made in public perceptions, policymaker's perceptions, and health provider perceptions. The report concludes that collaborations among all of the above will be necessary to eliminate health disparities (DHHS, 2000).

\section{Perceived Barriers to Dental Care Utilization}

The first phase of the Parental Help Seeking for Dental Care project involved the conduct of eight focus groups with parents of disadvantaged children in Louisville, Kentucky. The purpose of the focus groups was to identify psychosocial, structural, and cultural barriers to accessing dental care for their children (Kelly et al., 2005) and to guide the refinement of the planned telephone survey that would be used as an evaluation instrument in the second (intervention study) phase of the study. Focus group participants were categorized by race/ethnicity (Caucasian, African American) and dental utilization 
(Utilizers or Non-Utilizers). Parents were classified as being Utilizers if they had taken their child for dental care within the past two years; Non-Utilizers were those parents whose child had not received dental care for two years.

Medicaid utilization records were used to recruit a convenience sample of 2,000 parents/caregivers of Medicaid-insured children. Passport Health Plan, the Medicaid managed care organization for Jefferson County, Kentucky, invited parents/caregivers to contact the University of Louisville's Survey Research Center. A final sample of 76 parents/caregivers participated in eight focus groups with attendance rates ranging from $42 \%$ for white Utilizers to $62 \%$ for African American Utilizers.

The University of Louisville's Survey Research Center scheduled and moderated all focus group sessions. A moderator began with an introduction including a reference to the use of recording equipment, a brief overview of the subject matter to be covered and an explanation of the discussion rules. Video and audio-taping equipment for archiving the proceedings was used during each focus group session. Each focus group session followed a semi-structured format. An open-ended interview guide that was approved by the Institutional Review Board of the University of Louisville was used.

Two types of analyses were conducted: (1) an ethnographic summary of each focus group, including quotations and identification of themes and parental care seeking behavior-relevant factors, was produced by Dr. Susan Kelly, a qualitative sociologist, and (2) based on initial ethnographic summarization, content analysis of focus group transcripts were performed to verify identified 
themes and factors, identify additional themes and factors, and examine the contextual factors and inter-relationships among themes and factors (e.g., relationships among prior experience, attitudes toward dental care providers and extent of previous contact, and education and value placed on oral health).

A content analysis was then conducted using a modified version of the focused coding method of grounded theory (Charmaz, 1983). The analysis method allowed the identification of barriers that informed the development of an evaluation instrument (telephone survey) that was used in the present study. Several themes emerged from the focus group sessions that were categorized as psychosocial and structural and differences between Utilizers and Non-Utilizers were compared and contrasted.

Psychosocial factors included oral health beliefs, trust in dental providers, prior experiences with Medicaid providers, a caregiver's own prior dental experiences, and knowledge of Medicaid. While all parent groups discussed current dental health concerns including cavities and gum disease, emphases differed among groups. High Utilizing parents emphasized connections with overall health status while Low Utilizing parents focused on specific local problems. Compared to High Utilizing parents, Low Utilizing parents reported placing a greater emphasis on appearance, self-esteem, and pain than on health as reasons to take children to the dentist. Low Utilizing parents also reported having difficulty overcoming children's resistance to efforts to instill preventive dental habits. They reported being too busy, relying on schools and other 
external sources to teach children preventive habits, not perceiving dental health as important as overall health, and setting a poor example for their children.

Importantly, Low Utilizing parents were less likely to perceive ensuring children's dental health as integral to good parenting. They also expressed low self-efficacy in overcoming structural barriers such as transportation, school policies, and locating Medicaid-accepting dentists. Low Utilizing parents were also less able to separate their own dental fears and experiences from their children's care.

Structural barriers that were investigated included provider availability, time, transportation, school policies, coordinating schedules, and child care. High Utilizing African American parents reported little difficulty locating Medicaidaccepting providers, although some preferred to take their children to dentists who they paid out-of-pocket. Among parents who sought care from nonMedicaid providers, some commented on the cultural "whiteness" (e.g., music, literature) of dental offices located in middle class neighborhoods. High Utilizing Caucasian parents also reported little difficulty finding Medicaid-accepting dentists.

Low Utilizing African American parents reported difficulty locating Medicaid-accepting dental providers and believed that many or most dentists do not accept Medicaid. Transportation was also identified as a problem. Low Utilizing Caucasian parents reported difficulty locating pediatric dentists who accept Medicaid or new Medicaid patients. Many of the Low Utilizing parents reported delays in getting appointments with Medicaid-accepting dental 
providers, rescheduling and disruption of care, and negative treatment from dental staff for Medicaid-enrolled patients.

Norms of parental responsibility, sense of efficacy, and oral health beliefs may be important mediators of children's dental care. Low Utilizing parents were less likely than High Utilizing parents to link dental care to good parenting and overall health, and less able to overcome barriers including dental fear, transportation, school absence policies, discriminatory treatment, and locating Medicaid-accepting providers (Kelly et al., 2005).

The Parental Help Seeking for Dental Care project team concluded that public health staff and organizations, dental providers, and Medicaid administrators should coordinate steps to overcome these barriers. We hypothesized that if we could assist in overcoming structural barriers, build trust, and educate parents about the impact of child oral health on overall health, then we could assist disadvantaged parents in obtaining dental care and ultimately improve their child's oral health. Based on a review of the literature, we anticipated that a case manager/home visitor intervention could increase dental care utilization by providing assistance in overcoming structural and psychosocial barriers.

\section{Interventions to Improve the General Health of Disadvantaged Children}

Efforts to improve the outcomes of disadvantaged mothers and their children were undertaken in the 1960 s and early 1970 by the federal government. The intervention programs increased the number of services (i.e., medical, social, psychological) available to pregnant women and new mothers in 
office- and clinic-based settings (Felice et al., 1981; McAnarney et al., 1978; Stine \& Kelley, 1970). The effectiveness of these programs, however, was difficult to assess due to a lack of control groups and random assignment.

Specific interventions to change healthcare behaviors of mothers and to improve child health also were developed and evaluated in the 1970s and 1980s. Smoking cessation programs (Donovan, 1977; Sexton \& Hebel, 1984), prenatal nutritional supplementation (McDonald et al., 1981; Rush et al., 1980), and incentives for attendance at clinic (Elder \& Salgado, 1988) have been tested as interventions to improve child health. The results of these focused interventions were mixed, and researchers theorized that multifaceted interventions may be required to address the multiple determinants of healthcare outcomes for disadvantaged children.

In the late 1970s, David L. Olds and colleagues began a 25-year investigation into home visitation as a possible means of improving child health. His first randomized, controlled trial was conducted in a small, semi-rural county in the Appalachian region of New York state. Young pregnant women of low socioeconomic status were randomly assigned to a control group or to receive home visits by nurses who provided education, support, and assisted with overcoming structural barriers such as transportation. The intervention extended from pregnancy to the child's second birthday. Positive effects on maternal health, birth weight, and child health were found in the intervention group. Olds emphasized the need for systematic replication and evaluation of the intervention in other populations and geographic areas. 
Olds and colleagues subsequently conducted numerous additional studies evaluating the impact of home visiting by nurses to improve health outcomes of disadvantaged children (Kitzman et al., 1997a; Kitzman et al., 2000; Olds et al., 1998; Olds et al., 1995; Olds, 1992, 2002; Olds et al., 1997; Olds et al., 1994;

Olds \& Kitzman, 1990; Olds et al., 2004a; Olds et al., 2002; Olds et al., 2004b). Other investigators also have examined the effect of home visitation on child health with outcomes of improving resource use in a Universal Healthcare System in Canada (Tough et al., 2006), improving the health of children in Scotland (Shute \& Judge, 2005), delaying second births among adolescent mothers (Black et al., 2006), improving child care among American Indian adolescent mothers (Barlow et al., 2006), and enhancing parent and child development (Barlow et al., 2006). The interventions all produced a positive effect on the study outcomes but seemed to be most effective with those parents and children at the lowest poverty level and with the most risk factors for poor health.

Olds demonstrated that home visitation by nurses is effective in improving maternal and child health outcomes but he recognized that there is a shortage of nurses in the United States and this intervention may not be feasible across the country. He questioned whether paraprofessionals or community lay workers (persons without nurse training but who have similar social characteristics as the families they serve) could be as effective as nurses.

In 2004 , Olds reported the results of a randomized, controlled study that was designed to evaluate the differences between nurses and paraprofessionals 
home visitations in improving outcomes if the nurses and paraprofessionals followed well-developed program guidelines and received thorough training and supervision. Women in treatment group $1(n=253)$ received screening and referral for their children, women in treatment group $2(n=245)$ received the same services as those in group 1 plus paraprofessional home visiting for 2 years, and women in treatment group $3(n=250)$ received group 1 services plus nurse home visiting for 2 years. Results of the study showed positive effects on the mothers visited by paraprofessionals and positive effects on the children visited by the nurses. Olds (p. 1567) recommended that "promising findings produced in single randomized trials need to be replicated with other populations before they warrant public investment" (Olds et al., 2004b).

The Olds home visitation program is based on an ecological model with interventions targeting under-resourced first-time mothers. It was hoped that the nurse home visitation would improve the outcomes of pregnancy, early childrearing, and life-course development (Olds et al., 1988). Although Olds and colleagues used home visitation by nurses and paraprofessionals to assist and coordinate needed care, they did not emphasize a coordinated community and practice approach that integrated the nurse's home visitation with committed resources. Other investigators, including Margolis in North Carolina, developed conceptual frameworks and theoretical models that have been tested in large intervention studies (Stevens et al., 1996). The concept and theory of the home visitor providing education and social support to the parent, as well as serving as 
a coordinator of care between the families, providers, and community, is discussed in more detail in the next chapter.

\section{Interventions to Improve the Oral Health of Disadvantaged Children}

Efforts to increase dental care utilization among disadvantaged children have primarily focused on reducing structural barriers such as number of providers and cost. Little attention has been paid to psychosocial barriers that could be impacted by a case manager intervention. The primary structural barrier has been identified as the low number of dentists who accept Medicaid or who will provide charity care for the uninsured (Allukian, 2000).

Various methods for improving access to dental care for low-income preschool children have been explored. For example, the program entitled Increasing Access for Dental Care for Medicaid Preschool Children: The Access to Baby and Child Dentistry (ABCD) offered extended dental benefits and higher fees for certified providers in the state of Washington. The program was found to increase access for preschool children enrolled in Medicaid, reduce dental fear, and increase parent satisfaction with the Medicaid system (Grembowski \& Milgrom, 2000). The ABCD program primarily involved a practice intervention with an orientation and follow-up for families provided by the Medicaid administrator.

Other statewide programs in Alabama, Michigan, and North Carolina that increased provider payment, provided training for dentists and families, and utilized outreach staff to contact families and provide program orientation have had considerable success (dela Cruz et al., 2004; Eklund et al., 2003; Greene- 
Mclntyre et al., 2003; Grembowski \& Milgrom, 2000; Kaakko et al., 2002; Rozier et al., 2003).

Investigators also have recommended an emphasis on preventive oral care in primary pediatric settings to complement existing dental services (Mouradian et al., 2000). Other approaches to increasing access involve providing a usual source of dental care or "dental home" (Davidson et al., 1999; Macek et al., 2005; Shi \& Stevens, 2005; Skaret et al., 2001; Slifkin et al., 2004). As far as the researcher for this study has been able to determine, a dental case manager/home visitation intervention has not been studied as a means of increasing dental care utilization for disadvantaged children.

\section{Potential Moderators of Intervention Effects}

The analysis of randomized trial data for the effect of moderating factors is strongly recommended by Kraemer et al. (p. 877 ) because "moderators identify on whom and under what circumstances treatments have different effects" (Kraemer et al., 2002). A moderator is a characteristic or factor that precedes the treatment and is not correlated with the treatment (e.g., family income, child age, etc.). Analyses of moderating effects are hypothesis-generating and the results may be just as important as hypothesis testing of treatment effects (Kraemer et al., 2002).

The literature reveals that moderator analyses are becoming more common in medicine and the social sciences; however, only recently has it been conducted in dental intervention research and has not yet been widely reported. Although not reported as moderating effects, a few studies have reported 
potential moderators in intervention trials to improve access to care for disadvantaged children. For example, the ABCD program was found to be of the most benefit for younger children (Kaakko et al., 2002), perceived need for dental care among the treatment group was associated with increased utilization in the ABCD program (Grembowski \& Milgrom, 2000), and children in the study whose families were at the lowest poverty level benefited the most from enrollment in the New York State Children's Health Insurance Program (Szilagyi et al., 2004). The researcher analyzed these and other socioeconomic and psychosocial factors as potential moderator effects in this study.

\section{Summary}

The epidemic of oral disease in disadvantaged children is well documented and the consequences are serious. Parents who are at or below the poverty level have numerous demands on their time and money. Oral care for their children often becomes a low priority in light of the obstacles they face on a day-to-day basis. The decision to access dental care is made in the presence of numerous barriers that must be overcome, and for some the barriers are too great. As a result, children in our society suffer oral health disparities.

The next chapter will review the theoretical models that have been proposed for parental care seeking in medicine. Then, a conceptual model of the study is proposed - a case manager intervention with provider and community support, potential moderating factors, and an outcome of dental care utilization. The model will be used to describe how a case manager could facilitate dental 
care for disadvantaged children by overcoming these structural and psychosocial barriers. 


\section{CHAPTER 2}

\section{THEORETICAL MODELS, CONCEPTUAL FRAMEWORK, AND RESEARCH QUESTIONS}

\section{Parental Decision Making Theories}

Given that only one in five Medicaid-covered children receive a dental visit each year (NIDCR, February 2002), it would be of benefit to determine why disadvantaged parents or caregivers do not attempt to access dental care. A review of the literature yielded little theory-based research concerning how or why disadvantaged parents make decisions about accessing dental care for their children. In medicine, however, parental decision-making in the areas of immunization and infant health has been investigated using theoretical models.

Theories designed to explain health behaviors function as roadmaps to assist in synthesizing a body of research more easily, to understand a behavior more fully, and to propose ways in which an intervention is most likely to be effective (Lauver, 1992). For example, Niederhauser and colleagues examined parents' decision-making process before the action to vaccinate or refuse vaccination using the Awareness-to-Action Model (Niederhauser et al., 2001). They found that the decision-making process was influenced by how beneficial the parents thought the vaccine was to their child. The model was found to be effective in enabling healthcare providers to understand parental decisions about 
vaccines and could be used to develop interventions to increase vaccine compliance.

Mothers' decision-making processes regarding medical care for their children were also reported by Gross and Howard (Gross \& Howard, 2001). They used the Health Belief Model and Cox's Interaction Model of Client Health Behaviors to examine how mothers make decisions about healthcare for their children. One hundred and fourteen mothers in rural Nebraska completed questionnaires; seven of these underwent structured, in-depth interviews to provide qualitative data. Most of the mothers' decisions were based on the perceived degree of seriousness, mothers' degree of fear for the child's condition, attitude of the healthcare provider, previous experience, and social support.

Aday and Andersen's model for the study of access to care, first proposed in the mid-1970s, has been used extensively in health services research (Aday \& Andersen, 1974). The model posits that utilization of health services and consumer satisfaction are determined by health policy, characteristics of the health delivery system, and characteristics of the population at risk. Factors that characterize the population or individuals at risk are categorized as mutable and immutable predisposing and enabling factors as well as perceived and evaluated need. The model has been expanded to address psychosocial factors and how the predisposing, enabling, and need factors are interrelated (Bradley et al., 2002). Halfon and colleagues used the model to describe non-financial barriers to care for children and youth that include family characteristics. They 
recommended that service models for improving access to health care for highrisk children should integrate family characteristics into the Aday-Anderson Model (Halfon et al., 1995).

The Goldberg and Huxley Levels and Filters Model (Goldberg \& Huxley, 1980) describes how individuals navigate the pathway between the community and psychiatric care. In this model, levels are defined as the stage of the individual in the pathway to care-i.e., in the community, in the care of the general practitioner, or in the care of the specialist. The filters in the model are factors such as the decision by the patient to seek care, the recognition by the general practitioner of the need for referral, and finally, the decision by the psychiatrist to treat the patient. The model posits that in order to move from one level to the next, an individual must pass through a filter that serves to block access between levels.

The Levels and Filters Model was modified by Pavuluri to describe help seeking for behavior problems by parents of preschool children (Pavuluri et al., 1996). In the Pavuluri model, the first filter is parental recognition of a problem, the second filter is the parent's consideration of the need for help, and the third filter is the parent's ability to overcome any attitudinal or physical barriers to helpseeking, which leads to actually seeking help.

In the Pavuluri study of 320 parents of preschool children, only $19 \%$ of those with a behavioral disorder crossed all the filters in reaching for help (see Figure 2). The most common barriers reported were parents thinking that the problems would get better by themselves and parents thinking they should be 
able to handle the problems themselves. Parents with low income or who were single were significantly less likely to seek help (Pavuluri et al., 1996).

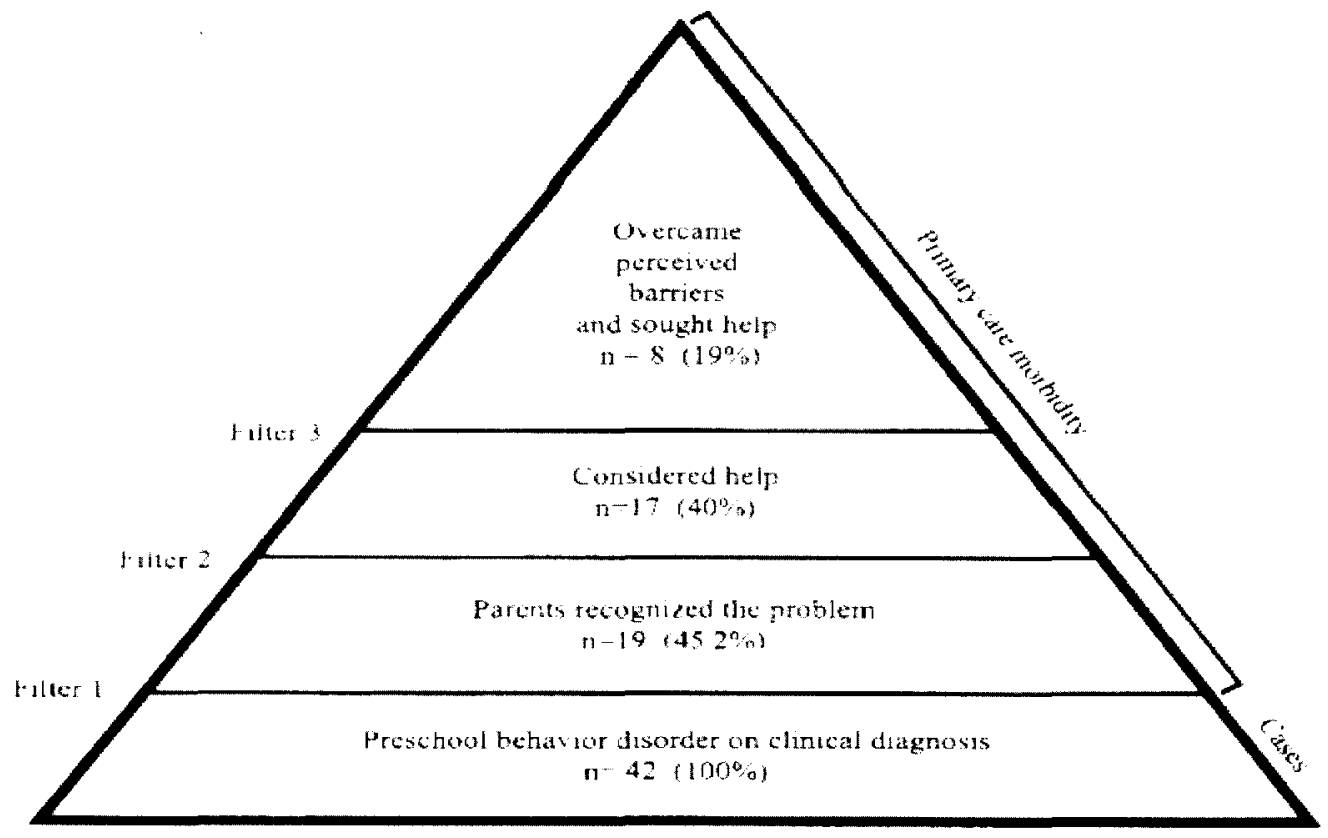

Figure 2. Model of Levels and Filters for Service Utilization (Pavuluri et al., 1996).

Based on this study, Pavuluri and colleagues developed a model of service utilization in preschool children that addresses potential avenues to overcoming the filters (barriers) and moving from one level to the next in parental care seeking. They suggest that moving from the first level of recognition of the problem to the second level of seeking care can best be overcome by educating parents and general practitioners to raise awareness. They also recommended that it was important to alter parental attitudes ("fear of labeling") to enable them to seek help. The investigators also emphasized the importance of dealing with the stress endured by disadvantaged parents and establishing stronger links between formal and informal child care agencies. The Pavuluri Model for Service 
Utilization in preschool children could serve as a basis for home visitation/case management interventions for disadvantaged families.

\section{Theoretical-Based Intervention to Improve Preventive Medical Care}

An intervention preventive health program was designed and implemented by Peter Margolis and colleagues in a North Carolina community (see Figure 3 below). The primary objective of the Margolis intervention program was to achieve changes in the process of medical care delivery at the level of the clinical interaction between care providers and families. The interventions involved home visitors/nurse case managers working with families and medical practices to improve processes of care delivery to families and children (Margolis et al., 2001).

The Model of Access to Personal Healthcare services was used by Margolis to design an intervention that included home visitation by nurses who not only provided education and support but also coordinated care with providers with community support. Margolis hypothesized that the integrated intervention would help to decrease barriers, increase the use of services, reduce the effect of mediators, and improve outcomes.

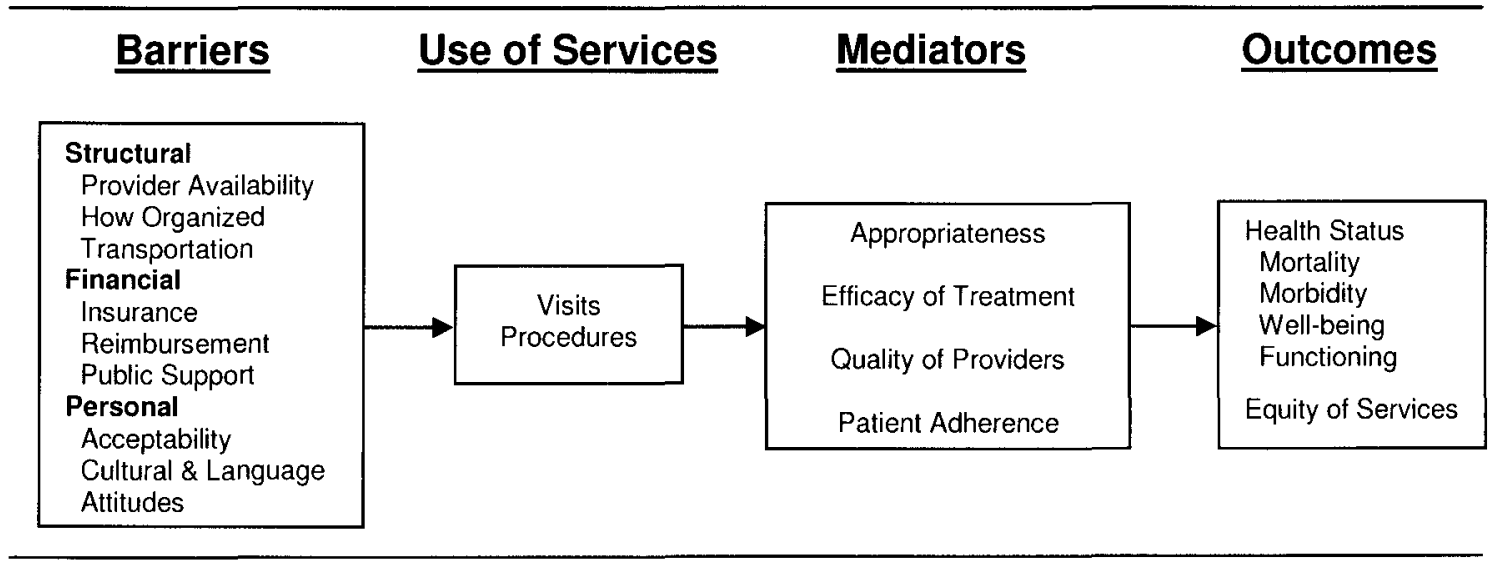

Figure 3. Model of Access to Personal Healthcare Services (Margolis et al., 1995). 
Low-income pregnant mothers and their infants, primary care practices, and departments of health and mental health participated in the intervention study. The community-level intervention sought to achieve policy-level changes that would result in changes in resources available, engage multiple practice organizations, improve communication and coordination, and avoid duplication of services. The family-level intervention involved home visitation that addressed the process of care delivery and education and social support of the mothers. The practice-level intervention sought to overcome specific barriers in the process of care delivery (e.g., Medicaid billing, failed appointments). Over a three-year time period, there were high levels of participation in the treatment group, changes in the organization of the delivery system, and improvements in preventive health outcomes.

\section{Conceptual Framework}

This study proposes to use the first two components of the Margolis Model (Barriers and Use of Services) as a conceptual framework to evaluate the effects of an intervention (case manager/home visitor in conjunction with provider and community involvement) to increase dental care utilization. Future investigations may reveal that increased use of services, mediated by Margolis's mediating factors (Appropriateness, Efficacy of Treatment, Quality of Providers, and Patient Adherence), could ultimately improve the oral health of disadvantaged children.

Figure 4 on the next page presents the conceptual framework for the present study. 


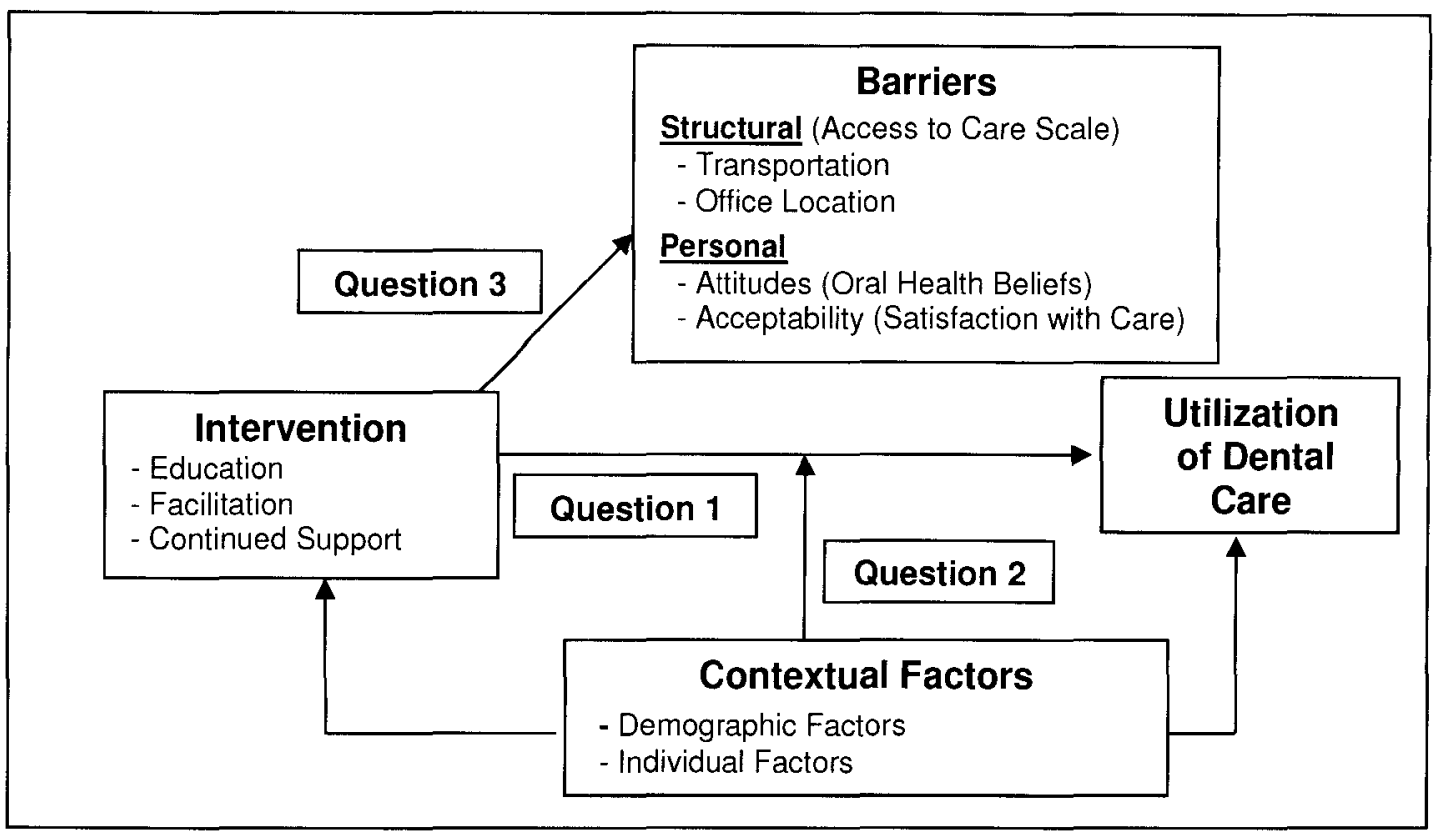

Figure 4. Conceptual Framework of Case Manager Intervention Study

In this framework, the researcher operationalized the barriers as factors that could be changed by the case manager and contextual factors as preexisting factors that may moderate how well the case manager intervention works for certain individuals. Barriers that could be impacted by the case manager were structural and personal factors. Changes in perceived structural factors were assessed with the change in Access to Dental Care Scale (e.g. availability of dentists, convenience of dental appointments, having a usual source of dental care) scores from baseline to the end of the study. Changes in personal factors were assessed by score changes in the Satisfaction with Dental Care Scale and the Oral Health Beliefs Scale.

Contextual or pre-existing factors that may moderate the effect of the intervention on dental care utilization were both individual (e.g., perceived need 
for dental care, self-efficacy) and demographic (e.g., child and parent age, socioeconomic status, employment, number of other children).

\section{Study Research Questions}

Based on the above conceptual framework shown in Figure 4, the following research questions are posed:

1) What is the direct effect of the intervention on dental care utilization?

2) Do contextual factors (individual and demographic) moderate the intervention effects on utilization?

3) What is the effect of the intervention on barriers?

\section{Summary}

There is clearly a need to improve the oral health of our nation's disadvantaged children and for interventions to facilitate accessing dental care by their parents. There are numerous reports of barriers that must be overcome and theoretical models that illustrate how this can be accomplished. None of these, however, specifically describes how a dental case manager could help parents recognize the need for oral care and assist them in obtaining dental care for their children.

The uniqueness of the conceptual framework for this study is the use of a theoretically based case manager/home visitation intervention that has been used in medicine but not in dentistry. Analyses from this study determined if the intervention can increase dental care utilization and if it can impact barriers. These exploratory analyses also determined if contextual (individual and demographic) factors moderate the effects of the intervention on utilization to 
determine if there are certain parents who may be best targeted for this intervention based on specific characteristics. This research does not investigate the role of structural or personal barriers as mediating variables because this analysis was done in the original study. 


\section{CHAPTER 3}

\section{RESEARCH METHODS}

This chapter describes the Parental Help Seeking for Dental Care funded project and the new analysis methodology used in the dissertation study. The first two sections describe the research team members that collaborated on the Parental Help Seeking project, and the research design and geographical area. The third section describes the sample, including sample size and power analysis, and subject recruitment and selection. In the fourth section, the intervention and sources of data are described, and in the fifth section, the study variables and preliminary results of the Parental Help Seeking Study are described. Finally, the sixth section presents the data analysis plan for the dissertation study.

\section{Research Team Members}

Susan Kelly, Ph.D., a Qualitative Medical Sociologist in the Department of Sociology at the University of Louisville, has extensive experience in qualitative studies of medical care seeking behavior, including the use of focus groups. She has been the Principal Investigator of an $\mathrm{NIH}$-funded study of rural population access to genetic services, involving in-depth interviews with 130 rural parents of children with a genetic condition. Dr. Kelly was also the qualitative medical sociologist on an $\mathrm{NIH}$-funded study to determine factors predicting 
medical care seeking for urinary incontinence (UI). The study involved conducting a series of focus groups similar to this study to develop predictor variables for a Theory of Incontinence Care Seeking Behavior to study care seeking for $\mathrm{UI}$ in a racially diverse female population. Previously, Dr. Kelly participated in a qualitative study of the experiences of a racially and ethnically diverse population of women at high familial risk for breast cancer with risk assessment and pre-symptomatic genetic testing conducted by B. A. Koenig (PI) at the Stanford Center for Biomedical Ethics.

Knowlton Johnson, Ph.D., a Senior Research Scientist at the Pacific Institute for Research and Evaluation, has extensive research experience in testing for the effects of interventions among at-risk populations. From 1989 to 1995, he implemented a randomized trial that tested for the effects of a substance abuse prevention intervention (Johnson et al., 1998). The results indicated that the intervention had a positive impact on the lives of families that participated in the program. In 1995, the study was modified and implemented in African American communities as a randomized trial. Dr. Johnson is currently the $\mathrm{PI}$ on several $\mathrm{NIH}$-funded $\mathrm{R} 01$ randomized community intervention trials to reduce inhalant abuse and risky sexual behavior.

Bruce Gale, M.S., Director of the Survey Research Center in the Urban Studies Institute of the University of Louisville, has 15 years of experience in conducting focus groups including studies on Medicaid, employment practices, governmental service issues, military recruiting, and higher education. Since its formation, the Center has undertaken well over 100 major field studies in rural 
and urban areas throughout Kentucky and across the nation. In addition, the Center provides analysis of primary and secondary data and shares data analysis staff and resources with the Kentucky State Data Center, which is also housed at the Urban Studies Institute.

\section{Parental Help Seeking for Dental Care Research Design}

The study used a two-group randomized repeated measures design with a telephone survey to administer ten scales and to collect demographic and selfreport information concerning perceived need for dental care, child oral health status, previous dental care, etc. Medicaid records were obtained at study end and were used to evaluate dental utilization before and during the study period. For control and experimental families, there were three assessment periods: baseline prior to intervention implementation (Wave 1); after the case manager provided the family intervention (Wave 2); and follow-up after the child was reported by the caregiver to have been taken to the dentist (Wave 3). Control subjects were matched with intervention subjects throughout the study. Subjects were randomly assigned to the intervention or control group upon completion of the first (Wave 1) telephone survey.

After the intervention phase of the study was completed, the case manager contacted all subjects in the control group and provided them with an opportunity to have similar assistance in obtaining dental care.

Human Subjects Protection. The Institutional Review Boards of the University of Louisville, the Pacific Institute for Research and Evaluation, and the 
Kentucky Cabinet for Health and Family Services reviewed the study and all consent and authorization forms.

\section{Geographical Study Area}

The study was conducted in Jefferson County, Kentucky, an area of 385 square miles with a population of 693,604 and a median household income of $\$ 38,733$. The population is approximately $77.4 \%$ white, $18.9 \%$ African American, 1.4\% Hispanic, and 1.4\% Asian/Pacific Islander (Wikipedia, 2007). The census tracts in the western portion of the county where the majority of African Americans reside are designated as a medical and dental healthcare provider shortage area by the United States Department of Health and Human Services (DHHS, 2007).

The State of Kentucky provides medical and dental health insurance for eligible children through the Medicaid program. The Medicaid program is administered in Jefferson County by Passport Health Plan, a managed care program. The dental component of the Medicaid program is administered by Doral Dental, a subcontractor to Passport.

\section{Parental Help Seeking for Dental Care Study Sample}

A power analysis was conducted to determine the number of families needed to distinguish a significant difference in dental care utilization between the intervention and control groups. The researcher used an effect size of $31 \%$ based on an earlier, similar intervention study reported by Grembowski and Milgrom (2000), who found that $43 \%$ of participants in an intervention group sought follow-up dental treatment while only $12 \%$ of participants in the control 
group did so. It can be estimated that $20 \%$ of the control group families in the present study would utilize dental care based on the report that only one in five Medicaid children routinely receive dental care (DHHS, 2000). Increasing the utilization rate to $45 \%$ in the intervention group would be a practical/clinically relevant effect, thus an event rate of .20 in the control group and .45 in the intervention group was selected.

A total sample of 120 subjects with 60 in the control and 60 in the intervention group with a criterion for significance (alpha) of .05 and a two-tailed test would provide power of $82 \%$-that is, there would be an $82 \%$ chance of detecting an effect size of this magnitude. An initial sample of 202 was recruited with the anticipation that attrition during the course of the study could be approximately $40 \%$, thus providing a final sample of at least 120 .

The inclusion criteria for the study were parents or caregivers of Medicaidinsured children aged 4 to 12 years in the Louisville, Kentucky, area who reportedly did not have claims paid for a cleaning or oral examination within the previous 24 months, a proxy measure which indicated that they most likely had not received routine dental care. The Medicaid administrators, Passport Health Plan and Doral Dental, entered these parameters into their database and produced a data set of eligible children and parents/caregivers. The researchers did not have access to any of the Medicaid utilization data until the end of the study activities.

A sampling frame of approximately 10,000 Medicaid-eligible children who lived in the Jefferson County, Kentucky, area was used for the study. Passport 
Health Plan selected a sample of 4,000 children aged 4 to 12 years who had not received a preventive dental procedure for the previous two years using a systematic interval technique. Systematic sampling is a process for randomly selecting cases by taking every $k^{\text {th }}$ case from a list of all cases. After starting at a random point, the interval, which is determined by dividing the desired sample size into the population size, is then used to identify cases for inclusion in the study.

Passport Health Plan prepared a letter inviting the parents to participate in the study that was mailed to the 4,000 randomly selected parents/caregivers. A Health Information Portability and Accountability (HIPAA) Research Authorization form, a form requesting contact information, and a stamped, self-addressed return envelope addressed to the investigators was enclosed with the invitation letter. The selection and participation process is described in Figure 5.

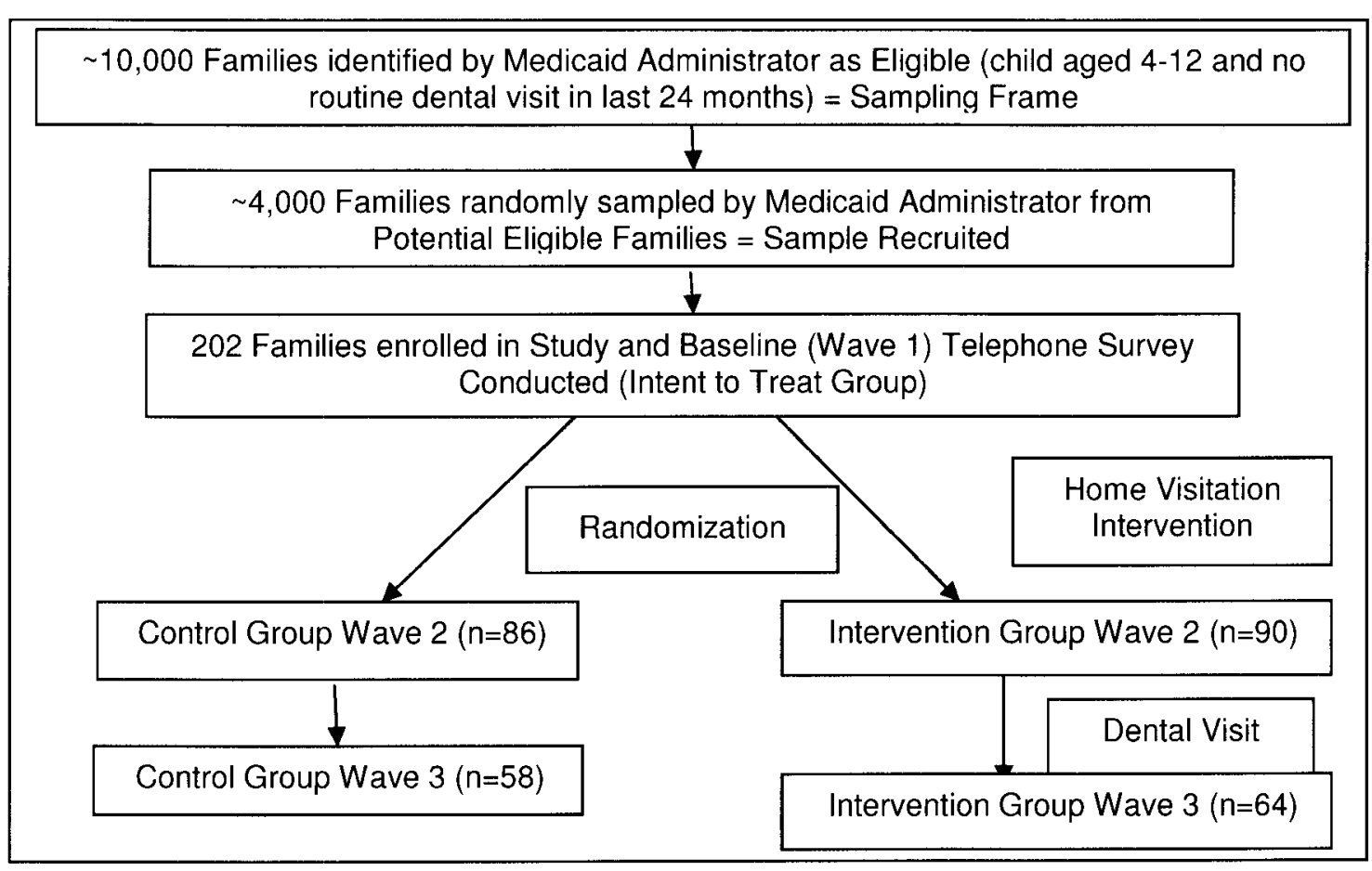

Figure 5. Subject Selection Process and Participation 
A copy of the signed HIPAA form was mailed to the subjects and the original was maintained by the investigators. Subjects who signed the HIPAA form were contacted by telephone and a consent statement approved by the Institutional Review Boards was read to the subject by the telephone interviewer. If the subject provided verbal consent, the telephone survey was conducted.

Incentives were provided to the subjects who completed the telephone surveys in the amount of $\$ 15$ for the first survey, $\$ 20$ for the second survey, and $\$ 25$ for the third survey. Money orders were mailed to the subjects within a few days of survey completion.

Parents' demographic data and the parent-reported baseline oral health status of the children in the Parental Help Seeking study are shown in Table 1.

Table 1.

Baseline Subject Characteristics ( $n=202)$

\section{Characteristic}

Intervention Group Control Group

Age, Mean (Range)

$37.25(20-74)$

$36.42(22-63)$

Gender, $\mathbf{n}$

Male

2

1

Female

99

100

Race/Ethnicity, n

African American

77

85

White

18

16

Asian

1

0

Table continues... 
Table 1 continued.

Baseline Subject Characteristics ( $n=202$ )

Characteristic

Intervention Group Control Group

\begin{tabular}{lcc}
\hline American Indian & 1 & 0 \\
Other & 2 & 0 \\
Education, $\mathbf{n}$ & & 23 \\
Did Not Complete High School & 11 & 34 \\
High School & 43 & 42 \\
Some College & 44 & 2 \\
Graduated College & 3 & \\
Income, $\mathbf{n}$ & & 30 \\
Under $\$ 5,000$ & 28 & 38 \\
$\$ 5,000-\$ 15,000$ & 37 & 29 \\
$\$ 15,000-\$ 25,000$ & 25 & 4 \\
Over $\$ 25,000$ & 7 & 19 \\
Employment Status, $\mathbf{n}$ & & 53 \\
Working & 49 & 27 \\
Not Working & 24 & \\
Other & 27 & $607 t h u e s$ \\
\hline
\end{tabular}

Table continues... 
Table 1 continued.

Baseline Subject Characteristics ( $n=202)$

\section{Characteristic}

Marital Status, $\mathbf{n}$

Single

Married/Partner

18

16

Divorced/Separated/Widowed

26

27

No. of Children Living at Home,

Mean (range)

$3.16(1-9)$

$3.15(1-9)$

Child Oral Health (Parent's estimate of child's oral health?), $n$

Poor

4

4

Fair

11

17

Good

33

30

Very Good

25

31

Excellent

15

13

Utilization 1 Year Prior, $\mathbf{n}(\%)$

$14 / 101(14 \%)$

$19 / 101(19 \%)$

Utilization 2 Years Prior, n (\%)

\section{Description of the Intervention}

The intervention primarily involved a case manager/home visitor with practice and community support. The intervention consisted of an initial home visit by the dental case manager with an oral presentation designed to provide oral health education including the importance of oral health in relation to general health. The case manager provided assistance in obtaining dental care, which 
included scheduling dental appointments and helping with the Medicaid eligibility process. The presentation was supplemented with written educational materials, oral hygiene instruction for the child, and oral care products such as toothbrushes, toothpaste, and mouth rinses. Parents/caregivers were provided assistance with scheduling and transportation to their current dentist or to a local dental practice. Assistance with transportation was provided (i.e., bus vouchers) when parents identified transportation as a barrier to obtaining dental care.

The case manager was hired and trained by the investigators before recruitment began, and then worked closely with the Medicaid Dental Program Manager (Doral Dental), staff from the Medicaid administrator (Passport Health Plan), the dental practice dentists and staff, and investigators throughout the study.

After subject enrollment, four established dental practices in the geographic areas of subject residences were recruited to participate in the study. The practices were provided assistance throughout the study in the billing and collecting of Medicaid charges. The case manager worked closely with each dental practice staff to increase the number of scheduled appointments that were kept by the intervention group subjects and to reduce tardiness for appointments.

\section{Source of Data}

Dental Utilization Data: Records of dental treatment provided by Medicaid dentists was obtained from Passport Health Plan and Doral Dental, the Medicaid administrators for the study area.

Telephone Survey: The data collection instrument for the demographic, socioeconomic, and psychosocial study variables was a 120-item telephone 
survey questionnaire administered with a Computer Assisted Telephone Interview (CATI) system. The instrument was developed and pilot-tested according to procedures described in Appendix 1.

The survey contained validated scales and questions to collect demographic information. The telephone surveys were conducted using a CATI by Horizons InFocus, a private company trained and experienced in conducting surveys of this type.

The telephone survey was administered to parents/caregivers three times over the course of the study: 1) at study entry/baseline before randomization (Wave 1); 2) after the home visit by the case manager when controls were paired with the intervention subjects (Wave 2); and 3) after the intervention parent took the child to the dentist as reported by the case manager or self-report by the parent (Wave 3).

The subjects were randomly assigned to the groups by the CATI software. The staff then informed the intervention subjects that the case manager would be contacting them in the near future. The script used by the interviewers to answer questions concerning the intervention is provided in Appendix 2.

\section{Study Variables}

Variables for Analysis of Research Questions \#1 and \#2. The dependent and independent variables for Research Question \#1 (What is the direct effect of the intervention on dental care utilization?) and Research Question \#2 (Do contextual — individual and demographic - factors moderate the intervention effects on utilization?) were operationalized as follows: 
Dependent variable: The dependent variable for these questions was utilization of dental care by Medicaid-insured children. Utilization of dental services was categorized as preventive or routine care. Procedures were considered to be preventive if they were for a recall, periodic, and/or comprehensive dental examination; prophylaxis (cleaning) with fluoride; radiographs; and sealants. Procedures were considered to be routine if they were for restorative procedures (fillings), orthodontics, or extractions. For analysis of study questions, study children who received preventive or routine dental care from the time of their study enrollment to the end of the study enrollment were considered to have utilized dental care and a dummy variable was created where $1=$ utilization, and $0=$ no utilization. Both preventive and routine care are elective and may be impacted by a case manager whereas a dental emergency most likely would not be impacted by the intervention.

Independent variable: The independent variable for these questions was assignment to the intervention or control group coded as $0=$ control group and 1 $=$ intervention group.

Potential covariates: According to the literature and theoretical models certain socioeconomic and psychosocial variables may have direct or moderating effects on parental decision making and dental care utilization. The researcher examined the following variables as potential confounders/covariates in the statistical analyses:

Demographic variables: Parent education, income, child age, race, employment, marital status, and prior dental utilization. 
Individual variables: Oral health beliefs, parental social support, parental stress, access to dental care, child fear, parental dental anxiety, perceived discrimination, and perceived need for dental care.

Moderators/Interactions: The data were examined for potential interactions between the independent variable and the covariates.

Variables for Analysis of Research Question \#3. The dependent and independent variables for Research Question \#3 (What is the effect of the intervention on barriers?) were operationalized as follows:

Dependent variable: The dependent variables for this question were changes in scale scores (from baseline telephone survey \#1 to final telephone survey \#3) for personal barriers (oral health beliefs scale and satisfaction with dental care scale) and structural barriers (access to dental care scale).

Independent variable: The independent variable for this question was assignment to the intervention or control group coded as $0=$ control group and 1 $=$ intervention group.

\section{Table 2.}

Summary of Study Variables

\begin{tabular}{|l|l|l|l|l|}
\hline Construct & $\begin{array}{c}\text { Variable } \\
\text { Label }\end{array}$ & $\begin{array}{c}\text { Variable } \\
\text { Description }\end{array}$ & $\begin{array}{c}\text { Variable } \\
\text { Type }\end{array}$ & \multicolumn{1}{|c|}{ Source } \\
\hline $\begin{array}{l}\text { Utilization of } \\
\text { Dental Care }\end{array}$ & UTIL & $\begin{array}{l}1=\text { Dental } \\
\text { Utilization } \\
0=\text { No } \\
\text { Utilization }\end{array}$ & $\begin{array}{l}\text { Dependent } \\
\text { (Questions 1 } \\
\text { and 2) }\end{array}$ & $\begin{array}{l}\text { Medicaid Dental } \\
\text { Utilization Records - } \\
\text { a preventive or } \\
\text { routine dental visit } \\
\text { during the study }\end{array}$ \\
\hline
\end{tabular}

Table continues... 
Table 2 continued.

$\underline{\text { Summary of Study Variables }}$

\begin{tabular}{|c|c|c|c|c|}
\hline Construct & $\begin{array}{c}\text { Variable } \\
\text { Label }\end{array}$ & $\begin{array}{c}\text { Variable } \\
\text { Description }\end{array}$ & $\begin{array}{c}\text { Variable } \\
\text { Type }\end{array}$ & Source \\
\hline $\begin{array}{l}\text { Intervention } \\
\text { Assignment }\end{array}$ & INT & $\begin{array}{l}0=\text { Control } \\
\text { Group } \\
1= \\
\text { Intervention } \\
\text { Group }\end{array}$ & $\begin{array}{l}\text { Independent } \\
\text { (Questions 1, } \\
\text { 2, and 3) }\end{array}$ & $\begin{array}{l}\text { Randomization } \\
\text { Records }\end{array}$ \\
\hline $\begin{array}{l}\text { Household } \\
\text { Income - } \\
\text { Annual }\end{array}$ & INCOME & $\begin{array}{l}0=\text { Less than } \\
\$ 5,000 \\
1=\$ 5,000 \text { or } \\
\text { more }\end{array}$ & $\begin{array}{l}\text { Covariate - } \\
\text { Socio- } \\
\text { economic }\end{array}$ & $\begin{array}{l}\text { Telephone Survey } \\
\text { Question }\end{array}$ \\
\hline Child Age & AGEchild & Continuous & $\begin{array}{l}\text { Covariate - } \\
\text { Demographic }\end{array}$ & $\begin{array}{l}\text { Telephone Survey } \\
\text { Question }\end{array}$ \\
\hline $\begin{array}{l}\text { Parent } \\
\text { Education }\end{array}$ & EDU & Categorical & $\begin{array}{l}\text { Covariate - } \\
\text { Socio- } \\
\text { economic }\end{array}$ & $\begin{array}{l}\text { Telephone Survey } \\
\text { Question }\end{array}$ \\
\hline Race-Parent & RACE & $\begin{array}{l}0=\text { White } \\
1=\text { African } \\
\text { American }\end{array}$ & $\begin{array}{l}\text { Covariate - } \\
\text { Socio- } \\
\text { economic }\end{array}$ & $\begin{array}{l}\text { Telephone Survey } \\
\text { Question }\end{array}$ \\
\hline Age-Parent & AGEparent & Continuous & $\begin{array}{l}\text { Covariate - } \\
\text { Demographic }\end{array}$ & $\begin{array}{l}\text { Telephone Survey } \\
\text { Question }\end{array}$ \\
\hline $\begin{array}{l}\text { Importance of } \\
\text { Dental Care }\end{array}$ & $\mathrm{OHB}$ & Continuous & $\begin{array}{l}\text { Covariate } \\
\text { (Questions } 1 \\
\& \text { 2) } \\
\text { Dependent } \\
\text { (Question 3) }\end{array}$ & $\begin{array}{l}\text { Oral Health Beliefs } \\
\text { Scale (Nakazono et } \\
\text { al., 1997) }\end{array}$ \\
\hline $\begin{array}{l}\text { Self-Efficacy } \\
\text { in Promoting } \\
\text { Oral Health in } \\
\text { Child }\end{array}$ & SelfEff & Continuous & $\begin{array}{l}\text { Covariate - } \\
\text { Psychosocial }\end{array}$ & $\begin{array}{l}\text { The Self-Efficacy for } \\
\text { Parenting Tasks } \\
\text { Index (Toddler Scale) } \\
\text { Instrumental Care/ } \\
\text { Structure/Routines } \\
\text { Subscale (Coleman \& } \\
\text { Karrakere, 2003) }\end{array}$ \\
\hline
\end{tabular}

Table continues... 
Table 2 continued.

Summary of Study Variables

\begin{tabular}{|c|c|c|c|c|}
\hline Construct & $\begin{array}{c}\text { Variable } \\
\text { Label }\end{array}$ & $\begin{array}{c}\text { Variable } \\
\text { Description }\end{array}$ & $\begin{array}{l}\text { Variable } \\
\text { Type }\end{array}$ & Source \\
\hline Child Fear & DFS & Continuous & $\begin{array}{l}\text { Covariate - } \\
\text { Psychosocial }\end{array}$ & $\begin{array}{l}\text { Dental Subscale of the } \\
\text { Children's Fear } \\
\text { Survey - Parent } \\
\text { Version (Cuthbert \& } \\
\text { Melamed, 1982) }\end{array}$ \\
\hline $\begin{array}{l}\text { Satisfaction } \\
\text { with Previous } \\
\text { Dental Care }\end{array}$ & Satisfac & Continuous & $\begin{array}{l}\text { Covariate } \\
\text { (Questions } 1 \\
\text { \& 2) } \\
\text { Dependent } \\
\text { (Question 3) }\end{array}$ & $\begin{array}{l}\text { Dental Satisfaction } \\
\text { Questionnaire (Davies } \\
\& \text { Ware, 1981; } \\
\text { Davies, 1982) }\end{array}$ \\
\hline $\begin{array}{l}\text { Parent Dental } \\
\text { Anxiety }\end{array}$ & DAS & Continuous & $\begin{array}{l}\text { Covariate - } \\
\text { Psychosocial }\end{array}$ & $\begin{array}{l}\text { Dental Anxiety Scale } \\
\text { (Corah, 1969) }\end{array}$ \\
\hline $\begin{array}{l}\text { Parental } \\
\text { Social Support }\end{array}$ & SocSupp & Continuous & $\begin{array}{l}\text { Covariate - } \\
\text { Psychosocial }\end{array}$ & $\begin{array}{l}\text { Multidimensional } \\
\text { Scale of Perceived } \\
\text { Social Support (Zimet, } \\
\text { 1988) }\end{array}$ \\
\hline $\begin{array}{l}\text { Parental } \\
\text { Stress }\end{array}$ & Stress & Continuous & $\begin{array}{l}\text { Covariate - } \\
\text { Psychosocial }\end{array}$ & $\begin{array}{l}\text { Perceived Stress } \\
\text { Scale (Cohen et al., } \\
1983 \text {; Cohen \& } \\
\text { Williamson, 1988) }\end{array}$ \\
\hline $\begin{array}{l}\text { Perceived } \\
\text { Bias from } \\
\text { Dental Staff }\end{array}$ & Bias & Continuous & $\begin{array}{l}\text { Covariate - } \\
\text { Psychosocial }\end{array}$ & $\begin{array}{l}\text { Perceived } \\
\text { Discrimination (new } \\
\text { scale) }\end{array}$ \\
\hline $\begin{array}{l}\text { Accessibility } \\
\text { of Dental Care }\end{array}$ & Access & Continuous & $\begin{array}{l}\text { Covariate } \\
\text { (Questions } 1 \\
\text { \& 3) } \\
\text { Dependent } \\
\text { (Question 3) }\end{array}$ & $\begin{array}{l}\text { Access to Dental Care } \\
\text { (new scale) }\end{array}$ \\
\hline $\begin{array}{l}\text { Parent } \\
\text { Recognition of } \\
\text { Need for } \\
\text { Dental Care }\end{array}$ & Need & Dichotomous & $\begin{array}{l}\text { Covariate- } \\
\text { Psychosocial }\end{array}$ & $\begin{array}{l}\text { Perceived Need = } \\
\text { "Does your child have } \\
\text { any cavities or gum } \\
\text { boils that need } \\
\text { treatment?" (Yes, No) }\end{array}$ \\
\hline
\end{tabular}




\section{Existing, Validated Measures/Scales Used in the \\ Parental Help Seeking for Dental Care Study}

Oral Health Beliefs Scale (Nakazono et al., 1997). The Oral Health Beliefs

Scale is an 18-item instrument that measures attitudes about the seriousness of oral disease, benefit of preventive practices, benefit of plaque control, perceived importance, and efficacy of dentists. The measure was administered to a population-based sample of 1,382 Baltimore whites, 387 Baltimore African Americans, 1,020 Navajo, 780 Lakota, 276 San Antonio whites, and 567 San Antonio Hispanics. Tests of construct validity indicated that the scales assessed distinct dimensions and correlations between scales that were statistically significant $(p<.01)$ across the ethnic groups. Reliability for the scales across all ethnic groups indicated that perceived seriousness and benefit of preventive practices had the highest Cronbach alpha values $(.53-.80)$, while perceived importance ranged from alpha values of .45 to .55 . Benefit of plaque control produced Cronbach's alpha values of .21 to .52 across all groups, and efficacy of dentists had the lowest alpha values ranging from .17 to .38 . In the Parental Help Seeking Project, the reliability coefficient of the Oral Health Beliefs Scale was .987 .

Table 3 on the next page presents the Oral Health Beliefs Scale items used for the present study. 
Table 3.

Oral Health Beliefs Scale

\section{Oral Health Beliefs Scale Item}

Responses:

[1 = Strongly agree; 2 = Agree; 3 = Disagree; 4 = Strongly disagree;

7 = DON'T KNOW; 8 = NO RESPONSE]

1. Tooth decay can make children look bad.

2. Dental problems can be serious for children.

3. Poor teeth will not affect children's school work or other aspects of their everyday life.

4. Having dental problems doesn't cause other health problems.

5. I will take my children to visit the dentist when they have dental problems no matter how busy I am.

6. Brushing children's teeth with fluoride toothpaste helps prevent tooth decay.

7. Using fluoride is a harmless way of preventing tooth decay.

8. Brushing teeth helps prevent gum problems.

9. Using dental floss helps prevent gum disease.

10. Eating sweet food causes tooth decay in children.

11. Going to the dentist will keep my children from having trouble with their teeth, gums, or dentures. 
The Self-Efficacy for Parenting Tasks Index (Toddler Scale) Instrumental Care/Structure/Routines Subscale (Coleman \& Karrakere, 2003) is designed to capture a parent's feelings concerning his/her ability to establish and maintain daily routines and habits. The internal consistency reliability coefficient (Cronbach's alpha) for the scale has been reported to be .91 by the authors. In the Parental Help Seeking Project, the reliability coefficient of the Self-Efficacy Index was .84.

Table 4.

Parental Self-Sufficiency Scale

\section{Parental Self-Sufficiency Scale Item}

Responses:

[1 = Strongly agree; 2 = Agree; 3 = Disagree; 4 = Strongly disagree;

7 = DON'T KNOW; 8 = NO RESPONSE]

1. I have been able to establish a regular flossing routine with my child that is comfortable for both of us.

2. My child sees me brushing my teeth everyday.

3. I have been able to establish a daily toothbrushing routine with my child that feels comfortable for both of us.

4. I am able to provide my child with a comfortable amount of daily oral hygiene.

5. I have been successful in getting my child to brush his/her teeth on a fairly regular schedule.

6. I feel like I have no control over my child's oral hygiene habits.

7. I am not very good at getting my child to stick to a regular daily schedule. 
Table 4 continued.

Parental Self-Sufficiency Scale

\section{Parental Self-Sufficiency Scale Item}

Responses:

[1 = Strongly agree; 2 = Agree; 3 = Disagree; 4 = Strongly disagree;

7 = DON'T KNOW; 8 = NO RESPONSE]

8. Although I have tried to train my child not to eat too many sweets, my efforts have been met with very little success.

9. I don't seem to be able to establish a regular bed-time routine with my child.

10. I have worked out a fairly regular morning routine with my child.

\section{Dental Subscale of the Children's Fear Survey (CFSS) - Parent Version} (Cuthbert \& Melamed, 1982). The CFSS is a 15 -item survey designed to be completed by parents that uses five-point Likert-type scales to measure how the parent rates the level of fear a child holds in regard to a specific stimulus. Mean scores have been reported as 81.6 in low-income families and the internal consistency has been reported to be high in a group of disadvantaged parents with a Cronbach's alpha of .90 (Milgrom et al., 1994). In the Parental Help Seeking Project, the reliability coefficient of the Child Fear Survey was .90.

Table 5 on the next page presents the Child Fear Scale items used for the present study. 


\section{Table 5.}

\section{$\underline{\text { Child Fear Scale }}$}

\section{Child Fear Scale Item}

\section{Responses:}

[0 $=$ Not afraid at all; $1=$ A little afraid; $2=$ A fair amount; $3=$ Pretty much afraid;

$4=$ Very afraid; 7 = DON'T KNOW; 8 = NO RESPONSE]

1. Dentists. Would you say he/she is not afraid at all, a little afraid, a fair amount afraid, pretty much afraid, or very afraid?

2. What about doctors?

3. What about injections (shots)?

4. Having somebody examine his/her mouth.

5. Having to open his/her mouth.

6. Having a stranger touch him/her.

7. Having somebody look at him/her.

8. Having somebody put instruments in his/her mouth.

9. Having to go to the hospital.

10. Having his/her teeth cleaned.

The Dental Satisfaction Questionnaire (Davies \& Ware, 1981; Davies, 1982) was developed by the Rand Corporation to measure patient satisfaction 
with dental care for the health insurance experiment. It contains 19 items measuring overall satisfaction with subscales of access, pain management, and quality. The instrument has been used with mothers of disadvantaged children and has a reliability coefficient of .90 . In the Parental Help Seeking Project, the reliability coefficient of the Dental Satisfaction Questionnaire was .92. Table 6 presents the Dental Satisfaction Questionnaire Scale items used for the present study.

Table 6.

Dental Satisfaction Questionnaire Scale

\section{Dental Satisfaction Scale Item}

Responses:

[1 = Strongly agree; 2 = Agree; 3 = Disagree; 4 = Strongly disagree;

$7=$ DON'T KNOW; 8 = NO RESPONSE]

1. There are things about the dental care my child receives that could be better.

2. The dentist is very careful to check everything when examining my child.

3. Sometimes I avoid taking my child to the dentist because it is so painful.

4. People are usually kept waiting a long time when they are at the dentist.

5. The dentist always treats my children with respect.

6. One of the reasons I take my children to the dentist where I do, is because there aren't enough dentists in my area.

7. The dental office is conveniently located.

8. The dentist is not a thorough as he/she should be. 


\section{Table 6 continued.}

\section{Dental Satisfaction Questionnaire Scale}

\section{Dental Satisfaction Scale Item}

Responses:

[1 = Strongly agree; 2 = Agree; 3 = Disagree; 4 = Strongly disagree;

$7=$ DON'T KNOW; 8 = NO RESPONSE]

9. My children see the same dentist just about every time they go to the office.

10. It's hard to get an appointment at the dentist for dental care right away.

11. The dentist is able to relieve or cure most dental problems that my child has.

12. Office hours at the dentist are good for most children.

13. The dentist usually explains what he/she is going to do and how much it will cost before they begin treatment.

14. Dentists should do more to keep children from having problems with their teeth.

15. The dental office is very modern and up-to-date.

16. I am not concerned about my children feeling pain when they go to the dentist.

Corah's Dental Anxiety Scale (DAS) (Corah, 1969) is a four-item measure that is the most widely used screening instrument for dental anxiety. Dental anxiety is conceptualized as the subject's response to the stress that is specific to the dental situation. The DAS has been normed with large groups of students, 
adults, and older individuals. The DAS is scored by summing individual scores from 1 to 5 for a total score (range of 4 to 20). The DAS has good internal consistency, with a reliability coefficient of .86 . The DAS also has good concurrent validity, with significant correlation to other measures of stress and anxiety related to dental work. The internal consistency and test-retest reliability are high (Newton \& Buck, 2000). The mean score for college psychology students is 9.07 , and researchers generally use a score of 12 or 13 and above to indicate anxious subjects and 15 or above to indicate fearful subjects. In the Parental Help Seeking Project, the reliability coefficient of the DAS was .87. Table 7 presents the Parental Dental Anxiety Scale.

\section{Table 7.}

\section{Parental Dental Anxiety Scale}

\section{Parental Dental Anxiety Scale Item}

Responses:

[ 0 = Relaxed; 1 = A little uneasy; $2=$ Tense; $3=$ Anxious; $4=$ So anxious you would break out into a sweat, $7=$ DON'T KNOW; 8 = NO RESPONSE]

1. If you had to go to the dentist tomorrow, how would you feel about it?

2. When you are waiting in the dentist's office for your turn in the chair, how do you feel?

3. When you are in the dentist's chair waiting while he/she gets the drill ready to begin working on your teeth, how do you feel?

4. You are in the dentist's chair to have your teeth cleaned. While you are waiting and the dentist or hygienist is getting out the instruments that he/she will use to scrape your teeth around the gums, how do you feel? 
The Multidimensional Scale of Perceived Social Support (MSPSS) (Zimet, 1988 ) is a 12-item instrument designed to measure perceived social support from family, friends, and significant others. The MSPSS has excellent internal consistency with alphas of .91 for the entire scale and .90 to .95 for the subscales. The author claims good test-retest reliability, good factorial validity, and good concurrent validity as well. In samples of individuals from diverse ethnic and socioeconomic backgrounds, the mean for the total score was 5.58 . In the pre-testing of the scale for the Parental Help Seeking Project, the reliability coefficient of the MSPSS was .90 . Table 8 presents the Parental Social Support Scale items used for the present study.

Table 8.

Parental Social Support Scale

\section{Parental Social Support Scale Item}

Responses:

[1 = Strongly agree; 2 = Agree $; 3=$ Disagree $; 4=$ Strongly disagree;

7 = DON'T KNOW; 8 = NO RESPONSE]

1. There is a special person who is around when I am in need.

2. My family really tries to help me.

3. My friends really try to help me.

4. I can count on my friends when things go wrong.

5. I can talk about my problems with my family. 
The Perceived Stress Scale (PSS) (Cohen et al., 1983; Cohen \& Williamson, 1988) is a 10-item instrument designed to measure the degree to which a person appraises situations in life as being stressful. In a national sample, the overall mean for the PSS was $13.02(S D=6.35)$ and yielded good internal consistency with an alpha of .78. The authors report good construct validity and correlation of the PSS with measures of help-seeking behavior. In the Parental Help Seeking Project, the reliability coefficient of the PSS was 89 .

\section{Table 9.}

\section{Parental Perceived Stress Scale}

\section{Parental Perceived Stress Scale Item}

Responses:

[ $0=$ Very often; 1 = Fairly often; 2 = Sometimes; 3 = Almost never; 4 = Never; 7 = DON'T KNOW; 8 = NO RESPONSE]

1. In the last month, how often have you been upset because of something that happened unexpectedly?

2. In the last month, how often have you felt you were unable to control the important things in your life?

3. In the last month, how often have you felt nervous and "stressed"?

4. In the last month, how often have you felt confident about your ability to handle your personal problems?

5. In the last month, how often have you felt that things were going your way?

6. In the last month, how often have you found that you could not cope with all the things that you had to do?

7. In the last month, how often have you been able to control irritations in your life?

8. In the last month, how often have you felt that you were on top of things? 
9. In the last month, how often have you been angered because of things that were outside of your control?

10. In the last month, how often have you felt difficulties were piling up so high that you could not overcome them?

\section{New Scales Developed for the Parental Help Seeking for Dental Care Study}

The literature did not provide any existing, validated measures to assess parents' perceived access to dental care, perceived discrimination toward disadvantaged families or Medicaid-eligible children, or the role of pediatricians in oral health that have been used in dentistry. The Parental Help Seeking for Dental Care team developed and pilot tested $(n=60)$ three new scales and conducted psychometric analyses of the scales before including them in the telephone survey for the study.

\section{Access to Dental Care (New Scale)}

A pilot test of the entire proposed telephone survey (including the new scales) was conducted with 60 individuals who had participated in the Phase I Focus Groups of the Parental Help Seeking Study. A principal component analysis was used to derive an inter-item correlation matrix, a component matrix with factor loadings, and eigenvalues. A single factor emerged with an eigenvalue of 2.231 , which explained $52.78 \%$ of the variance.

Table 10 on the next page presents the factor analysis for the Access to Dental Care Scale items used for the present study. 
Table 10.

Access to Dental Care Factor Analysis

\section{Access to Dental Care Scale Item}

Responses:

[0 = Very difficult; 1 = Difficult; 2 = Easy; 4 = Very easy;

7 = DON'T KNOW; 8 = NO RESPONSE]

1. How easy or difficult do you think it is to find a dentist for your child/children who will accept

Factor Loading

Corrected Medicaid or Passport?

2. If your child had a dental appointment during school hours, how easy or difficult do you think it would be to get your child out of school?

3. How easy or difficult do you think it is to get an appointment for your child that is convenient for you?

4. How easy or difficult do you think it is to transport your child to the dentist that takes Medicaid?

A reliability analysis provided an internal consistency coefficient (Cronbach's alpha) of .73 based on standardized items. Consistent with the results of the factor and internal consistency analyses, substantial (greater than +.35) corrected item total correlations were evident for each item.

The baseline (Wave 1) Parental Help Seeking for Dental Care survey data $(n=202)$ was analyzed in an identical manner. The Access to Dental Care scale again loaded onto one factor with loadings ranging from .537 to .730 ; however, the Cronbach's alpha dropped to .54. The Cronbach's alpha for Wave $2(n=176)$ was .65 and for Wave $3(n=122)$ was .70 . 


\section{Perceived Discrimination (New Scale)}

Identical factor and internal consistency analyses also were conducted with the new Perceived Discrimination scale in the Parental Help Seeking Pilot study. A single factor emerged with an eigenvalue of 2.62 , which explained $65.4 \%$ of the variance.

\section{Table 11.}

Perceived Discrimination Factor Analysis

\section{Perceived Discrimination Care Scale Item}

Responses:

[1 = Strongly agree; 2 = Agree; 3 = Disagree;

Factor Corrected

4 = Strongly disagree; 7 = DON'T KNOW; Loading Item Total $8=$ NO RESPONSE]

1. The dental staff always treats my children with .726 .542 respect.

2. My children and I are treated differently because .843 .689 we have Medicaid.

3. My children and I are treated differently because of our income.

4. My children and I are treated differently because of .816 .653 our race/ethnicity.

A reliability analysis provided an internal consistency coefficient (Cronbach's alpha) for the Perceived Discrimination scale of .82. Consistent with the results of the factor and internal consistency analyses, substantial (greater than +.35 ) corrected item total correlations were evident for each item. 
The baseline (Wave 1) Parental Help Seeking for Dental Care survey data $(n=202)$ was analyzed in an identical manner. The Perceived Discrimination Care scale again loaded onto one factor with loadings ranging from .626 to .891 , with a Cronbach's alpha dropped to .83 . The Cronbach's alpha for Wave 2 $(n=176)$ was .77 ; it was .77 for Wave $3(n=122)$ as well.

\section{Pediatrician Role (New Scale)}

Factor and internal consistency analyses also were conducted with the new Pediatrician Role scale with the Parental Help Seeking study. A single factor emerged with an eigenvalue of 1.86 which explained $62.3 \%$ of the variance.

\section{Table 12.}

\section{$\underline{\text { Pediatrician Role Factor Analysis }}$}

\section{Pediatrician Role Scale Item}

\section{Responses:}

[1 = Strongly agree; 2 = Agree; 3 = Disagree;

4 = Strongly disagree; 7 = DON'T KNOW;

Factor Corrected

Loading

$8=$ NO RESPONSE]

1. My child's doctor/pediatrician has told me that

.821

.409 dental care is important.

2. My child's doctor/pediatrician checks my child for dental problems.

3. My child's doctor/pediatrician has referred me to a good dentist.

A reliability analysis provided an internal consistency coefficient (Cronbach's alpha) for the Pediatrician Role scale of .693. Consistent with the 
results of the factor and internal consistency analyses, substantial (greater than +.35) corrected item total correlations were evident for each item.

The baseline (Wave 1) Parental Help Seeking for Dental Care survey data $(n=202)$ was analyzed in an identical manner. The Pediatrician Scale again loaded onto one factor with loadings ranging from .725 to .789 , with a Cronbach's alpha dropped to .638 . The Cronbach's alpha was .620 for Wave $2(n=176)$ and .681 for Wave $3(n=122)$.

\section{Data Management}

Respondent Identification and Data Linkage: Each parent and child pair was assigned a unique identification number that was associated with all parent telephone surveys and dental utilization data. The program staff maintains this number in a confidential manner. All study subjects have been de-identified in the data set used for analysis.

Data Processing, Clean-up, and Retention: Telephone survey and utilization data were entered using the SPSS direct entry input screen. All data were checked for logic inconsistencies, missing data, and out-of-range responses. All electronic files are being maintained confidentially for five years after completion of the project.

Quality Controls: The minimum quality control procedures for data management included the following steps: (1) data coding and keying specifications were constructed for every item in each instrument; (2) a computational plan was prepared that specified each stage of data processing, scale construction, analysis and file storage; (3) SPSS syntax files were reviewed 
for accuracy, then retained and labeled according to each analysis step so results can be replicated; and (4) data files are password protected and accessible only by the investigator. All files were backed up nightly onto disc.

Computational Plan: The data files were created and cleaned. Factor analyses and assessment of the reliability of scales were conducted for the potential covariate variables (e.g., Oral Health Beliefs scale, Perceived Need, Social Support, Stress). Statistical validity checks were conducted including univariate distribution checks, variable transformation to correct for non-normal distribution if needed, and homogeneity of variance and group comparisons were conducted.

\section{Results of Initial Parental Help Seeking for Dental Care Analyses}

Study Subjects: The parents/caregivers in the study were predominantly African American females. The demographic characteristics of the intervention and control groups were approximately equal as shown in Table 1.

A total of 202 parents/caregivers were included in the final analysis with an intention to treat-that is, they were included in the analyses whether they had completed all study activities or had not completed all study activities including the final (Wave 3) telephone survey. A total of 176 (or $87 \%$ of the sample) families ( $n=86$ Control, $n=90$ Intervention) completed the Wave 2 survey, and 122 families or $60 \%$ of the sample ( $n=58$ Control, $n=64$ Intervention) completed the Wave 3 survey. Sixty-nine percent $(n=140)$ of the baseline sample reported having a usual source of dental care, with $n=71$ in the control group and $n=69$ in the intervention group. 
Intervention Processes: The following intervention characteristics were evaluated and the results are briefly summarized below for the 101 intervention subjects:

- Home Visit Occurred in Some Manner - 52 received a face-to-face visit and 47 received materials in the mail.

- Length of Home Visit $-87 \%$ of the visits were 90 minutes or less.

- Number of Calls to Schedule a Home Visit $-60 \%$ were scheduled on the first call, $30 \%$ required 2 to 7 phone calls, and the remainder required 8 to 16 calls.

- Number of Times a Home Visit Was Cancelled - Information was collected on this process for only 22 subjects: 6 cancelled once, 15 cancelled twice, and 1 cancelled 3 times.

- Was the Home Visit Interrupted? - $66 \%$ of home visits were interrupted.

- Was a Dental Visit Scheduled During The Home Visit? - The case manager was able to schedule a dental visit $30 \%$ of the time during his home visit.

- Was Transportation Funded for Dental Visit? - 24 families requested transportation assistance and were provided with bus tickets.

- Did the Child and Family Meet the Dentist and Dental Staff? - 22 intervention families met the dental staff with the case manager.

- Did the Child and Family Tour the Dental Facility? - 22 intervention families toured the dental office with the case manager. 
Fidelity of Intervention: Staff not involved in the intervention study conducted a brief telephone survey with parents/caregivers in the intervention group after the case manager reported conducting a home visit. The purpose of the survey was to determine the subject's satisfaction with the intervention and with the professional qualities of the case manager. The following questions were asked with responses of $0=$ poor, $1=$ below average, $2=$ average, $3=$ good, $4=$ excellent, $88=$ no response, and $99=$ don't know.

\section{$\underline{\text { Satisfaction with Dental Case Manager Fidelity Scale }}$}

1. How would you rate the Dental Coordinator on how he answered any questions you may have had?

2. How respectfully did the Dental Coordinator treat you and your family?

3. How would you rate the courteousness of the Dental Coordinator?

4. How would you rate the enthusiasm of the Dental Coordinator?

Thirty-two subjects completed the Case Manager Fidelity Scale with a mean response of $3.8(S D=.3)$ suggesting very high satisfaction with the professionalism of the case manager.

\section{Satisfaction with Intervention Fidelity Scale}

1. How would you rate the quality of the dental health information that was presented to you and your family?

2. How would you rate the usefulness of the dental health information?

Forty-two subjects completed the Intervention Fidelity Scale with a mean response of $3.8(S D=.4)$ suggesting high satisfaction with the educational materials provided. 


\section{Impact of the Intervention on Utilization}

Examination of utilization data for the two-year period prior to the study indicated that $24 \%(n=48)$ of all the study children had previously utilized dental care, with 23 in the control and 25 in the intervention groups. Dental utilization after the baseline (Wave 1) telephone survey and before the end of the study period was $36 \%$ (36 of 101) for the control group and $42 \%$ (42 of 101) for the intervention group $\left(\chi^{2}=.75, p=.39\right)$.

A logistic regression analysis indicated that children in the intervention group were no more likely to utilize dental care than those from the control group (odds ratio $[O R]=1.24, p=.48$ ), after controlling for perceived need for dental care, income, employment, having a usual source of dental care, and prior dental usage. The results for covariates suggest that children whose parents earned more than $\$ 5,000$ (odds ratio $=3.62, p=.001$ ) per year were more likely to attend the dentist.

\section{Dissertation Study Analyses}

This dissertation study consists of an analysis of the effectiveness of the intervention as well as an exploratory analysis of factors that might or might not predict the effectiveness of the home visitation/case manager intervention to increase dental care utilization by disadvantaged children. Due to the relatively small sample size of this pilot study, the researcher was only able to examine potential associations and was not able to examine causal relationships.

Bivariate ( $t$-tests for continuous variables and Fisher's exact test for categorical variables) analyses were conducted to determine if there were any 
significant differences in the independent variable and potential covariates between parents/caregivers who utilized dental care for their children and those who did not utilize dental care.

A separate attrition analysis was performed to compare those participants who completed the study ("Completers"; $n=122$ ) with those who were lost to follow-up ("Droppers"; $n=80$ ). Fisher's exact test was used to compare the groups in terms of baseline categorical characteristics (gender, ethnicity, etc.), and the two-sample $t$-test was used for the continuous baseline variables. (The MannWhitney-Wilcoxon test was used for ordinal variables and any of the continuous variables that exhibited extreme skewness.) Results of these analyses were used in guiding the discussions included here on the generalizability of the study findings.

Correlations between the independent variables and potential covariates were examined to determine if there was any potential multicollinearity that would preclude certain variables being entered together in a multiple regression analysis. Multicollinearity occurs when two or more variables are very highly intercorrelated and it can yield misleading results with, for example, regression coefficients with the wrong sign, or inflated standard errors (Tabachnick \& Fidell, 2001). Tests for multicollinearity based on the tolerance $\left(1-R^{2}\right.$ or $1-$ squared multiple correlation) and the Variance Inflation Factor (VIF), which is the reciprocal of the tolerance for each variable, were performed. A variable with a VIF greater than 10 was investigated further for potential multicollinarity. 
Multivariate (logistic and multiple regression) analyses were conducted to examine the main effects of the independent variable on the dependent variable while controlling for potential confounders. A probability of .05 or less was used as the criterion for statistical significance. Two tailed tests of significance were used throughout since there is no a priori expectation for the direction of the alternative hypothesis (Dawson \& Trapp, 2001). Data were analyzed using SPSS 15.0 Base System software (SPSS, Inc., Chicago, IL).

Three research questions were answered by using the analysis techniques described below. Each analysis was run twice, once using intentionto-treat (all 202 parents enrolled in the study) and again as a Completer analysis (all 122 parents who completed the study).

Research Question \#1: What is the direct effect of the intervention on dental care utilization?

\section{Method: Logistic Regression with Forward Selection}

The dichotomous dependent/outcome variable (utilization coded as $0=$ no utilization, and $1=$ utilization) and the dichotomous independent/predictor variable (intervention coded $0=$ control, and $1=$ intervention) were entered into the logistic regression (Hosmer \& Lemeshow, 2000).

Using forward selection, the potential confounder that had the strongest association with utilization, after allowing for the association of utilization with the intervention, was determined. Next, the potential confounder that had the strongest association with utilization was selected, after allowing for the association of utilization with the intervention and the most important confounder. 
This process continued until there were no longer any significant confounding variables to be added to the model. Potential confounding variables that were considered included socioeconomic variables (income, education, employment, etc.) and psychosocial variables (social support, stress, self-efficacy, perceived need, etc.). The logistic regression coefficients were used to calculate adjusted odds ratios for the significant independent variables retained in the model.

\section{Research Question \#2: Do contextual (individual and demographic)}

\section{factors moderate the intervention effects on utilization?}

\section{Method: Logistic Regression}

Moderating variables affect the direction and/or strength of the relation between an independent/predictor (intervention) and dependent/outcome (utilization) variable. A moderator changes the effect of an explanatory variable on the outcome variable. For example, the effect of the intervention on child utilization may depend on whether the child is white or African American and then the child's race is a moderator of the relation between the effect of the intervention and utilization. Previous studies and theoretical models investigated the effect of demographic and individual factors such as child age (Kaakko et al., 2002), poverty (Szilagyi et al., 2004), and perceived need for dental care (Milgrom et al., 1998) as potential moderators of the effect of the intervention on utilization. The determination of moderators that were included in the final regression models provided information concerning parents or families who could benefit the most from a case manager intervention. 
Per Tabachnick and Fidell (p. 151), the potential continuous moderator variables were centered "conversion to deviation scores so that each variable has a mean of zero" (Tabachnick \& Fidell, 2001) to avoid potential multicollinarity and model-fitting problems (Crohbach, 1987; Jaccard et al., 1990; Tabachnick \& Fidell, 2001). Interaction terms were created by multiplying the intervention times each moderator. The independent variable was entered first into the regression equation followed by the potential moderator (e.g., perceived

need) and then, if appropriate, the interaction variable.

Post-hoc probing of significant moderational effects (Holmbeck, 2002) was conducted to determine whether the specific relationship between the moderator (e.g., perceived need) and the independent variable (intervention/control) is significant for one or the other samples or both.

Research Question \#3: What is the effect of the intervention on

\section{barriers?}

\section{Method: Multiple Regression With Forward Selection}

The same analysis strategy used to analyze Research Question \#1 was applied to Research Question \#3 but with barriers (structural and personal) designated as the dependent variables. The barriers were the scale or ordinal variables (change in scores from the baseline telephone survey to the final/third telephone survey for the Access to Dental Care Scale, Satisfaction with Dental Care Scale, and Oral Health Beliefs Scale); thus, multiple regression was used.

Treating each barrier variable as the dependent variable, the barrier variable and the dichotomous independent/predictor variable (intervention coded 
$0=$ control, and $1=$ intervention) were entered into the multiple regression equation.

Using forward selection, the potential confounder that had the strongest association with the dependent variable was determined, after allowing for the association of the dependent variable with the intervention. Next, the potential confounder that had the strongest association with the dependent variable, after allowing for the association of the dependent variable with the intervention and the most important confounder, was selected. This process continued until there were no longer any significant confounding variables to be added to the model. Potential confounding variables that were considered included socioeconomic variables (income, education, employment, etc.) and psychosocial variables (social support, stress, self-efficacy, perceived need, etc.).

The standardized regression coefficients were used to describe the relative importance for each of the significant independent variables retained in the model. This multiple regression analysis was performed separately for each of the barrier dependent variables.

\section{Summary}

The goal of this study was to determine if a case manager/home visitation intervention can improve access to dental care for disadvantaged children and which parents may benefit most from this intervention. The primary goal of the statistical analyses was to find parsimonious models that describe the associations between dental care utilization and the intervention, and the associations between the intervention and barriers to utilization after adjusting for 
significant confounding variables. A secondary goal of the analysis was to determine if there are parents with particular characteristics (e.g., extremely low income) who may benefit most from the intervention. It is hoped that these findings will help to direct future intervention research to improve the oral health of our nation's disadvantaged children. 


\section{CHAPTER 4}

\section{RESULTS}

This chapter presents the results of the data analyses for this dissertation study. First, the statistical validity checks performed on the data are described. Following that is discourse that compares the demographic characteristics of all the enrolled parents who took their child to the dentist according to Medicaid records (Utilizers) to those of parents who did not take their child to the dentist (Non-Utilizers) during the time immediately after the first telephone survey until the end of the study. A similar comparison is then provided as an attrition analysis to describe the characteristics of parents who completed the study (Completers), as evidenced by completion of the third telephone interview, with the entire sample including those who dropped out of the study (Droppers). Next, a comparison of the study variables for Utilizers and Non-Utilizers is presented. Finally, the results of the analyses directed toward each of the three Research Questions are provided.

\section{Statistical Validity Checks}

Univariate Distribution Checks: Descriptive statistics for all variables to be used in final inferential analyses were calculated using the SPSS frequencies command. The frequencies command was used because it produces the following descriptive statistics useful for determining the distribution of data: 
skewness, SE of skewness, kurtosis, and SE of kurtosis. As described by the SPSS 15.0 Base System software, skewness is:

...A measure of the asymmetry of a distribution. The normal distribution is symmetric and has a skewness value of 0 . A distribution with a significant positive skewness has a long right tail. A distribution with a significant negative skewness has a long left tail. As a guideline, a skewness value more than twice its standard error is taken to indicate a departure from symmetry. Kurtosis is a measure of the extent to which observations cluster around a central point. For a normal distribution, the value of the kurtosis statistic is zero. Positive kurtosis indicates that the observations cluster more and have longer tails than those in the normal distribution, and negative kurtosis indicates that the observations cluster less and have shorter tails. (SPSS 15.0 Base System)

Kolmogorov-Smirnov tests for normality indicated that only the Access to Dental Care baseline scale score $(p=.607)$ was normally distributed. All other Scale Factor scores were not normally distributed $(p \leq .05)$. The skewness and kurtosis statistics were all within acceptable limits except for the Child Fear, Dental Satisfaction, Discrimination, and Parental Anxiety Scale scores which had a skewness that was more than twice the skewness standard error. Due to the lack of normality for all the scales, the Mann-Whitney-Wilcoxon test was used in all two-group comparisons (Dawson \& Trapp, 2001). 


\section{Table 13.}

Univariate Analysis of Skewness and Kurtosis for Baseline Survey Factor Scores

\begin{tabular}{|l|r|r|r|r|r|r|}
\hline & & & & & & \\
& & & & & & \\
& Mean & Std. Dev. & $\begin{array}{l}\text { Skew } \\
\text { ness }\end{array}$ & $\begin{array}{l}\text { S.E. } \\
\text { Of Skew } \\
\text { ness }\end{array}$ & Kurtosis & $\begin{array}{c}\text { S.E. of } \\
\text { Kurtosis }\end{array}$ \\
\hline FS \#1 Access to Dental Scale & .0135 & .89515 & -.293 & .171 & .364 & .341 \\
FS \#2 Oral Health Belief Scale & .0216 & .93343 & .115 & .171 & -1.277 & .341 \\
FS \#3 Pediatrician's Role & -.0099 & .81352 & -.191 & .171 & .241 & .341 \\
FS \#4 Parental Self-Sufficiency & .0230 & .95378 & -.085 & .171 & -.004 & .341 \\
Scale & & & & & \\
FS \#5 Child Fear & -.0342 & .92892 & 1.492 & .171 & 2.079 & .341 \\
FS \#6 Dental Quality & .0353 & .94867 & .582 & .171 & -.104 & .341 \\
FS \#7 Discrimination & .0236 & .95684 & -.480 & .171 & 1.574 & .341 \\
FS \#8 Parental Anxiety & -.0319 & .97646 & .851 & .171 & -.056 & .341 \\
FS \#9 Parental Social Support & -.0090 & .97058 & -.396 & .171 & .073 & .341 \\
FS \#10 Parental Perceived Stress & -.0272 & .92643 & -.012 & .171 & -.591 & .341 \\
\hline
\end{tabular}

\section{Profile of Utilizers and Non-Utilizers}

A total of 202 parents completed the baseline telephone survey and eventually 78 parents took their child to the dentist (Utilizers), according to Medicaid utilization data. Among the group who had not utilized dental care in the prior two years $(n=154)$, utilization during the study was $37 \%$ (57 out of 154 ). Among those who had utilized dental care in the prior two years $(n=48), 44 \%$ (21 out of 48) obtained dental care during the study.

The Utilizers and Non-Utilizers groups were similar in demographics with the exception of attrition from the study, income, and employment as described in Table 14 below. 
Table 14.

Bivariate Analyses of Utilizers and Non-Utilizers

\begin{tabular}{|c|c|c|c|}
\hline Characteristic & $\begin{array}{l}\text { Utilizers } \\
(n=78)\end{array}$ & $\begin{array}{l}\text { Non-Utilizers } \\
\quad(n=124)\end{array}$ & $p$ value \\
\hline Intervention Group, n (\%) & $42(54 \%)$ & $59(48 \%)$ & \\
\hline Control Group, n (\%) & $36(46 \%)$ & $65(52 \%)$ & \\
\hline Attrition at $3^{\text {rd }}$ Survey, $n(\%)$ & $22(28 \%)$ & $58(47 \%)$ & $.012^{*}$ \\
\hline Age, Mean (Range) & $38 \pm 11$ & $36 \pm 8.4$ & .246 \\
\hline \multicolumn{4}{|l|}{ Gender, n (\%) } \\
\hline Male & $2(3 \%)$ & $1(1 \%)$ & \\
\hline Female & $76(97 \%)$ & $123(99 \%)$ & \\
\hline Race/Ethnicity, n (\%) & & & .421 \\
\hline African American & $62(80 \%)$ & $100(81 \%)$ & \\
\hline White & $15(19 \%)$ & $19(15 \%)$ & \\
\hline Asian & $1(1 \%)$ & 0 & \\
\hline American Indian & 0 & $1(1 \%)$ & \\
\hline Other & 0 & $4(3 \%)$ & \\
\hline Education, n (\%) & & & .192 \\
\hline Did Not Complete High School & $10(13 \%)$ & $24(19 \%)$ & \\
\hline High School & $32(41 \%)$ & $45(36 \%)$ & \\
\hline Some College & $34(44 \%)$ & $52(42 \%)$ & \\
\hline Graduated College & $2(2 \%)$ & $3(2 \%)$ & \\
\hline
\end{tabular}

Table continues... 
Table 14 continued.

Bivariate Analyses of Utilizers and Non-Utilizers

\begin{tabular}{|c|c|c|c|}
\hline Characteristic & $\begin{array}{l}\text { Utilizers } \\
\text { (n=78) }\end{array}$ & $\begin{array}{l}\text { Non-Utilizers } \\
\qquad(n=124)\end{array}$ & $p$ value \\
\hline Income, n (\%) & & & $.018^{*}$ \\
\hline Under $\$ 5,000$ & $13(17 \%)$ & $45(37 \%)$ & \\
\hline$\$ 5,000-\$ 15,000$ & $35(45 \%)$ & $40(33 \%)$ & \\
\hline$\$ 15,000-\$ 25,000$ & $26(34 \%)$ & $28(23 \%)$ & \\
\hline Over $\$ 25,000$ & $3(4 \%)$ & $8(7 \%)$ & \\
\hline Employment Status, n (\%) & & & $.040^{*}$ \\
\hline Working & $29(38 \%)$ & $59(48 \%)$ & \\
\hline Not Working & $25(33 \%)$ & $40(33 \%)$ & \\
\hline Other & $22(29 \%)$ & $24(19 \%)$ & \\
\hline Marital Status, n (\%) & & & .099 \\
\hline Single & $39(50 \%)$ & $76(61 \%)$ & \\
\hline Married/Partner & $15(19 \%)$ & $19(15 \%)$ & \\
\hline Divorced/Separated/Widowed & $24(31 \%)$ & $29(24 \%)$ & \\
\hline No. Children Living at Home, Mean & 3.01 & 3.17 & .157 \\
\hline $\begin{array}{l}\text { Child Oral Health (Parent's estimate } \\
\text { of child's oral health?), n (\%) }\end{array}$ & & & .650 \\
\hline Poor & $3(4 \%)$ & $5(4 \%)$ & \\
\hline Fair & $15(19 \%)$ & $15(12 \%)$ & \\
\hline Good & $26(33 \%)$ & $47(38 \%)$ & \\
\hline Very Good & $23(29 \%)$ & $38(31 \%)$ & \\
\hline
\end{tabular}

Table continues... 
Table 14 continued.

Bivariate Analyses of Utilizers and Non-Utilizers

\begin{tabular}{lccc}
\hline Characteristic & $\begin{array}{c}\text { Utilizers } \\
(\mathbf{n}=78)\end{array}$ & $\begin{array}{c}\text { Non-Utilizers } \\
(\mathbf{n = 1 2 4 )}\end{array}$ & p value \\
\hline $\begin{array}{l}\text { Child Oral Health (Parent's estimate } \\
\text { of child's oral health?), } \mathbf{n}(\%)\end{array}$ & $12(15 \%)$ & $18(15 \%)$ & .650 \\
$\quad$ Excellent & $15 / 78(19 \%)$ & $18 / 124(14.5 \%)$ & .294 \\
Utilization 1 Year Prior, $\mathbf{n}(\%)$ & $21 / 78(27 \%)$ & $27 / 124(22 \%)$ & .403 \\
\hline
\end{tabular}

${ }^{*}=$ Significant at .05 level

\section{Group Comparison Tests - Utilizers vs. Non-Utilizers}

Fisher's exact test for categorical variables and $t$-tests for continuous variables were used to compare characteristics between parents who utilized and those who did not utilize dental care for their children. Individual variables that were used included:

- Q45 - Number of days children absent from school.

- Q48 - Does your child have any medical problems now?

- Q50 - How many times has your child been to the doctor/pediatrician in the past 12 months?

- Q51 - Does your child have teeth with cavities or fillings to replace or gumboils that require a visit to the dentist soon?

- Q53 - Has your child ever been to see a dentist?

- Q54 - How many times did your child visit the dentist last year?

- Q85 - How would you rate the appearance of your teeth? 
- Q86 - Are you missing teeth in your mouth?

- Q87 - Do you currently have a dentist you could go to if you had a problem?

- Q115 - Do you plan on moving or relocating?

The only statistically significant difference in these individual characteristics between parents who utilized and those who did not utilize dental care was perceived need for dental care (Q51 - Does your child have teeth with cavities or fillings to replace or gumboils that require a visit to the dentist soon?). Parents who thought their child needed treatment (Perceived Need) were significantly more likely to obtain dental care for their child during the study, $\chi^{2}=$ $6.23, p=.013$, Fisher's Exact test $p=.014$.

Finally, groups were compared in terms of scores on the baseline measures in the survey with the Mann-Whitney $U$ test. The measures included access to dental care, oral health beliefs, pediatrician role, parental self-efficacy, child fear, dental satisfaction, perceived discrimination, parent dental anxiety, parental social support, and parental stress. There were no significant differences between Utilizers and Non-Utilizers on any of these scores at baseline as shown in Table 15 on the next page. 
Table 15.

Baseline Scale Factor Scores for Utilizers and Non-Utilizers

Utilizers $(n=78)$ vs. Non-Utilizers $(n=124)$

\begin{tabular}{|c|c|c|c|c|}
\hline Scale Factor Score & Type & Mean & S.D. & $\begin{array}{c}\text { Mann- } \\
\text { Whitney } \\
p \text { value }\end{array}$ \\
\hline \multirow[t]{2}{*}{ Access to Dental Care } & Utilizers & .0524 & .8756 & .68 \\
\hline & Non-Utilizers & -.0484 & .9271 & \\
\hline \multirow[t]{2}{*}{ Oral Health Beliefs } & Utilizers & .0125 & .9378 & .87 \\
\hline & Non-Utilizers & .0359 & .9323 & \\
\hline \multirow[t]{2}{*}{ Pediatrician role } & Utilizers & .0182 & .8151 & .47 \\
\hline & Non-Utilizers & -.0546 & .8143 & \\
\hline \multirow[t]{2}{*}{ Self-Efficacy } & Utilizers & .0099 & .8808 & .84 \\
\hline & Non-Utilizers & .0437 & 1.065 & \\
\hline \multirow[t]{2}{*}{ Child Fear } & Utilizers & -.0054 & .9080 & .22 \\
\hline & Non-Utilizers & -.0801 & .9654 & \\
\hline \multirow[t]{2}{*}{ Satisfaction with Dental Care } & Utilizers & -.0312 & .9136 & .09 \\
\hline & Non-Utilizers & .1411 & .9987 & \\
\hline \multirow[t]{2}{*}{ Discrimination } & Utilizers & -.0332 & .99423 & .23 \\
\hline & Non-Utilizers & .1138 & .8930 & \\
\hline \multirow[t]{2}{*}{ Parental Anxiety } & Utilizers & -.0516 & .8968 & .76 \\
\hline & Non-Utilizers & -.0007 & 1.0966 & \\
\hline \multirow[t]{2}{*}{ Social Support } & Utilizers & -.0605 & .9925 & .39 \\
\hline & Non-Utilizers & .0730 & .9351 & \\
\hline \multirow[t]{2}{*}{ Perceived Stress } & Utilizers & -.0084 & .9304 & .87 \\
\hline & Non-Utilizers & -.0570 & .9254 & \\
\hline
\end{tabular}




\section{Attrition Analysis}

Subjects who completed the study (Completers) were compared with subjects enrolled but who did not complete the study (Droppers) in terms of demographic and individual characteristics. The demographic results are summarized in Table 16 below.

Table 16.

Bivariate Analyses of Completers and Droppers

\begin{tabular}{lccc}
\hline Characteristic & $\begin{array}{c}\text { Completers } \\
(\mathbf{n = 1 2 2})\end{array}$ & $\begin{array}{c}\text { Droppers } \\
(\mathbf{n}=80)\end{array}$ & $\boldsymbol{p}$ value \\
\hline Intervention Group, $\mathbf{n}(\%)$ & $64(52.5 \%)$ & $37(46 \%)$ & .472 \\
Control Group, $\mathbf{n}(\%)$ & $58(47.5 \%)$ & $43(54 \%)$ & \\
Age (Mean/Range) & $38.5(20-74)$ & $34.3(22-63)$ & $.002^{*}$ \\
Gender, $\mathbf{n}(\%)$ & & & \\
Male & $3(2.5 \%)$ & 0 & .339 \\
Female & $119(97.5 \%)$ & $80(100 \%)$ & \\
Race/Ethnicity, $\mathbf{n}(\%)$ & & $61(80 \%)$ & \\
African American & $101(83 \%)$ & $16(20 \%)$ & \\
White & $18(15 \%)$ & 0 & \\
Asian & 1 & 0 & \\
American Indian & 0 & 2 & \\
Other & & & \\
\hline
\end{tabular}

Table continues... 
Table 16 continued.

Bivariate Analyses of Completers and Droppers

\begin{tabular}{|c|c|c|c|}
\hline Characteristic & $\begin{array}{l}\text { Completers } \\
\qquad(n=122)\end{array}$ & $\begin{array}{c}\text { Droppers } \\
\qquad(n=80)\end{array}$ & $p$ value \\
\hline Education, $\mathrm{n}(\%)$ & & & .566 \\
\hline Did Not Complete High School & $18(15 \%)$ & $16(20 \%)$ & \\
\hline High School & $48(39 \%)$ & $29(36 \%)$ & \\
\hline Some College & $54(44 \%)$ & $32(40 \%)$ & \\
\hline Graduated College & $2(2 \%)$ & $3(4 \%)$ & \\
\hline Income, n (\%) & & & .075 \\
\hline Under $\$ 5,000$ & $29(24 \%)$ & $29(36 \%)$ & \\
\hline$\$ 5,000-\$ 15,000$ & $43(35 \%)$ & $32(40 \%)$ & \\
\hline$\$ 15,000-\$ 25,000$ & $42(34 \%)$ & $12(15 \%)$ & \\
\hline Over $\$ 25,000$ & $6(5 \%)$ & $5(6 \%)$ & \\
\hline Employment Status, n (\%) & & & .260 \\
\hline Working & $55(46 \%)$ & $33(41 \%)$ & \\
\hline Not Working & $37(32 \%)$ & $28(35 \%)$ & \\
\hline Other & $27(22 \%)$ & $19(24 \%)$ & \\
\hline Marital Status, n (\%) & & & .078 \\
\hline Single & $67(55 \%)$ & $48(60 \%)$ & \\
\hline Married/Partner & $20(16 \%)$ & $14(18 \%)$ & \\
\hline Divorced/Separated/Widowed & $35(29 \%)$ & $18(22 \%)$ & \\
\hline $\begin{array}{l}\text { No. Children Living at Home, Mean } \\
\text { (range) }\end{array}$ & $3.02(1-9)$ & $3.25(1-9)$ & .325 \\
\hline
\end{tabular}

Table continues... 
Table 16 continued.

Bivariate Analyses of Completers and Droppers

\begin{tabular}{lccc}
\hline Characteristic & $\begin{array}{c}\text { Completers } \\
(\mathbf{n = 1 2 2})\end{array}$ & $\begin{array}{c}\text { Droppers } \\
(\mathbf{n}=80)\end{array}$ & $p$ value \\
\hline $\begin{array}{l}\text { Child Oral Health (Parent's estimate } \\
\text { of child's oral health?), } \mathbf{n}(\%)\end{array}$ & & .501 \\
$\quad$ Poor & $5(4 \%)$ & $3(4 \%)$ & \\
Fair & $20(16 \%)$ & $9(11 \%)$ & \\
Good & $44(36 \%)$ & $31(39 \%)$ & \\
Very Good & $35(29 \%)$ & $26(32 \%)$ & \\
Excellent & $18(15 \%)$ & $11(14 \%)$ & \\
Utilization 1 Year Prior, $\mathbf{n}(\%)$ & $21 / 122(17 \%)$ & $13 / 80(16 \%)$ & .718 \\
Utilization 2 Years Prior, $\mathbf{n}(\%)$ & $29 / 122(24 \%)$ & $19 / 80(24 \%)$ & .997 \\
\hline
\end{tabular}

${ }^{*}=$ Significant at .05 level

Analysis of the differences between Completers and Droppers individual characteristics was conducted in the same manner as the comparisons of the Utilizers and Non-Utilizers. Independent sample $t$-tests with attrition from baseline to study end (Yes, No) as the grouping variable were performed for continuous variables and Fisher's exact test was performed for categorical variables. The results of this analysis suggest that participants who are younger are significantly more likely to drop out of the study $(p=.002)$. There was a trend toward those with lower income $(p=.075)$ and those who were never married $(p=.078)$ to drop out of the study as well. There were no differences in the 
individual characteristics such as parent missing teeth or days off from school between the Completers and the Droppers.

Analysis of scale factor scores with the Mann-Whitney independent $t$-tests with attrition as the grouping variable on the 10 measures (e.g., access to care, oral health beliefs) did not show any significant differences between the Completers and Droppers as shown in Table 17.

\section{Table 17.}

Baseline Scale Factor Scores for Completers and Droppers

\begin{tabular}{|c|c|c|c|c|}
\hline \multicolumn{5}{|c|}{ Completers $(n=122)$ vs. Droppers $(n=80)$} \\
\hline Scale Factor Score & Type & Mean & S.D. & $\begin{array}{c}\text { Mann- } \\
\text { Whitney } \\
p \text { value }\end{array}$ \\
\hline \multirow[t]{2}{*}{ Access to Dental Care } & Completers & -.031 & .911 & .62 \\
\hline & Droppers & .081 & .872 & \\
\hline \multirow[t]{2}{*}{ Oral Health Beliefs } & Completers & .111 & .909 & .11 \\
\hline & Droppers & -.115 & .959 & \\
\hline \multirow[t]{2}{*}{ Pediatrician role } & Completers & -.047 & .856 & .36 \\
\hline & Droppers & .046 & .745 & \\
\hline \multirow[t]{2}{*}{ Self-Efficacy } & Completers & -.074 & .984 & .22 \\
\hline & Droppers & .171 & .892 & \\
\hline \multirow[t]{2}{*}{ Child Fear } & Completers & -.644 & .965 & .22 \\
\hline & Droppers & .012 & .875 & \\
\hline \multirow[t]{2}{*}{ Satisfaction with Dental Care } & Completers & -.033 & .954 & .43 \\
\hline & Droppers & .094 & .943 & \\
\hline \multirow[t]{2}{*}{ Discrimination } & Completers & -.029 & .992 & .41 \\
\hline & Droppers & .103 & .901 & \\
\hline
\end{tabular}


Table 17 continued.

Baseline Scale Factor Scores for Completers and Droppers

Completers $(n=122)$ vs. Droppers $(n=80)$

\begin{tabular}{llccc}
\hline Scale Factor Score & Type & Mean & S.D. & $\begin{array}{c}\text { Mann- } \\
\text { Whitney } \\
\boldsymbol{p} \text { value }\end{array}$ \\
\hline Parental Anxiety & Completers & -.049 & .965 & .81 \\
& Droppers & -.006 & .999 & \\
Social Support & Completers & -.026 & 1.01 & .71 \\
& Droppers & .016 & .920 & \\
Perceived Stress & Completers & .062 & .929 & .10 \\
& Droppers & -.163 & .911 & \\
\hline
\end{tabular}

A propensity to attrit score was created by regressing the logit of the dichotomous "attritted at the third telephone survey" variable on the significant variables of parent age and income. A propensity score was created to be used as a covariate in the Intent-to-Treat analyses. Thus, this approach uses the variance unaccounted for in attrition by parent age, marital status, and income as a potential predictor of the outcome variable (Graham \& Donaldson, 1993; Hansen et al., 1985).

\section{Research Question \#1 - Intent-to-Treat Analyses ( $n=202)$}

The first research question sought to determine if the case manager intervention had a direct effect on the utilization of dental care. Thirty-six of the 101 control parents took their child to the dentist during the study while 42 of the 101 intervention parents utilized dental care during the study. Initially, the dichotomous dependent/outcome variable (utilization coded $0=$ no utilization, 
and $1=$ utilization) and the dichotomous independent/predictor variable (intervention coded $0=$ control, and $1=$ intervention) were entered into the logistic regression. As expected, for the Intent-to-Treat analysis $(n=202)$, the intervention did not prove significant in predicting utilization $(p=.386)$ with an estimated odds ratio of 1.285 and a $95 \%$ confidence interval of .73 to 2.27 . Table 18 shows the logistic regression coefficient, Wald test, and the estimated odds ratio $[\operatorname{Exp}(B)]$ for the dependent variable utilization regressed on the dependent variable intervention/control for all subjects enrolled in the study.

Table 18.

Logistic Regression Intent-to-Treat $(n=202)$

Variables in the Equation

\begin{tabular}{|c|c|c|c|c|c|c|c|}
\hline & B & S.E. & Wald & df & Sig. & $\operatorname{Exp}(B)$ \\
\hline Stap & InterDummy & .251 & .290 & .751 & 1 & .386 & 1.285 \\
\hline 1 & Constant & -.591 & .208 & 8.089 & 1 & .004 & .554 \\
\hline
\end{tabular}

a. Variable(s) entered on step 1: InterDummy.

Although the purpose of the study was to assist parents who had not utilized dental care in the past two years, our sample contained approximately $24 \%$ who had utilized dental care in the past two years. Therefore the data using only subjects who had not utilized dental care in the two years prior to study entry were analyzed but the intervention was still not a significant predictor of utilization $(p=.196)$ during the study.

Although the intervention was not a statistically significant predictor of utilization, demographic and individual characteristics were examined to determine what factors predicted utilization in the sample as a whole and to build a parsimonious model limited to significant variables that could help to predict 
utilization in a future study. The model was built using forward selection logistic regression and the goodness of fit of the model was assessed with the HosmerLemeshow statistic.

First, a univariable analysis was conducted by regressing utilization on each of the potential predictors individually for all 202 subjects as shown in Table 19. Demographic factors and individual factors such as baseline scores on the various scales were included in the analyses.

Table 19.

Logistic Regression of Potential Predictors of Utilization

\begin{tabular}{lcccc}
\hline Factor & $\begin{array}{c}\text { Wald } \\
\text { Statistic }\end{array}$ & $\begin{array}{c}\text { Signifi- } \\
\text { cance }\end{array}$ & $\begin{array}{c}\text { Odds } \\
\text { Ratio } \\
\text { (OR) }\end{array}$ & $\begin{array}{c}\text { 95\% Confidence } \\
\text { Interval for OR }\end{array}$ \\
\hline Parent Age & 1.525 & .217 & 1.019 & $.989,1.049$ \\
Child Age & 1.386 & .242 & 1.066 & $.958,1.187$ \\
Married & .525 & .471 & 1.316 & $.624,2.773$ \\
Race White & .521 & .471 & 1.316 & $.624,2.773$ \\
High School Graduate & .455 & .500 & 1.221 & $.683,2.183$ \\
Income $>\$ 5,000$ & 5.130 & $.024^{*}$ & 2.001 & $1.09,3.67$ \\
Unemployed & 1.825 & .177 & 1.494 & $.834,2.675$ \\
Perceived Need for Care & 6.126 & $.013^{*}$ & 2.131 & $1.170,3.879$ \\
Prior Utilization & .699 & .403 & 1.324 & $.686,2.554$ \\
Number of Children & .435 & .510 & .943 & $.791,1.123$ \\
\hline
\end{tabular}

Table continues... 
Table 19 continues.

Logistic Regression of Potential Predictors of Utilization

\begin{tabular}{lcccc}
\hline Factor & $\begin{array}{c}\text { Wald } \\
\text { Statistic }\end{array}$ & $\begin{array}{c}\text { Signifi- } \\
\text { cance }\end{array}$ & $\begin{array}{c}\text { Odds } \\
\text { Ratio } \\
\text { (OR) }\end{array}$ & $\begin{array}{c}\text { 95\% Confidence } \\
\text { Interval for OR }\end{array}$ \\
\hline Has Dentist & .087 & .768 & 1.097 & $.592,2.033$ \\
$\begin{array}{l}\text { Access to Dental Care } \\
\text { Scale }\end{array}$ & .608 & .435 & .881 & $.641,1.211$ \\
Oral Health Beliefs & .030 & .861 & 1.027 & $.758,1.392$ \\
Pediatrician Role & .384 & .535 & .895 & $.63,1.270$ \\
Parent Self-Efficacy & .060 & .806 & 1.038 & $.771,1.398$ \\
Child Fear & .310 & .577 & .915 & $.671,1.249$ \\
Satisfaction with Care & 1.576 & .209 & 1.211 & $.898,1.633$ \\
Discrimination & 1.127 & .288 & 1.178 & $.870,1.595$ \\
Parent Dental Anxiety & .130 & .718 & 1.055 & $.790,1.409$ \\
Parent Social Support & .907 & .341 & 1.155 & $.859,1.553$ \\
Parent Stress & .133 & .716 & .945 & $.695,1.284$ \\
Propensity to Attrit & 2.272 & .132 & .221 & $.031,1.573$ \\
\hline * Significant at the .05 level & & & &
\end{tabular}

The only variables in Table 19 that were found to be significant predictors of utilization were income $>\$ 5,000$ and perceived need for dental care. Parent age, child age, baseline satisfaction with dental care, and propensity to attrit were significant at $p \leq .25$ and were thus considered as candidates for initial entry into the multivariable model because they can be considered clinically important (Hosmer \& Lemeshow, 2002). 
The model was built using forward selection to enter the potential confounders that had the strongest association with utilization (income and perceived need) and also the other potential covariates (parent age, child age, satisfaction with care, and propensity to attrit). The results of the Hosmer and Lemeshow Goodness of Fit (which tests the null hypothesis that the data adequately fits the model) were $X^{2}=2.493$ with d.f. $=2, p=.287$, indicating that the model adequately fit the data. The potential predictors of parent age, satisfaction with care, and propensity to attrit were not significant in this model. Only income over $\$ 5,000$ (adjusted odds ratio $=2.74,95 \% \mathrm{Cl} 1.37-5.46$ ) and perceived need (adjusted odds ratio $=2.00,95 \% \mathrm{Cl} 1.08-3.68$ ) were significant predictors and were thus included in the final model as shown in Table 20.

\section{Table 20.}

\section{Logistic Regression Predictors of Utilization ( $\mathrm{n}=202$ )}

\section{Variables in the Equation}

\begin{tabular}{|c|c|c|c|c|c|c|c|c|c|}
\hline & \multirow[b]{2}{*}{ B } & \multirow[b]{2}{*}{ S.E. } & \multirow[b]{2}{*}{ Wald } & \multirow[b]{2}{*}{ df } & \multirow[b]{2}{*}{ Sig. } & \multirow[b]{2}{*}{$\operatorname{Exp}(B)$} & \multicolumn{2}{|c|}{$\begin{array}{c}95.0 \% \text { C.I.for } \\
\operatorname{EXP}(B)\end{array}$} \\
\hline & & & & & & & & Lower & Upper \\
\hline \multirow{5}{*}{$\begin{array}{l}\text { Step } \\
1 \\
\text { Step } \\
2\end{array}$} & IncomeOver5Thousan & 1.060 & .348 & 9.288 & 1 & .002 & 2.887 & 1.460 & 5.710 \\
\hline & Constant & -1.232 & .304 & 16.455 & 1 & .000 & .292 & & \\
\hline & IncomeOver5Thousan & 1.008 & .352 & 8.218 & 1 & .004 & 2.741 & 1.376 & 5.463 \\
\hline & PerceivedNeed & .691 & .313 & 4.878 & 1 & .027 & 1.995 & 1.081 & 3.681 \\
\hline & Constant & -1.435 & .323 & 19.697 & 1 & .000 & .238 & & \\
\hline
\end{tabular}

a. Variable(s) entered on step 1: IncomeOver5Thousand.

b. Variable(s) entered on step 2: PerceivedNeed. 


\section{Research Question \#1 - Completer Analyses}

Identical analyses were conducted for the 122 subjects who completed all the study activities. The regression of the dental utilization variable on the intervention was not significant $(p=.093)$ as illustrated in Table 21 .

\section{Table 21.}

Completer Logistic Regression ( $n=122$ )

Variables in the Equation

\begin{tabular}{|c|c|c|c|c|c|c|c|}
\hline & B & S.E. & Wald & $\mathrm{df}$ & Sig. & $\operatorname{Exp}(B)$ \\
\hline Stap & Intervention & .618 & .369 & 2.805 & 1 & .094 & 1.855 \\
\hline 1 & Constant & -.492 & .271 & 3.312 & 1 & .069 & .611 \\
\hline
\end{tabular}

a. Variable(s) entered on step 1: Intervention.

Again, given that approximately $20 \%$ of the study sample included dental utilizers (prior utilizers), data were analyzed using only subjects who had not utilized dental care in the two years prior to study entry and who completed the study. This logistic regression analysis indicated that the intervention was a significant predictor of utilization $(p=.031)$ with an estimated odds ratio of 2.51 and a $95 \%$ confidence interval of $1.09-5.84$ for those that completed the study as shown in Table 22.

Table 22.

Univariate Regression of Intervention Completers with No Prior Utilization ( $n=93$ ) Variables in the Equation

\begin{tabular}{|ll|r|r|r|r|r|r|}
\hline & & \multicolumn{1}{|c|}{ B } & \multicolumn{1}{|c|}{ S.E. } & Wald & \multicolumn{1}{c|}{ df } & \multicolumn{1}{c|}{ Sig. } & \multicolumn{1}{|c|}{ Exp(B) } \\
\hline Step & Intervention & .924 & .428 & 4.657 & 1 & .031 & 2.519 \\
1 & Constant & -.661 & .308 & 4.616 & 1 & .032 & .516 \\
\hline
\end{tabular}

a. Variable(s) entered on step 1: Intervention.

b. A dental visit occurred within 2 years prior of HIPAA mailing $=0$ 
A logistic regression analysis was again conducted for the Completer subjects $(n=122)$ to investigate what demographic and individual factors may predict utilization in subjects who completed the study and to build a parsimonious model to predict utilization among those who completed the study.

Table 23.

Demographic and Individual Factors of Completer Subjects ( $n=122$ )

\begin{tabular}{|c|c|c|c|c|}
\hline Factor & $\begin{array}{l}\text { Wald } \\
\text { Statistic }\end{array}$ & $\begin{array}{l}\text { Signifi- } \\
\text { cance }\end{array}$ & $\begin{array}{l}\text { Odds } \\
\text { ratio } \\
\text { (OR) }\end{array}$ & $\begin{array}{l}\text { 95\% Confidence } \\
\text { Interval for OR }\end{array}$ \\
\hline Parent Age & .563 & .453 & 1.014 & $.978,1.051$ \\
\hline Child Age & .662 & .416 & 1.058 & $.924,1.211$ \\
\hline Married & .162 & .688 & 1.217 & $.466,3.177$ \\
\hline Race White & .143 & .706 & 1.213 & $.466,3.301$ \\
\hline High School Graduate & 1.213 & .271 & 1.508 & $.726,3.131$ \\
\hline Income $>\$ 5,000$ & 1.955 & .162 & .538 & $.226,1.284$ \\
\hline Unemployed & 2.123 & .145 & 1.724 & $.829,3.583$ \\
\hline Perceived Need for Care & 2.009 & .156 & 1.724 & $.812,3.662$ \\
\hline Prior Utilization & .086 & .769 & 1.133 & $.492,2.612$ \\
\hline Number of Children & .459 & .498 & .924 & $.736,1.161$ \\
\hline Has Dentist & .402 & .526 & .783 & $.367,1.670$ \\
\hline $\begin{array}{l}\text { Access to Dental Care } \\
\text { Scale }\end{array}$ & .313 & .576 & .894 & $.603,1.325$ \\
\hline Oral Health Beliefs & .091 & .762 & .941 & $.635,1.395$ \\
\hline Pediatrician Role & 2.807 & .094 & .536 & $.258,1.112$ \\
\hline Parent Self-Efficacy & .062 & .803 & 1.047 & $.728,1.507$ \\
\hline
\end{tabular}

Table continues... 
Table 23 continued.

Demographic and Individual Factors of Completer Subjects ( $\mathrm{n}=122$ )

\begin{tabular}{lcccc}
\hline Factor & $\begin{array}{c}\text { Wald } \\
\text { Statistic }\end{array}$ & $\begin{array}{c}\text { Signifi- } \\
\text { cance }\end{array}$ & $\begin{array}{c}\text { Odds } \\
\text { ratio } \\
\text { (OR) }\end{array}$ & $\begin{array}{c}95 \% \text { Confidence } \\
\text { Interval for OR }\end{array}$ \\
\hline Child Fear & .179 & .672 & .911 & $.591,1.404$ \\
Satisfaction with Care & 1.257 & .262 & 1.242 & $.850,1.814$ \\
Discrimination & 1.025 & .311 & 1.404 & $.728,2.708$ \\
Parent Dental Anxiety & .126 & .723 & 1.069 & $.738,1.549$ \\
Parent Social Support & .345 & .557 & 1.113 & $.778,1.592$ \\
Parent Stress & .351 & .553 & .890 & $.605,1.309$ \\
Propensity to Attrit & 1.119 & .290 & 1.612 & $.666,3.903$ \\
\hline
\end{tabular}

As shown in Table 23, only income, unemployment, baseline perceived need, and baseline pediatrician role were significant at $p \leq .25$ in predicting utilization among the subjects who completed the study. When utilization was regressed on these variables for those who completed the study regardless of prior utilization, there were no significant results from the logistic regression equations.

In the subsequent logistic regression analyses, only the intervention was a predictor of dental utilization $(p=.028)$ during the study after controlling for the potential covariates of income, unemployment, perceived need, and pediatrician role. The estimated adjusted odds ratio for the intervention was 2.60 with a $95 \%$ confidence interval of $1.11-6.09$. 
Table 24.

Regression Controlling for Covariate Completers with No Prior Utilization $(n=93)$

Variables in the Equation ${ }^{b}$

\begin{tabular}{|ll|r|r|r|r|r|r|}
\hline & & \multicolumn{1}{|c|}{ B } & \multicolumn{1}{c|}{ S.E. } & Wald & \multicolumn{1}{c|}{ df } & \multicolumn{1}{c|}{ Sig. } & \multicolumn{1}{|c|}{ Exp(B) } \\
\hline Step & Intervention & .956 & .434 & 4.845 & 1 & .028 & 2.600 \\
1 & Constant & -.693 & .316 & 4.805 & 1 & .028 & .500 \\
\hline
\end{tabular}

a. Variable(s) entered on step 1: Intervention.

b. A dental visit occurred within 2 years prior to HIPAA mailing $=0$

Variables not in the Equation ${ }^{a}$

\begin{tabular}{|lll|r|r|r|}
\hline & & \multicolumn{1}{|c|}{ Score } & df & Sig. \\
\hline Step & Variables & Unemployed & 1.328 & 1 & .249 \\
& & PerceivedNeed & 2.904 & 1 & .088 \\
& & W1FS_Pediatrician & 3.090 & 1 & .079 \\
& & & 6.397 & 3 & .094 \\
\hline
\end{tabular}

a. A dental visit occurred within 2 years prior to HIPAA mailing $=0$

The researcher then proceeded to investigate what, if any, other individual factors might have been impacted by study enrollment and whether the case manager intervention was a significant predictor of dental utilization. Utilization was thus regressed on the change in scores from baseline to Wave 2 (immediately after the case manager intervention) and on change in scores from baseline to Wave 3 . The results of the stepwise regression equation with utilization as the dependent variable and the Wave 1 to Wave 2 and the Wave 1 to Wave 3 change in scores did not have any significant results.

Research Question \#2: Do contextual (individual and demographic) factors moderate the intervention effects on utilization?

Method: Logistic Regression

Since the intervention was not a significant predictor of utilization in all 202 subjects regardless of prior utilization, it was not possible to investigate any 
moderating effects of contextual factors. Therefore, the researcher investigated the potential moderating effects of contextual factors in the group where the intervention was effective in predicting utilization-those who did not utilize dental care for two years prior to the study and who completed all study activities.

Based on previous studies, theoretical models, and the bivariate analyses conducted in this study, the researcher investigated the effect of demographic and individual factors such as child age, low income, and perceived need for dental care as potential moderators of the effect of the intervention on utilization. The potential continuous moderator variable (e.g., child age) was centered to avoid potential multicollinarity and model-fitting problems. Interaction terms were created by multiplying the independent/predictor intervention variable times each potential moderator to create interaction variables. The logistic regression equation included first the independent intervention variable, then the potential moderator (e.g., perceived need), and then, if appropriate, the interaction term.

\section{Table 25.}

Potential Moderator Variables in Completers with No Prior Utilization ( $n=93$ )

Variables not in the Equation

\begin{tabular}{|c|c|c|c|c|c|}
\hline & & & Score & $\mathrm{df}$ & Sig. \\
\hline \multirow{13}{*}{$\begin{array}{l}\text { Step } \\
1\end{array}$} & Variables & Perceived Need & 2.904 & 1 & .088 \\
\hline & & child_age_center & 1.830 & 1 & .176 \\
\hline & & Age_Actual & .097 & 1 & .755 \\
\hline & & Unemployed & 1.328 & 1 & .249 \\
\hline & & Marital_Categ & .906 & 1 & .341 \\
\hline & & Child Oral Health & .279 & 1 & .598 \\
\hline & & High School Grad & .239 & 1 & .625 \\
\hline & & Race & .249 & 1 & .618 \\
\hline & & \#days absent from & chool .117 & 1 & .732 \\
\hline & & Number of children & .909 & 1 & .340 \\
\hline & & Have dentist & .744 & 1 & .388 \\
\hline & & Age Under 9 & 3.786 & 1 & .052 \\
\hline & Overall Statistics & & 9.105 & 12 & .694 \\
\hline
\end{tabular}

a. A dental visit occurred within 2 years prior to HIPAA mailing $=0$ 
None of the potential contextual factors were significant predictors of utilization in the prior Non-Utilizers Completer group, although perceived need $(p=.088)$ and child age less than 9 years $(p=.052)$ were close to being significant predictors. Then, only the intervention and perceived need were entered in the logistic regression. In the next logistic regression only the intervention and age under 9 years were entered. The intervention was still significant at $p=.031$, but the potential moderators were not significant. Thus, post-hoc probing of significant moderational effects was not possible.

\section{Subgroup or Stratified Analysis for Potential Moderators of Entire Sample}

The researcher investigated the potential moderating effect of demographic and individual factors on the intervention for the entire sample of families (including those that did not complete all study activities). A subgroup or stratified regression analysis was used to determine if families with certain factors benefited more from the case manager intervention. In the subgroup or stratified analyses, separate regressions were performed for families with different characteristics such as income, child age, and perceived need. Only child age was a potential moderator of the effect of the intervention on utilization.

Child age was categorized as 1) under 9 years and 2) over 9 years. Separate regression analyses were conducted for all children enrolled in the study in the two categories. First the intervention variable was entered and then the covariates of income, perceived need and propensity to attrit score. The results of the logistic regression indicated that the intervention was a significant predictor of utilization for families with children under the age of 9 after controlling 
for income, perceived need, and propensity to attrit with an estimated adjusted odds ratio of $3.5, p=.034, \mathrm{Cl}$ of $1.1-11.5$ as shown in Table 26 below. The result of this analysis suggests that families with younger children may have benefited more from the intervention than families with older children.

\section{Table 26.}

Logistic Regression of Entire Sample with Child Age Under 9 Years $(n=202)$

Variables in the Equation

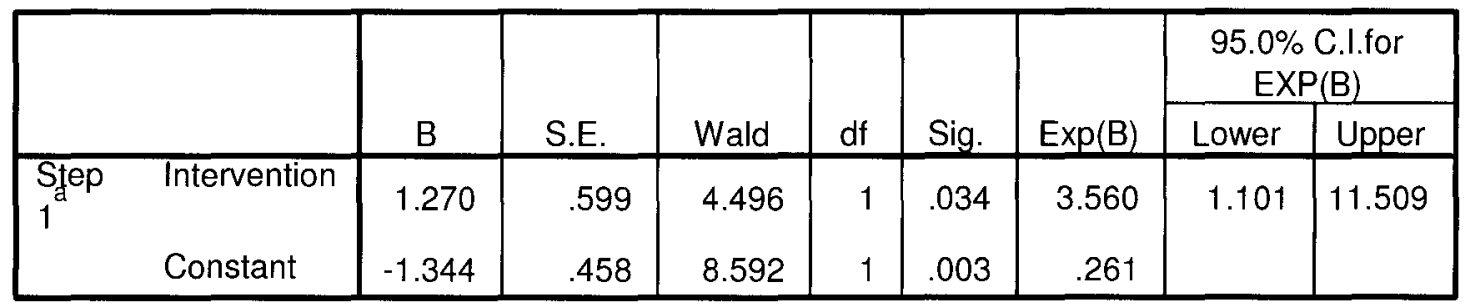

a. Variable(s) entered on step 1: Intervention. b. Age Under $9=1$

\section{Subgroup or Stratified Analysis for Potential Moderators of Prior Non-Utilizers}

Similar stratified regression analyses were conducted with the families who had not been routine Utilizers of dental care prior to the study. Only income was found to be a potential moderator of the intervention on utilization.

Income: Annual incomes were categorized as 1) less than $\$ 15,000$ and 2) more than $\$ 15,000$. Separate regression analyses were conducted for prior NonUtilizing subjects in both income levels. First the intervention variable was entered and then the covariates of perceived need and propensity to attrit score. The results of the logistic regression indicated that the intervention was a significant predictor of utilization for families with incomes of less than $\$ 15,000$ per year with an estimated odds ratio of $3.1, p=.011, \mathrm{Cl}$ of $1.3-7.4$ as shown in 
Table 27 below. The intervention was not a significant predictor of utilization for the other income subgroup (data not shown). The result of this analysis suggests that families with lower incomes may have benefited the most from the intervention.

Table 27.

Logistic Regression Prior Non-Utilizers with Income Less than $\$ 15,000$ Variables in the Equation

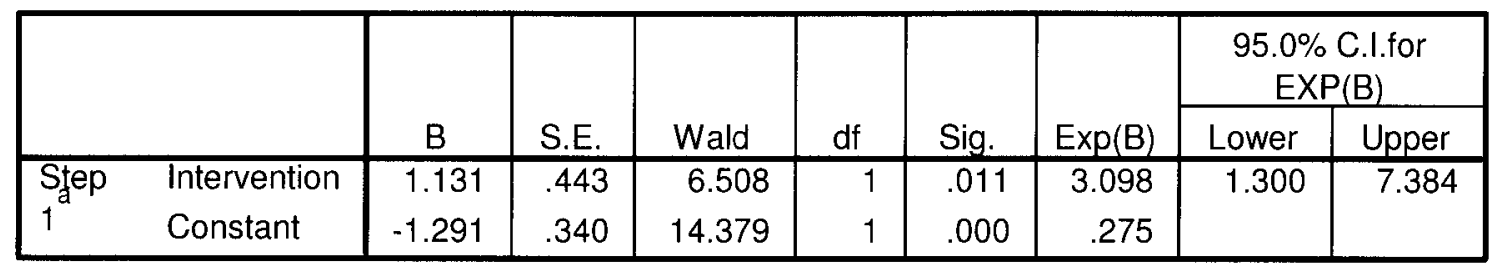

a. Variable(s) entered on step 1: Intervention. b. Income Under 15 Thousand $=1$

In summary, child age moderated the effect of the intervention on utilization in the entire sample of families. Annual family income less than $\$ 15,000$ moderated the effect of the intervention on utilization in prior nonutilizing families. None of the other potential individual or socioeconomic factors appear to have moderating effects.

\section{Research Question \#3: What is the effect of the intervention on barriers?}

Method: Multiple Regression with Forward Selection

An Intent-to-Treat analysis was not conducted given that the dependent variables for this research question are the change in scores on the Access to Dental Care, Oral Health Beliefs, and Satisfaction with Dental Care Scales. Thus, only those who completed the study (i.e., completed the final Wave 3 survey) could be included in the analysis. The investigation of the effect of the intervention was therefore limited to the Completer group $(n=122)$. The effect of 
the intervention was analyzed in this group first with all subjects regardless of prior utilization and then with those who had not utilized dental care in the previous two years.

The same analysis strategy used to analyze Research Question \#1 was applied to Research Question \#3, but with barriers (structural and personal) designated as the dependent variables. The barriers were the scale or ordinal variables [change in scores from the baseline (Wave 1) telephone survey to the final/third (Wave 3) telephone survey for the Access to Dental Care Scale, Satisfaction with Dental Care Scale, and Oral Health Beliefs Scale] and thus multiple regression was used.

Treating each barrier variable as the dependent variable, the barrier variable and the dichotomous independent/predictor variable (intervention coded $0=$ control, and $1=$ intervention) were entered into the multiple regression equation. There were no significant results for the effect of the intervention on the change from baseline to study end for Access to Dental Care $(p=.617)$, Oral Health Beliefs $(p=.560)$, or Satisfaction with Dental Care $(p=.169)$ factor scores in either all those completing the study regardless of prior utilization status or in those who were prior Non-Utilizers. Therefore, the intervention did not impact the potential perceived barriers to dental care utilization.

\section{Summary}

The analyses of the first research question indicated that the case manager intervention did not significantly predict dental care utilization in the Intent-to-Treat (the entire sample including $\sim 24 \%$ who were routine utilizers) 
analyses. The only significant predictors of utilization when all the subjects enrolled in the study were included in the analyses were perceived need for dental care and income greater than $\$ 5,000$ per year. The intervention, however, was a significant predictor of utilization in those who had not been to the dentist in the previous two years who completed all study activities, even after controlling for income and perceived need.

The analyses for the second research question identified child age under 9 years as having a potential moderating effect on the intervention for the entire sample. Annual family income of less than $\$ 15,000$ was a potential moderator of the intervention in families who were not routine dental utilizers.

Finally, the analyses for the third research question indicated that the intervention did not have any impact on the change in potential perceived barriers such as access to dental care, oral health beliefs, or satisfaction with dental care from baseline to the end of the study. The interpretation of these results and potential implications for future research are presented in the next chapter. 


\section{CHAPTER 5}

\section{DISCUSSION}

This chapter summarizes and interprets the results of the study. A summary of findings regarding the study sample, the results for each of the research questions and the limitations of the study are presented. A discussion of the theoretical implications of the study follows. Finally, discourse is provided regarding the potential considerations for future research and policy to improve the oral health of disadvantaged children, thus reducing oral health disparities.

\section{Summary of Findings of the Study Sample}

The first findings relate to the study sample socioeconomic characteristics. The socioeconomic status of the families was consistent with the original goal of the study, which was to assist parents who had the greatest financial and demographic barriers to accessing dental care. The parents were almost entirely African American females and $83 \%$ were single heads of household. More than $66 \%$ of the families had an annual income of less than $\$ 15,000$. Each family had an average of three children and because most of the parents/caregivers were single, the majority of the families lived well below the 2005 poverty guideline of $\$ 19,350$ for a family of four (U.S. Department of Health \& Human Services, 2005). Only about half of the parents were working either full or part-time despite 
the fact that $80 \%$ of the parents had either a high school diploma or some college education.

The second finding relates to parental assessment of the child's oral health and of their own oral health. Despite the fact that more than $75 \%$ of the children had not seen a Medicaid dentist for two years prior to the study, only $18 \%$ of the parents estimated their child's oral health to be poor or fair. Only $30 \%$ of parents who estimated their child's oral health to be fair or poor thought that their child needed to see a dentist soon. A third of the parents (62 of 202) reported their own health as fair or poor and this was significantly associated with not having a regular source of dental care $\left(\chi^{2}=23.91, p<.001\right)$.

The third finding was the discrepancy between the Medicaid utilization data and the parent's report of when the child had last been to the dentist. Over $80 \%$ of parents reported a dental visit in the two past years but the Medicaid utilization records indicated that only $24 \%$ of the children had previously utilized dental care prior to study enrollment. This finding is consistent with the results of the focus groups with Non-Utilizing parents according to Medicaid records conducted during Phase I of the Parental Help Seeking for Dental Care project (Kelly et al., 2005). Quantitative data on dental utilization was not collected during the focus groups; however, a substantial number of Non-Utilizing parents reported that they had taken their children to the dentist.

Some of the parents in the Phase I Non-Utilizing focus groups reported that they chose to take their child to a non-Medicaid dentist and pay out-ofpocket rather than deal with difficulties encountered in scheduling, perceived 
discrimination, and other problems at a Medicaid provider's office. There is the possibility that some of the parents in this study also took their child to a nonMedicaid provider for dental care and this could partially explain the discrepancy between self-report utilization and Medicaid record utilization. The discrepancy between self-report and Medicaid utilization reports could also be due to parents providing socially desirable responses.

Another interesting finding was that perceived need for dental care, a significant predictor of utilization in this study, was significantly associated with not having a regular source of dental care $\left(\chi^{2}=11.43, p=.001\right)$. A usual source of dental care has been shown to be important in dental care utilization (Davidson et al., 1999). Fifty percent of parents (31 of 62) who reported that they did not have a dentist stated that their child had dental problems that required treatment as opposed to $26 \%$ ( 36 of 140 ) who stated they had a dentist and their child needed dental care. Although this was a significant difference, having a usual source of dental care was not a significant predictor of utilization in this study nor was it a significant covariate in any of the analyses for this study. Consistent with Pavuluri's model of Levels and Filters (Pavuluri et al., 1996), the primary predictor of dental care utilization among all the subjects in this study was parental perceived need for dental care. As discussed in a previous chapter, Pavuluri's levels correspond to the stage of the parent in the pathway to utilizing care for their child. In order to move from one level to the next, parents have to overcome barriers, also known as filters. The first filter is parental recognition of a problem, the second filter is considering obtaining 
treatment, and the third filter is the parent's ability to overcome barriers to helpseeking, which actually leads to seeking help or utilizing care. While predictors of advancing from one of Pavuluri's levels to the next level were not investigated in this study, it can be postulated that moving independently from one level to the next may be easier for parents who are in the higher socioeconomic strata. This is evidenced by the fact that an annual household income greater than $\$ 5,000$ was a predictor of dental care utilization for all subjects in the study.

The fourth finding relates to prior dental utilization based on Medicaid data reports and attrition from the study. Although the study was designed to provide a case manager intervention to parents who had not utilized dental care for their children for at least two years, $24 \%$ of parents in the entire sample had taken their child to the dentist in the past two years. Information on the utilization status of study subjects was not available until study end when complete utilization data from the Medicaid administrator was acquired. Failure to obtain this information before subjects were enrolled is a limitation of the study and will be discussed later in this chapter.

As other researchers have reported (Hansen et al., 1985), attrition is a significant issue when conducting prevention research and it can threaten both internal and external validity. Threats to internal validity can occur when there is differential attrition in the control and intervention groups. The $40 \%$ attrition was approximately equal in both groups in this study and therefore randomization of subjects successfully minimized the threat of attrition to internal validity. 
Threats to external validity occur when there is a question concerning whether the results of a study can be generalized to other populations or settings (Grembowski, 2001). In this study, selection-treatment interaction threats may exist because parents who volunteered for the study may have already been motivated to obtain dental care for their children. In addition, the Intent-to-Treat analyses included $24 \%$ of parents who had already successfully overcome barriers to accessing dental care for their children.

There also may have been setting and treatment interaction effects because all the parents were aware that they were participating in a study concerning dental care for children. Parents in the control group may have been more motivated to obtain care (the "Hawthorne effect") simply by responding to the multiple telephone surveys. These threats to external validity limit the generalizability of the results of this pilot study to larger populations of Medicaid children and require replication of the study in other settings.

In summary, the study was conducted with disadvantaged minority families, some of which were routine dental Utilizers. Those who recognized that their child needed dental care were more likely to overcome barriers and obtain care, consistent with Pavuluri's theoretical model (Pavuluri et al., 1996). The following sections discuss how the results of the study questions do or do not support Margolis's theoretical model (Margolis et al., 2001) of improving access to care with a case manager intervention. 


\section{Research Question \#1}

Research Question \#1 sought to determine the direct effect of the intervention on increasing dental care utilization by disadvantaged children. As previously discussed, the study was originally designed to assist parents of children who had not utilized dental care in the past two years and to collect complete data on all subjects. A total of $24 \%$ of the study sample, however, had prior utilization, and $40 \%$ of the subjects dropped out of the study. Nonetheless, the effect of the intervention on all subjects that were randomized, as well as the effect on those who completed the study, was examined. A positive finding of the effect of the case manager intervention would support the theory of Margolis (Margolis et al., 2001) that barriers to care experienced by disadvantaged children can be reduced by providing support and assistance to the families by a case manager.

The results of the Intent-to-Treat analyses for all subjects enrolled in the study did not support the direct effect of the case manager intervention on increasing dental care utilization by Medicaid children, even after excluding those who had utilized dental care in the previous two years. The most important variables that predicted utilization for all the subjects enrolled in the study were perceived need for dental treatment and income. The lack of a direct effect of the intervention on the entire sample did not provide support for Margolis's theory nor for the conceptual framework developed in this study.

However, the results of the analyses for the study, either as it was originally designed or the sub-group (Completer) analyses, did support Margolis's 
theory of Access to Care and the conceptual framework. The case manager intervention had a direct effect on dental care utilization for families randomized to the intervention who had not utilized dental care in the previous two years and who completed all aspects of data collection in the study. Parents in the intervention group were more than twice as likely (odds ratio $2.5,95 \% \mathrm{Cl} 1.01$ 5.8) to take their child to the dentist than were parents in the control group. The intervention had a significant effect even after controlling for various socioeconomic and individual factors that were important predictors of utilization of care for all subjects enrolled in the study.

Although the direct effect of the intervention on utilization for the entire sample was not statistically significant, the intervention and/or study participation increased dental care utilization among all the children to a clinically relevant level. During the nine months of study participation, prior Utilizers apparently continued their utilization patterns with $48 \%$ of those in the control group and $42 \%$ of those in the intervention group obtaining dental care. Children who had no utilization in the past two years (Non-Utilizers) had $41 \%$ utilization in the intervention group and $32 \%$ in the control group, a clinically relevant increase from no utilization.

Given that only $20 \%$ of Medicaid-insured children nationwide receive annual dental care (NIDCR, February 2002), the utilization rate during the study for intervention subjects was more than double the national rate and utilization for control subjects was $50 \%$ greater than the national rate. Furthermore, the intervention brought prior Non-Utilizers up to approximately the same level of 
utilization during the study as prior Utilizers. Finally, participation in the study alone may have contributed to the $32 \%$ of prior Non-Utilizers in the control group utilizing dental care during the study.

In summary, the results of the study for disadvantaged Non-Utilizing families supported Margolis's theory of improving access to care with a case manager intervention. More importantly, there was a clinically relevant increase in dental care utilization among all the children in the study that may have improved their oral health and thus reduced health disparities. Finally, this pilot intervention study provided valuable information that can be used in future research and to inform public policy, as will be discussed later in this chapter.

\section{Research Question \#2}

The second research question sought to expand on the results of the first research question by determining if certain characteristics moderated the effect of the intervention. The analyses for this research question were motivated by the conceptual framework and sought to determine if pre-existing individual factors could interact with the intervention and affect the outcome of the intervention. In other words, were parents who had certain socioeconomic or psychosocial factors that existed before the intervention more likely to benefit from the case manager intervention?

Prior research among disadvantaged families suggests that parents who do not have a usual source of dental care (Skaret et al., 2001), those who perceive that their child needs care (Milgrom et al., 1998), those with younger children (Kaakko et al., 2002), and those with low income (Grembowski \& 
Milgrom, 2000) may be more likely to benefit from interventions to increase dental care utilization.

As discussed earlier, for the entire sample of families the intervention did not have a significant effect on dental care utilization. As a result, investigation of potential moderators using interaction terms was limited to the prior Non-Utilizing Completer sample where the intervention did have a significant effect on utilization. None of the potential moderators of the intervention, however, had an effect on utilization in this sample although parental perceived need for dental care was an independent predictor of dental utilization for the entire sample.

Subgroup or stratified analysis of the entire sample of families $(n=202)$ by child age indicated that the intervention was more effective for children who were younger than for older children. Children under the age of 9 years were three and a half times more likely to benefit from the intervention and receive dental care than older children (odds ratio $=3.5, p=.034, \mathrm{Cl} 1.1-11.5$ ). This result was significant even after controlling for perceived need, income, and likelihood of dropping out of the study.

Additional subgroup regression analyses indicated that families who did not routinely utilize dental care $(n=154)$ and with lower income $(<\$ 15,000$ per year) were three times more likely to benefit from the intervention and obtain dental care for their children (odds ratio $=3.1, p=.011, \mathrm{Cl} 1.3-7.4$ ) than the control group. These results hold implications for future research and public policy by suggesting that efforts to increase utilization may be best directed 
toward those with the lowest family incomes and those with younger children. How this could be accomplished is discussed later in this chapter.

\section{Research Question \#3}

The final research question explored the role of the case manager intervention on potential perceived barriers to dental care utilization as described in the literature. A parent who finds dental care difficult to access (Guay, 2004), who does not value oral health (Milgrom et al., 1998), and who is dissatisfied with the dental care delivery that their child has received in the past (Lam et al., 1999) may be less likely to take their child to the dentist. A case manager may be able to impact these factors by providing assistance in obtaining care, education, and an alternative dental care provider.

The intervention was designed to assist parents in obtaining care by providing assistance in scheduling dental appointments, providing free bus transportation, and providing referral to a Medicaid dentist that was located near the family's home. It was hoped that the case manager would be able to significantly reduce barriers to dental care (Guay, 2004) and improve access for the intervention families. The evaluation of this component of the intervention was performed not only with examination of the dental utilization data provided by the Medicaid administrator but also focused on the change in scores on the Access to Dental Care Scale from baseline to study end.

The intervention also was designed to provide education to the parents and children concerning the value of oral health including oral hygiene, nutrition, and consequences of untreated caries in children. Parental belief that oral health 
is important has been described as predictive of dental care utilization (Milgrom et al., 1998). In an effort to impress the importance of oral health upon the parents, the case manager provided written educational materials and, if he was able to conduct a home visit, he also made an oral presentation with visual aids. Oral hygiene materials including toothbrushes, toothpaste, and mouth rinses also were provided. Evaluation of this component of the intervention was focused on examination of the change in scores on the Oral Health Beliefs Scale from baseline to study end.

The intervention also sought to provide dental care that was satisfactory to parents who may have had negative experiences in the past with their child's dentist and staff. The four dental practices that the case manager used for referral were not only convenient for the parents but were staffed with dentists and dental staff that were enthusiastic about the study and who provided a professional and hospitable environment for the children. It was hoped that parents who had been dissatisfied with their previous experiences would find these dental practices to be more satisfactory. Evaluation of this component of the intervention was focused on an examination of the change in score on the Satisfaction with Dental Care Scale from baseline to study end.

The lack of a difference between groups in the analysis of change in scores on the Access to Dental Care, Oral Health Beliefs, and Satisfaction with Dental Care Scales between the intervention and control group is disappointing but may not be surprising. As discussed in the following section, response bias may have occurred with respondents providing socially desirable answers (Tang 
et al., 2005) to questions in the survey. If that were the case, then the researcher could have made a Type II error which occurs when it is inferred that an intervention or program has no effect when it actually does.

The lack of a difference in change in scores between the intervention and control group also could be due to the fact that the case manager only conducted home visits with half of the intervention families. Without the face-to-face educational component it may be less likely that there would have been any change in the Oral Health Beliefs Scale factor scores, and possibly the Access to Dental Care and Dental Satisfaction Scale scores. As discussed in the following sections, there are challenges and obstacles in home visitation and alternative strategies may need to be developed and evaluated in future studies.

It should be noted that evaluation of a change in attitudes and beliefs due to a case manager intervention has not been undertaken to date in dental access to care research. To the best of the researcher's knowledge, this is the first time that these scales have been used in a randomized controlled dental intervention trial. It is possible that these scales or evaluation strategies are not adequate to detect small changes in attitude or that they do not measure what they were intended to measure in this study (construct validity). In a following section (Implications for Interventions to Improve Disadvantaged Children's Oral Health), potential alternative strategies for future intervention studies are discussed.

\section{Limitations of the Study}

Before discussing the potential theoretical and policy implications of the study results, it is important that the limitations of the study be discussed. In the 
following section, five specific limitations are discussed: sample generalizability, potential response bias, attrition from the study, characteristics of the case manager, and intervention process and fidelity issues.

Sample Selection and Generalizability. A key limitation of this study concerns the characteristics of the sample of subjects and possible selection bias that could result in potential problems with generalizability of the study results. The methods used to identify and recruit the study sample described in earlier chapters may have provided a sample of parents who were already concerned about oral health and who were already motivated to obtain dental care for their children. For example, $24 \%$ of the parents in the entire sample were already routinely taking their child to the dentist. Randomization of study subjects, however, minimized the threat of selection bias because there were $23 \%$ of subjects in the control group and $25 \%$ of subjects in the intervention group who were prior routine dental Utilizers. Nevertheless, the results of the Intent-to-Treat analyses did not show any effect of the intervention for the entire sample. The results of the study may not be generalized to all Medicaid-eligible children in the area of Louisville, Kentucky, or to other similar populations because the subjects may not represent the actual population.

Potential for Response Bias. As in any study, the potential for subjects to provide socially desirable responses to questions may have been present. Response bias occurs when subjects provide a response that they believe is consistent with community standards rather than what is actually true (Huang et al., 1998). This bias could have affected this study in two ways. First, subjects in 
this study may have provided positive responses to queries concerning the importance of oral health and satisfaction with dental care possibly because they believed positive attitudes are socially desirable. Second, they may have overreported their child's attendance at the dentist because they believed that obtaining routine dental care is considered a component of good parenting and they wanted to appear to be a responsible parent.

Attrition. Attrition can be especially problematic when conducting research in disadvantaged populations owing to the subject's limited financial resources required to maintain a stable home site, telephone service, and other services. Study design, especially power analysis and sample size estimates, is an important factor when planning a study where attrition may become an issue.

For this study, the sample size estimate was based on the expectation that $15 \%$ of the subjects could attrit from the baseline to the second telephone survey (Wave 2) and another 15\% could attrit from the second survey to the third survey (Wave 3). The power analysis indicated that 60 subjects in each group would provide adequate numbers to detect a clinically significant effect of the intervention on dental utilization as described in an earlier chapter.

The attrition that occurred in this study was greater than initially estimated in that $13 \%$ of the original sample attritted from baseline to Wave 2 (202 to 176) and $27 \%$ attritted from Wave 2 to Wave 3 (176 to 122). Although the study attrition of $40 \%$ exceeded the estimated $30 \%$, the final sample of 122 provided adequate power to meet the study's objectives. 
The attrition in the study is a limitation despite extensive efforts to maintain contact with the families, which included multiple means of contact (home phone, cell phone, postal address) as well as multiple locators and informants (subjects were asked to provide the names, addresses, and phone numbers of at least three individuals who would always know their whereabouts). This highlights the difficulties faced by investigators conducting research in disadvantaged populations in conducting Intent-to-Treat analyses.

Parents who dropped out of the study included those who could no longer be contacted by telephone after numerous attempts, a common problem reported by the case manager and the individuals conducting the telephone surveys. As discussed in the Results chapter, subjects who dropped out of the study were more likely to have a lower income and to be younger. As expected, the attrition based on these two factors was approximately equal in the intervention and control groups.

The attrition of $40 \%$ is an important limitation of this study caused by the loss of parents who had the lowest income and who had children who could benefit the most from the intervention, and the negative results of the Intent-toTreat analysis. Although the attrition was not differential between the intervention and control groups and thus was not a threat to internal validity, the attrition may have introduced a selection bias that threatens the external validity of the results (Grembowski, 2001).

Case Manager Characteristics. The case manager was recruited and hired before the study sample was identified and therefore was not matched by 
race or gender to the subjects. The research team expected that potential subjects would most likely reside in geographic areas primarily populated with persons of low socioeconomic status and where crime was more prevalent than in other areas of Jefferson County, Kentucky. The expectation was also established that an individual who had training and experience in interacting with disadvantaged persons would be more likely to have success in motivating subjects to obtain dental care for their children than an inexperienced individual.

The case manager selected and hired was a young Caucasian male who had an undergraduate degree with a major in Psychology. He had seven years of experience as a case manager for disadvantaged individuals and apparently had excellent organizational, interpersonal, and information technology skills. We believed that he would be best suited to perform the duties of case manager and would be able to function relatively safely in the potentially high crime areas where the subjects would reside.

As reported in earlier chapters, the study subjects who were recruited and enrolled were primarily African American females of low socioeconomic status and single heads of household. The case manager reported having great difficulty throughout the study in contacting and accessing the parents to conduct the intervention visits. It is possible that the subjects were reluctant to invite a Caucasian male into their homes, and this may have had a negative impact on the intervention implementation. There also could have been other reasons for the difficulties in accessing the parents including lack of time, intermittent 
telephone service, parents moving from one location to another location, and family stresses.

There is a growing body of literature concerning factors essential for case manager's or home visitor's success in improving healthcare outcomes in at-risk families. Prevent Child Abuse America, a national organization devoted to providing resources for parents, professionals, and organizations to prevent all forms of child abuse (Prevent Child Abuse America, 2003), launched Healthy Families America (HFA). Healthy Families America is a national initiative that provides home visiting and other services for at-risk families to promote positive parenting and child health and development. The home visiting program is based on an extensive review of the literature and input from child abuse organizations.

HFA programs must adhere to a series of Critical Elements (Healthy Families America, 2001) based on the most current knowledge about home visitation programs. The elements concerning the home visitor characteristics do not mandate that the staff be of the same race/ethnicity or gender as the parent but HFA suggests that, if possible, the case manager/home visitor could be matched and ideally be from the same community. The literature supports matching of the subject and case manager as evidenced by successful home visitor programs such as those aimed at reducing second births among low income, African American adolescent mothers (Black et al., 2006) and improving child care among American Indian adolescent mothers (Barlow et al., 2006). The 
fact that our case manager was not matched may be considered a limitation of this study.

Intervention Processes. Evaluation of process refers to the assessment of the implementation of an intervention program. Process evaluation determines if a program was implemented as it was intended (internal fidelity), if it was given for the intended number of times (dosage), if it was delivered to the targeted group (reach), and if it was delivered in a manner of high quality to study subjects (satisfaction). This study was designed so that the process of the intervention and the fidelity of the intervention could be evaluated with various methods.

Satisfaction with the intervention was evaluated by an individual not involved in the intervention via a brief telephone survey. This individual was only able to contact less than half of the intervention subjects for the satisfaction survey. These missing data are a limitation of the study because it remains unknown how satisfied $50 \%$ of the intended recipients of the study were with the content and delivery of the intervention. Complete results would have assisted in refining the intervention design for future studies.

The internal fidelity of the home visit intervention was evaluated by the case manager recording whether he was able to access the parent and conduct a face-to-face intervention. In the event that he could not conduct the intervention in person and was limited to telephone communication and mailing of educational and oral hygiene materials, he was instructed to document the reasons and his actions. He also was instructed to record the number of 
sessions and the time he spent with the parent and child and whether the session was interrupted or cancelled so that the dosage of the intervention could be documented. The internal fidelity component of the intervention that involved assistance in obtaining dental care was also supposed to be documented by the case manager. He was instructed to record whether transportation was provided, if the family met the dentist and staff, and what, if any, dental care was provided for the child.

Intervention process was to be evaluated by documenting the time from the baseline (Wave 1) telephone survey until the case manager could deliver the intervention, the number of calls necessary to schedule a home visit, the number of cancelled home visits, the time from the second telephone survey until being able to schedule a dental visit, and the number of dental appointments that were kept. The reach of the intervention was evaluated by the number of intervention subjects who received the intervention.

Unfortunately, the case manager's documentation was not carefully monitored until near to the end of the study. There were a great deal of missing data concerning fidelity and dose; this presents a limitation of the study. Similar to the results of the satisfaction evaluation, these missing data pose a limitation in the ability to evaluate and refine the intervention processes for future research.

One of the Healthy Families America Critical Elements is close supervision of the case manager/home visitor. Critical Element \#12 (ף 15) states that "Service providers should receive on-going, effective supervision" (Healthy Families America, 2001). The results of this study indicate that our case 
manager did not receive adequate supervision or monitoring of data collection during the study and this has been a lesson learned that will be discussed later in this chapter.

Challenges encountered by the case manager in implementation of the intervention were numerous and have also recently been reported in other studies in the medical and nursing literature (Bedell et al., 2000; Jack et al., 2005; Kitzman et al., 1997b). Gaining access to the families proved to be especially problematic. The case manager was able to conduct face-to-face meetings with only 52 of the 101 intervention parents despite numerous telephone and mail contacts. The case manager primarily used the telephone to contact the parent/caregiver and found that frequently interrupted and/or lost telephone service made access difficult.

Similar issues have been reported in other case manager/home visitor intervention studies. Social exchange, a form of interaction that involves the voluntary transfer of resources between two people, has been proposed as a theoretical framework for client-nurse interaction during home visits (Byrd, 2006). The exchange perspective was used to develop strategies to initiate and maintain a working relationship between the client and home visitor.

A theory of maternal engagement with home visitors has been proposed to describe why mothers of at-risk children are difficult to access and retain in case management programs (Jack et al., 2005). Twenty mothers in the Jack et al. (2005) study participated in in-depth interviews that explored their perceptions and experiences in a home visitation program. The mothers reported that they 
felt vulnerable and often powerless when they allowed the case managers/home visitors into their home. Those mothers that became engaged with the case managers had to overcome fear, build trust, and seek mutuality. The ability of the case manager to build trust was more important than the case manager's demographic characteristics in accessing and engaging the mothers.

Summary of Limitations. The major limitations of this study provide opportunities to inform future research. Case management intervention research to reduce oral health disparities is a relatively new field. The lessons learned in this study include the importance of identifying the sampling frame, adequately testing the evaluation mechanisms, employing rigorous efforts to reduce attrition, case manager selection and training, and supervision of the case manager. These lessons are further discussed below.

\section{Theoretical Implications}

This study was based on the proximal factors in Margolis's Model of Access to Care, specifically the Barriers and Use of Services factors. The study sought to determine if a case manager can reduce structural and personal barriers to parental care seeking and increase dental care utilization by disadvantaged children. The conceptual framework posited that a case manager, in conjunction with dental provider and dental community involvement, could assist parents in obtaining care for their children and reduce parental perceived barriers to care. The role of parental recognition of the need for treatment in actually seeking dental care, as proposed by Pavuluri's Model of Levels and Filters, was also explored. 
The study lends empirical support for both models, but with different groups of parents. The strongest support was for Pavuluri's theory stating that care seeking begins with parental recognition of the need for treatment. Perceived need was almost as important as family income in predicting dental care utilization in the entire sample of parents in this study. Parents who thought their child needed to see a dentist were almost three times as likely to take their child to the dentist as those who did not perceive a need.

The study also lends empirical support for Margolis's theory. Families in the intervention group were almost three times more likely to use services than were the control families, if they had not previously routinely utilized dental care for their children and if they stayed in the study. How this was accomplished, however, is unclear based on the measures used to assess change in personal barriers. The intervention did not have any apparent impact on parent's perceptions of how easy dental care was to obtain (Access to Dental Care Scale), their belief in the importance of oral health in their children (Oral Health Beliefs Scale), or their attitudes about their dental care provider and staff (Satisfaction with Care Scale).

The implications of these findings can inform theory and future interventions to improve access to care. Most importantly, parental perceived need should be recognized as a barrier to care in Margolis's theoretical model. Parents who are unaware of the need for regular preventive dental care may well experience a personal barrier to care seeking. If they do not know that children require at least annual dental care, they may not perceive a need and will not 
take their child to the dentist. The blending of Margolis's and Pavuluri's models could provide a more useful theory of parental care seeking. Interventions that raise the level of parent's awareness of the need for dental care, either through education or examination of the child and referral, could increase use of services and, ultimately, health outcomes.

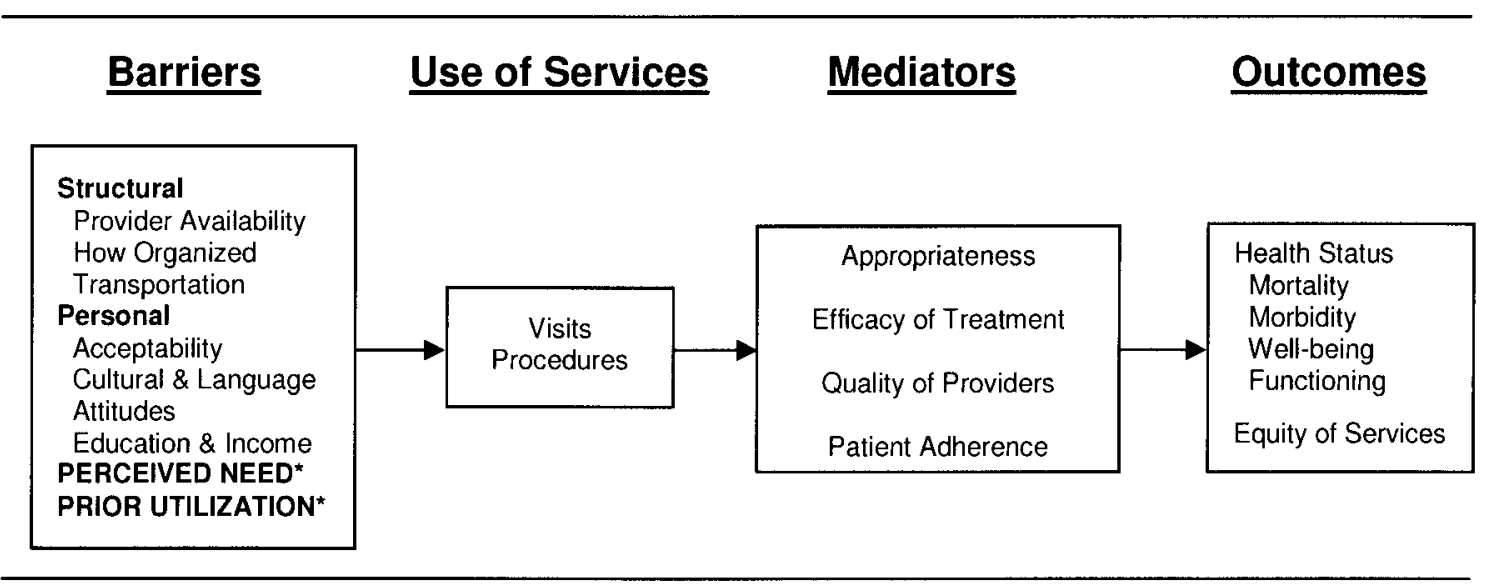

Figure 6. Model of Access to Personal Healthcare Services (Margolis et al., 1995). (Modified for Medicaid Eligible Parents and Children ${ }^{\star}$ )

Margolis's model also could be improved by the inclusion of prior utilization patterns as a personal barrier. Some disadvantaged parents do seem to be able to obtain dental care for their children despite numerous obstacles. Interventions based on Margolis's Access to Care Model could target only parents who had not previously utilized care for their child, thereby conserving research and/or public health resources.

In summary, the findings of this study have added to the knowledge of factors that influence parental care seeking and that can improve the theories of access to care. Successful intervention will be based on recognition of barrier factors and impacting them appropriately. Additional research is needed to 
determine how these theories are supported by interventions in larger and more diverse populations.

\section{Implications for Interventions to Improve Disadvantaged Children's Oral Health}

Although the case manager intervention was significantly effective in increasing dental care utilization only for children who had not recently been to the dentist, who were at the lowest income levels, and whose parents completed study activities, a great deal was learned from the study that can assist in the design and conduct of future studies. Lessons can be learned concerning subject recruitment, case manager characteristics, minimizing attrition, monitoring data collection, and greater involvement of dental professionals and community leaders. These issues will be discussed in greater detail in this section.

1. Subject Selection. A limitation of this study is that the research team unknowingly recruited and enrolled some parents who were already routine Utilizers of dental care for their children. This occurred due to HIPAA privacy requirements that required the investigators to rely on Medicaid administrator personnel to examine utilization records to randomly select potential study subjects. Furthermore, even after potential subjects had signed a HIPAA authorization, the research team did not request Medicaid records to verify their utilization history prior to consenting them for the study, and instead only obtained Medicaid utilization records retrospectively at study end. As a result, 
study resources were expended on subjects who apparently did not require assistance in obtaining dental care for their children.

In the future, this problem could be avoided by seeking the assistance of the Medicaid administrator in obtaining utilization data on potential study subjects who have signed HIPAA authorizations prior to consenting and enrolling them in the study. This simple act would ensure that the entire study sample will comprise parents and children who could benefit the most from interventions. An entire sample of prior Non-Utilizers also would assure that power analyses and sample size estimates to test the effect of the intervention would be accurate.

Alternative methods of sampling such as recruiting families directly from the community or schools should be explored. These sampling methods would require significantly greater financial resources due to increased personnel costs and may require more time to implement. The study subjects, however, would be more representative of the population and study results would be more generalizable.

2. Case Manager Characteristics. The case manager for this study, a young Caucasian male, was not matched by gender or race to the study parents. Although we did not qualitatively assess the impact of this factor on the intervention subject participation, it is possible that this diminished the potential for a good relationship between the subjects and the case manager. The African American female parents may well have related to and cooperated better with a case manager who was of the same race and gender. In future studies it may be beneficial to make efforts to match the case manager to the study subjects to 
improve study outcomes. Most importantly, subjects should be enrolled prior to selection of the case manager to permit matching the manager with the subjects on race and gender.

Throughout the study, the case manager reported to the investigators that the study subjects often assumed that he was a dental professional and asked him to provide dental advice and sometimes dental examinations. He stated that he believed if he had the ability to examine a child's teeth and tell the parents that the child definitely needed care that the parent would have been more likely to let him assist with obtaining dental treatment. In the future, consideration could be given to selecting dental hygienists as case managers so that a brief oral examination could be conducted to document dental needs and provide parents with an assessment of the child's need for dental care.

3. Attrition. The $40 \%$ attrition in this study is in line with published reports of $20 \%$ to $67 \%$ attrition in other well-designed home visiting programs (Gomby, 1999). Gomby states that "families leave for a variety of reasons, including mobility out of the community, lack of interest, and, perhaps, a belief that they have already derived as much benefit as they can from the program" (p. 41). Methods to reduce attrition, including more rigorous follow-up, a smaller case load for the home visitors and engaging the families in sites other than the home have been recommended. Attrition, however, is a consistent problem in home visitation programs and continues to threaten internal and external validity of study results. 
4. Monitoring Intervention Process Data Collection. The researcher learned that training is as important as monitoring and supervising the case manager. Minimal training in data collection was provided initially, and its importance may not have been stressed to the case manager in evaluating the intervention implementation. Future studies should include intensive training and continuous monitoring of data collection and quality.

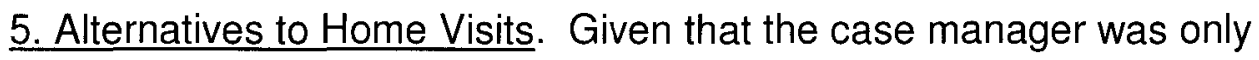
able to engage with and access the home of $50 \%$ of the intervention families, it is worth considering alternative methods of providing the intervention content other than mailing written materials to the parents. There may be opportunities to meet with families at school, church, or other community settings. How this could be accomplished would require additional research, perhaps with focus groups and/or a pilot study.

6. Practice and Community Involvement. Although there were four dental practices participating in the study and the Medicaid dental administrator was closely involved in study activities, greater involvement of the community may have improved program outcomes. Other demonstration projects have enlisted the support of medical practices (dela Cruz et al., 2004; Rozier et al., 2003), schools (Melvin, 2006), and public health nurses (Jack et al., 2005) to provide support and referral. It is recommended that researchers work toward a community context where support for all parents is the norm (Daro \& Harding, 1999). 


\section{Conclusions}

The Parental Help Seeking for Dental Care project sought to determine if a case manager intervention could increase dental care utilization by disadvantaged children. It was hoped that a secondary analysis of data from the study would elucidate factors that would predict utilization or identify certain subgroups of study subjects who benefited more from the intervention than others. The results of the dissertation analyses are important because interventions to reduce oral health disparities will be most effective if they target parents who need assistance the most.

Although there was no significant positive effect of the case manager intervention on increasing utilization in the entire sample, the more detailed analyses of subjects revealed significant positive effects of the intervention. Families who needed the most assistance in accessing dental care, such as those who had not routinely obtained dental care in the past, those with the lowest income, and those with the youngest children benefited the most. This research suggests that the theoretical model and case manager intervention may have a significant impact on the poorest families and families with younger children. The study results may thus be viewed as positive and the lessons learned may benefit future research and clinical practice to reduce oral health disparities.

The theoretical implications of the study results may have an impact on the design of future dental case manager interventions. Margolis's Model of Access to Care could be improved by the addition of utilization history and 
parental perceived need for treatment as barriers to the use of services.

Research is needed to determine if interventions designed to impact these new barriers in Margolis's model support this addition to theory to improve oral health outcomes in disadvantaged children.

Finally, the design, conduct, and secondary data analyses of this study have provided the researcher with invaluable training and experience in biobehavioral and intervention research. From this dissertation it is evident that, despite the best study design and plans, problems and issues will emerge during any study which, with hindsight, could have been foreseen and avoided. Most importantly, this experience has proven that research is an on-going learning process and that a collaborative team approach is vital to the success of any study. 


\section{REFERENCES}

Aday, L. A., \& Andersen, R. (1974). A framework for the study of access to medical care. Health Serv Res, 9(3), 208-220.

Allukian, M., Jr. (2000). The neglected epidemic and the surgeon general's report: a call to action for better oral health. Am J Public Health, 90(6), 843-845.

Ashton, C. M., Haidet, P., Paterniti, D. A., Collins, T. C., Gordon, H. S., O'Malley, K., et al. (2003). Racial and ethnic disparities in the use of health services: bias, preferences, or poor communication? J Gen Intern Med, 18(2), 146152.

Banoczy, J., \& Marthaler, T. M. (2004). [History of fluoride prevention: successes and problems (literature review)]. Fogorv Sz, 97(1), 3-10.

Barlow, A., Varipatis-Baker, E., Speakman, K., Ginsburg, G., Friberg, I., Goklish, N., et al. (2006). Home-visiting intervention to improve child care among American Indian adolescent mothers: a randomized trial. Arch Pediatr Adolesc Med, 160(11), 1101-1107.

Bedell, J. R., Cohen, N. L., \& Sullivan, A. (2000). Case management: the current best practices and the next generation of innovation. Community Ment Health J, 36(2), 179-194.

Black, M. M., Bentley, M. E., Papas, M. A., Oberlander, S., Teti, L. O., McNary, $S$., et al. (2006). Delaying second births among adolescent mothers: a randomized, controlled trial of a home-based mentoring program. Pediatrics, 118(4), e1087-1099.

Bradley, E. H., McGraw, S. A., Curry, L., Buckser, A., King, K. L., Kasl, S. V., et al. (2002). Expanding the Andersen model: the role of psychosocial factors in long-term care use. Health Serv Res, 37(5), 1221-1242.

Burgess, D. J., Fu, S. S., \& van Ryn, M. (2004). Why do providers contribute to disparities and what can be done about it? J Gen Intern Med, 19(11), 1154-1159.

Butters, J. W., D. (2000). Report on the Colgate Kids Program. Louisville, Kentucky: University of Louisville School of Dentistry. 
Byrd, M. E. (2006). Social exchange as a framework for client-nurse interaction during public health nursing maternal-child home visits. Public Health Nurs, 23(3), 271-276.

Charmaz, K. (1983). Contemporary Field Research: A Collection of Readings. Boston, MA: Little, Brown and Company.

Cohen, S., Kamarck, T., \& Mermelstein, R. (1983). A global measure of perceived stress. J Health Soc Behav, 24(4), 385-396.

Cohen, S., \& Williamson, G. (1988). Perceived Stress in a probability sample of the United States. In S. Spacapan \& S. Oskamp (Eds.), The Social Psychology of Health. Newbury Park, CA: Sage.

Coleman, P., \& Karrakere, K. (2003). Maternal Self-Efficacy Beliefs, Competence in Parenting, and Toddlers' Behavior and Developmental Status. Infant Mental Health Journal, 24(2), 126-148.

Corah, N. L. (1969). Development of a dental anxiety scale. J Dent Res, 48(4), 596.

Crohbach, L. (1987). Statistical tests for moderator variables: flaws in analysis recently proposed. Psychol Bull, 102, 414-417.

Cuthbert, M. I., \& Melamed, B. G. (1982). A screening device: children at risk for dental fears and management problems. ASDC J Dent Child, 49(6), 432436.

Daro, D. A., \& Harding, K. A. (1999). Healthy Families America: using research to enhance practice. Future Child, 9(1), 152-178.

Davidson, P. L., Cunningham, W. E., Nakazono, T. T., \& Andersen, R. M. (1999). Evaluating the effect of usual source of dental care on access to dental services: comparisons among diverse populations. Med Care Res Rev, 56(1), 74-93.

Davies, A. R., \& Ware, J. E., Jr. (1981). Measuring patient satisfaction with dental care. Soc Sci Med [A], 15(6), 751-760.

Davies, A. R. W., JE, Jr. (1982). Development of a dental satisfaction questionnaire for the health insurance experiment. Santa Monica, CA: The Rand Corporation.

Dawson, B., \& Trapp, R. (2001). Basic \& Clinical Biostatistics (3rd ed.). New York, NY: McGraw-Hill. 
dela Cruz, G. G., Rozier, R. G., \& Slade, G. (2004). Dental screening and referral of young children by pediatric primary care providers. Pediatrics, 114(5), e642-652.

Dey, A. N., \& Bloom, B. (2005). Summary Health Statistics for U.S. Children: National Health Interview Survey, 2003. Hyattsville, MD: US Department of Health and Human Services, Centers for Disease control, National Center for Health Statistics NCHS.

DHHS. (2000). Oral Health in America: A Report of the Surgeon General: National Institute of Dental \& Craniofacial Research.

DHHS, U. S. (2007). Health Professional Shortage Areas. Jefferson County Kentucky: U.S. Department of Health and Human Services, Health Resources and Services Administration, Bureau of Health Professions.

Donovan, J. W. (1977). Randomised controlled trial of anti-smoking advice in pregnancy. Br J Prev Soc Med, 31(1), 6-12.

Edelstein. (2002). Disparities in oral health and access to care: findings of national surveys. Ambul Pediatr, 2(2 Suppl), 141-147.

Edelstein, B., Vargas, C. M., Candelaria, D., \& Vemuri, M. (2006). Experience and policy implications of children presenting with dental emergencies to US pediatric dentistry training programs. Pediatr Dent, 28(5), 431-437.

Edelstein, B. L., \& Douglass, C. W. (1995). Dispelling the myth that 50 percent of U.S. schoolchildren have never had a cavity. Public Health Rep, 110(5), 522-530; discussion 521, 531-523.

Eklund, S. A., Pittman, J. L., \& Clark, S. J. (2003). Michigan Medicaid's Healthy Kids Dental program: an assessment of the first 12 months. J Am Dent Assoc, 134(11), 1509-1515.

Elder, J. P., \& Salgado, R. (1988). The well baby lottery: motivational procedures for increasing attendance at maternal and child health clinics. Int $J$ Health Serv, 18(1), 165-171.

Felice, M. E., Granados, J. L., Ances, I. G., Hebel, R., Roeder, L. M., \& Heald, F. P. (1981). The young pregnant teenager. Impact of comprehensive prenatal care. J Adolesc Health Care, 1(3), 193-197.

Goldberg, D., \& Huxley, P. (1980). Mental Illness in the community: The pathway to psychiatric care. London: Travisock Publications.

Gomby, D. S. (1999). Understanding evaluations of home visitation programs. Future Child, 9(1), 27-43. 
Graham, J. W., \& Donaldson, S. I. (1993). Evaluating Interventions With Differential Attrition - The Importance Of Nonresponse Mechanisms And Use Of Follow-Up Data. Journal Of Applied Psychology, 78(1), 119-128.

Greene-McIntyre, M., Finch, M. H., \& Searcy, J. (2003). Smile Alabama! Initiative: interim results from a program to increase children's access to dental care. J Rural Health, 19 Suppl, 407-415.

Grembowski, D. (2001). The Practice of Program Evaulation. Thousand Oaks, CA: Sage Publications, Inc.

Grembowski, D., \& Milgrom, P. M. (2000). Increasing access to dental care for medicaid preschool children: the Access to Baby and Child Dentistry (ABCD) program. Public Health Rep, 115(5), 448-459.

Gross, G. J., \& Howard, M. (2001). Mothers' decision-making processes regarding health care for their children. Public Health Nurs, 18(3), 157168.

Guay, A. H. (2004). Access to dental care: solving the problem for underserved populations. J Am Dent Assoc, 135(11), 1599-1605; quiz 1623.

Guthrie, B. J., Young, A. M., Williams, D. R., Boyd, C. J., \& Kintner, E. K. (2002). African American girls' smoking habits and day-to-day experiences with racial discrimination. Nurs Res, 51(3), 183-190.

Guyll, M., Matthews, K. A., \& Bromberger, J. T. (2001). Discrimination and unfair treatment: relationship to cardiovascular reactivity among African American and European American women. Health Psychol, 20(5), 315325.

Halfon, N., Inkelas, M., \& Wood, D. (1995). Nonfinancial barriers to care for children and youth. Annu Rev Public Health, 16, 447-472.

Hansen, W. B., Collins, L. M., Malotte, C. K., Johnson, C. A., \& Fielding, J. E. (1985). Attrition In Prevention Research. Journal Of Behavioral Medicine, $8(3), 261-275$.

Haugejorden, O., \& Birkeland, J. M. (2002). Evidence for reversal of the caries decline among Norwegian children. Int J Paediatr Dent, 12(5), 306-315.

Healthy Families America. (2001). Critical Elements. Retrieved April 9, 2007, from

http://www.healthyfamiliesamerica.org/downloads/critical_elements_ration ale.pdf 
Holmbeck, G. N. (2002). Post-hoc probing of significant moderational and mediational effects in studies of pediatric populations. J Pediatr Psychol, 27(1), 87-96.

Hosmer, D., \& Lemeshow, S. (2000). Applied Logistic Regression (2nd ed.). Hoboken, NJ: John Wiley \& Sons, Inc.

Hosmer, D. W., \& Lemeshow, S. (2002). Applied Logistic Regression (2nd ed.): John Wiley \& Sons.

Huang, C. Y., Liao, H. Y., \& Chang, S. H. (1998). Social desirability and the clinical self-report inventory: methodological reconsideration. $J$ Clin Psychol, 54(4), 517-528.

Jaccard, J., Turrisi, R., \& Wan, C. K. (1990). Interaction Effects in Multiple Regression. Newbury Park, CA: Sage Publications.

Jack, S. M., DiCenso, A., \& Lohfeld, L. (2005). A theory of maternal engagement with public health nurses and family visitors. J Adv Nurs, 49(2), 182-190.

Johnson, K., Bryant, D. D., Collins, D. A., Noe, T. D., Strader, T. N., \& Berbaum, M. (1998). Preventing and reducing alcohol and other drug use among high-risk youths by increasing family resilience. Soc Work, 43(4), 297-308.

Kaakko, T., Skaret, E., Getz, T., Hujoel, P., Grembowski, D., Moore, C. S., et al. (2002). An ABCD program to increase access to dental care for children enrolled in Medicaid in a rural county. J Public Health Dent, 62(1), 45-50.

Karlamangla, A. S., Singer, B. H., Williams, D. R., Schwartz, J. E., Matthews, K. A., Kiefe, C. I., et al. (2005). Impact of socioeconomic status on longitudinal accumulation of cardiovascular risk in young adults: the CARDIA Study (USA). Soc Sci Med, 60(5), 999-1015.

Karlsen, S., \& Nazroo, J. Y. (2002). Relation between racial discrimination, social class, and health among ethnic minority groups. Am J Public Health, 92(4), 624-631.

Karlsen, S., Nazroo, J. Y., \& Stephenson, R. (2002). Ethnicity, environment and health: putting ethnic inequalities in health in their place. Soc Sci Med, 55(9), 1647-1661.

Kelly, S. E., Binkley, C. J., Neace, W. P., \& Gale, B. S. (2005). Barriers to careseeking for children's oral health among low-income caregivers. Am J Public Health, 95(8), 1345-1351.

Kitzman, H., Olds, D. L., Henderson, C. R., Jr., Hanks, C., Cole, R., Tatelbaum, R., et al. (1997a). Effect of prenatal and infancy home visitation by nurses 
on pregnancy outcomes, childhood injuries, and repeated childbearing. A randomized controlled trial. JAMA, 278(8), 644-652.

Kitzman, H., Olds, D. L., Sidora, K., Henderson, C. R., Jr., Hanks, C., Cole, R., et al. (2000). Enduring effects of nurse home visitation on maternal life course: a 3-year follow-up of a randomized trial. JAMA, 283(15), 19831989.

Kitzman, H. J., Cole, R., Yoos, H. L., \& Olds, D. (1997b). Challenges experienced by home visitors: A qualitative study of program implementation. Journal of Community Psychology, 25(1), 95.

Kozol, J. (1991). Savage Inequalities: Children in America's Schools. New York, New York.

Kraemer, H. C., Wilson, G. T., Fairburn, C. G., \& Agras, W. S. (2002). Mediators and moderators of treatment effects in randomized clinical trials. Arch Gen Psychiatry, 59(10), 877-883.

Lam, M., Riedy, C. A., \& Milgrom, P. (1999). Improving access for Medicaidinsured children: focus on front-office personnel. J Am Dent Assoc, 130(3), 365-373.

Landrine, H., \& Klonoff, E. A. (2000). Racial discrimination and cigarette smoking among Blacks: findings from two studies. Ethn Dis, 10(2), 195-202.

Landrine, H., Klonoff, E. A., \& Alcaraz, R. (1996). Asking age and identification may decrease minors' access to tobacco. Prev Med, 25(3), 301-306.

Lantz, P. M., Lynch, J. W., House, J. S., Lepkowski, J. M., Mero, R. P., Musick, M. A., et al. (2001). Socioeconomic disparities in health change in a longitudinal study of US adults: the role of health-risk behaviors. Soc Sci Med, 53(1), 29-40.

Lauver, D. (1992). A theory of care-seeking behavior. Image J Nurs Sch, 24(4), 281-287.

LaValle, P. S., Glaros, A., Bohaty, B., \& McCunniff, M. (2000). The Effect of Parental Stress on the Oral Health of Children. Journal of Clinical Psychology in Medical Settings, 7(4), 197.

Litt, M. D., Reisine, S., \& Tinanoff, N. (1995). Multidimensional causal model of dental caries development in low-income preschool children. Public Health Rep, 110(5), 607-617.

Macek, M. D., Wagner, M. L., Goodman, H. S., Manz, M. C., \& Marrazzo, I. D. (2005). Dental visits and access to dental care among Maryland schoolchildren. J Am Dent Assoc, 136(4), 524-533. 
Margolis, P. A., Carey, T., Lannon, C. M., Earp, J. L., \& Leininger, L. (1995). The rest of the access-to-care puzzle. Addressing structural and personal barriers to health care for socially disadvantaged children. Arch Pediatr Adolesc Med, 149(5), 541-545.

Margolis, P. A., Stevens, R., Bordley, W. C., Stuart, J., Harlan, C., Keyes-Elstein, L., et al. (2001). From concept to application: the impact of a communitywide intervention to improve the delivery of preventive services to children. Pediatrics, 108(3), E42.

Marthaler, T. M. (2004). Changes in dental caries 1953-2003. Caries Res, 38(3), 173-181.

McAnarney, E. R., Roghmann, K. J., Adams, B. N., Tatelbaum, R. C., Kash, C., Coulter, M., et al. (1978). Obstetric, neonatal, and psychosocial outcome of pregnant adolescents. Pediatrics, 61(2), 199-205.

McDonald, E. C., Pollitt, E., Mueller, W., Hsueh, A. M., \& Sherwin, R. (1981). The Bacon Chow study: maternal nutrition supplementation and birth weight of offspring. Am J Clin Nutr, 34(10), 2133-2144.

Melvin, C. S. (2006). A collaborative community-based oral care program for school-age children. Clin Nurse Spec, 20(1), 18-22.

Milgrom, P., Jie, Z., Yang, Z., \& Tay, K. M. (1994). Cross-cultural validity of a parent's version of the Dental Fear Survey Schedule for children in Chinese. Behav Res Ther, 32(1), 131-135.

Milgrom, P., Mancl, L., King, B., Weinstein, P., Wells, N., \& Jeffcott, E. (1998). An explanatory model of the dental care utilization of low-income children. Med Care, 36(4), 554-566.

Mofidi, M., Rozier, R. G., \& King, R. S. (2002). Problems with access to dental care for Medicaid-insured children: what caregivers think. Am J Public Health, 92(1), 53-58.

Mouradian, W. E. (2001). The face of a child: children's oral health and dental education. J Dent Educ, 65(9), 821-831.

Mouradian, W. E., Wehr, E., \& Crall, J. J. (2000). Disparities in children's oral health and access to dental care. JAMA, 284(20), 2625-2631.

Nakazono, T. T., Davidson, P. L., \& Andersen, R. M. (1997). Oral health beliefs in diverse populations. Adv Dent Res, 11(2), 235-244.

Nazroo, J. Y. (2003). The structuring of ethnic inequalities in health: economic position, racial discrimination, and racism. Am J Public Health, 93(2), 277284. 
NCHS, N. C. f. H. S. (2004). Health, United States, 2004 With Chartbooks on Trends in the Health of Americans. Retrieved July 6, 2005, from http://www.cdc.gov/nohss/DSMain.htm\#nhanes

Newton, J. T., \& Buck, D. J. (2000). Anxiety and pain measures in dentistry: a guide to their quality and application. J Am Dent Assoc, 131(10), 14491457.

Newton, J. T., Thorogood, N., Bhavnani, V., Pitt, J., Gibbons, D. E., \& Gelbier, S. (2001). Barriers to the use of dental services by individuals from minority ethnic communities living in the United Kingdom: findings from focus groups. Prim Dent Care, 8(4), 157-161.

NIDCR. (February 2002). A Plan to Eliminate Craniofacial, Oral and Dental Health Disparities. Besthesa, MD: National Institute of Dental and Craniofacial Research.

Niederhauser, V. P., Baruffi, G., \& Heck, R. (2001). Parental decision-making for the varicella vaccine. J Pediatr Health Care, 15(5), 236-243.

Nowak, A. J., \& Casamassimo, P. S. (2002). The dental home: a primary care oral health concept. J Am Dent Assoc, 133(1), 93-98.

Olds, D., Henderson, C. R., Jr., Cole, R., Eckenrode, J., Kitzman, H., Luckey, D., et al. (1998). Long-term effects of nurse home visitation on children's criminal and antisocial behavior: 15-year follow-up of a randomized controlled trial. JAMA, 280(14), 1238-1244.

Olds, D., Henderson, C. R., Jr., Kitzman, H., \& Cole, R. (1995). Effects of prenatal and infancy nurse home visitation on surveillance of child maltreatment. Pediatrics, 95(3), 365-372.

Olds, D. L. (1992). Home visitation for pregnant women and parents of young children. Am J Dis Child, 146(6), 704-708.

Olds, D. L. (2002). Prenatal and infancy home visiting by nurses: from randomized trials to community replication. Prev Sci, 3(3), 153-172.

Olds, D. L., Eckenrode, J., Henderson, C. R., Jr., Kitzman, H., Powers, J., Cole, R., et al. (1997). Long-term effects of home visitation on maternal life course and child abuse and neglect. Fifteen-year follow-up of a randomized trial. JAMA, 278(8), 637-643.

Olds, D. L., Henderson, C. R., Jr., \& Kitzman, H. (1994). Does prenatal and infancy nurse home visitation have enduring effects on qualities of parental caregiving and child health at 25 to 50 months of life? Pediatrics, 93(1), 89-98. 
Olds, D. L., \& Kitzman, H. (1990). Can home visitation improve the health of women and children at environmental risk? Pediatrics, 86(1), 108-116.

Olds, D. L., Kitzman, H., Cole, R., Robinson, J., Sidora, K., Luckey, D. W., et al. (2004a). Effects of nurse home-visiting on maternal life course and child development: age 6 follow-up results of a randomized trial. Pediatrics, 114(6), 1550-1559.

Olds, D. L., Robinson, J., O'Brien, R., Luckey, D. W., Pettitt, L. M., Henderson, C. R., Jr., et al. (2002). Home visiting by paraprofessionals and by nurses: a randomized, controlled trial. Pediatrics, 110(3), 486-496.

Olds, D. L., Robinson, J., Pettitt, L., Luckey, D. W., Holmberg, J., Ng, R. K., et al. (2004b). Effects of home visits by paraprofessionals and by nurses: age 4 follow-up results of a randomized trial. Pediatrics, 114(6), 1560-1568.

Olivan, G. (2003). Untreated dental caries is common among 6 to 12-year-old physically abused/neglected children in Spain. Eur J Public Health, 13(1), 91-92.

Pavuluri, M. N., Luk, S. L., \& McGee, R. (1996). Help-seeking for behavior problems by parents of preschool children: a community study. J Am Acad Child Adolesc Psychiatry, 35(2), 215-222.

Pettigrew, T. F., \& Meertens, R. W. (1995). Subtle and blatant prejudice in western Europe. European Journal of Social Psychology, 25, 57-75.

Prevent Child Abuse America. (2003). Health Families America. Retrieved April 9, 2007, from http://www.preventchildabuse.org/index.shtml

Quinonez, R. B., Keels, M. A., Vann, W. F., Jr., Mclver, F. T., Heller, K., \& Whitt, J. K. (2001). Early childhood caries: analysis of psychosocial and biological factors in a high-risk population. Caries Res, 35(5), 376-383.

Rozier, R. G., Sutton, B. K., Bawden, J. W., Haupt, K., Slade, G. D., \& King, R. S. (2003). Prevention of early childhood caries in North Carolina medical practices: implications for research and practice. J Dent Educ, 67(8), 876885.

Rush, D., Stein, Z., \& Susser, M. (1980). A randomized controlled trial of prenatal nutritional supplementation in New York City. Pediatrics, 65(4), 683-697.

Schulz, A., Israel, B., Williams, D., Parker, E., Becker, A., \& James, S. (2000). Social inequalities, stressors and self reported health status among African American and white women in the Detroit metropolitan area. Soc Sci Med, 51(11), 1639-1653. 
Sexton, M., \& Hebel, J. R. (1984). A clinical trial of change in maternal smoking and its effect on birth weight. JAMA, 251(7), 911-915.

Shi, L., \& Stevens, G. D. (2005). Disparities in access to care and satisfaction among U.S. children: the roles of race/ethnicity and poverty status. Public Health Rep, 120(4), 431-441.

Shute, J. L., \& Judge, K. (2005). Evaluating "Starting Well", the Scottish national demonstration project for child health: outcomes at six months. J Prim Prev, 26(3), 221-240.

Skaret, E., Milgrom, P., Raadal, M., \& Grembowski, D. (2001). Factors influencing whether low-income mothers have a usual source of dental care. ASDC J Dent Child, 68(2), 136-139, 142.

Slifkin, R. T., Silberman, P., \& Freeman, V. (2004). Moving from Medicaid to North Carolina Health Choice: changes in access to dental care for NC children. NC Med J, 65(1), 6-11.

Stevens, R., Margolis, P., Harlan, C., \& Bordley, C. (1996). Access to care: a home visitation program that links public health nurses, physicians, mothers, and babies. J Community Health Nurs, 13(4), 237-247.

Stine, O. C., \& Kelley, E. B. (1970). Evaluation of a school for young mothers. The frequency of prematurity among infants born to mothers under 17 years of age, according to the mother's attendance of a special school during pregnancy. Pediatrics, 46(4), 581-587.

Szilagyi, P. G., Dick, A. W., Klein, J. D., Shone, L. P., Zwanziger, J., \& Mclnerny, T. (2004). Improved access and quality of care after enrollment in the New York State Children's Health Insurance Program (SCHIP). Pediatrics, 113(5), e395-404.

Tabachnick, B., \& Fidell, L. (2001). Using Multivariate Statistics (4th ed.). Needham Heights, MA: Allyn \& Bacon.

Tang, C., Quinonez, R. B., Hallett, K., Lee, J. Y., \& Whitt, J. K. (2005). Examining the association between parenting stress and the development of early childhood caries. Community Dent Oral Epidemiol, 33(6), 454-460.

Tennant, M., Namjoshi, D., Silva, D., \& Codde, J. (2000). Oral health and hospitalization in Western Australian children. Aust Dent J, 45(3), 204207.

Thomas, C. W., \& Primosch, R. E. (2002). Changes in incremental weight and well-being of children with rampant caries following complete dental rehabilitation. Pediatr Dent, 24(2), 109-113. 
Thomson, W. M., Poulton, R., Milne, B. J., Caspi, A., Broughton, J. R., \& Ayers, K. M. (2004). Socioeconomic inequalities in oral health in childhood and adulthood in a birth cohort. Community Dent Oral Epidemiol, 32(5), 345353.

Tough, S. C., Johnston, D. W., Siever, J. E., Jorgenson, G., Slocombe, L., Lane, C., et al. (2006). Does supplementary prenatal nursing and home visitation support improve resource use in a universal health care system? A randomized controlled trial in Canada. Birth, 33(3), 183-194.

U.S. Department of Health \& Human Services. (2005). THE 2005 HHS POVERTY GUIDELINES. from http://aspe.hhs.gov/poverty/figures-fed-reg.shtml

van Ryn, M. (2002). Research on the provider contribution to race/ethnicity disparities in medical care. Med Care, 4O(1 Suppl), |140-151.

van Ryn, M., \& Burke, J. (2000). The effect of patient race and socio-economic status on physicians' perceptions of patients. Soc Sci Med, 50(6), 813828.

van Ryn, M., \& Fu, S. S. (2003). Paved with good intentions: do public health and human service providers contribute to racial/ethnic disparities in health? Am J Public Health, 93(2), 248-255.

Vargas, C. M., Monajemy, N., Khurana, P., \& Tinanoff, N. (2002). Oral health status of preschool children attending Head Start in Maryland, 2000. Pediatr Dent, 24(3), 257-263.

Vargas, C. M., \& Ronzio, C. R. (2006). Disparities in early childhood caries. BMC Oral Health, 6 Suppl 1, S3.

Wikipedia. (2007). Wikipedia, the free encyclopedia: Wikimedia Foundation, Inc.

Williams, D. R., Neighbors, H. W., \& Jackson, J. S. (2003). Racial/ethnic discrimination and health: findings from community studies. Am J Public Health, 93(2), 200-208.

Yen, I. H., Ragland, D. R., Greiner, B. A., \& Fisher, J. M. (1999a). Racial discrimination and alcohol-related behavior in urban transit operators: findings from the San Francisco Muni Health and Safety Study. Public Health Rep, 114(5), 448-458.

Yen, I. H., Ragland, D. R., Greiner, B. A., \& Fisher, J. M. (1999b). Workplace discrimination and alcohol consumption: findings from the San Francisco Muni Health and Safety Study. Ethn Dis, 9(1), 70-80.

Zimet, G. (1988). The Multidimensional Scale of Perceived Social Support. Journal of Personality Assessment, 52, 30-41. 


\section{APPENDIX 1}

\section{Telephone Survey Pre-Test and Pilot Testing}

Construction. The telephone survey was constructed to collect demographic information, self-reported dental utilization data, and data on psychosocial factors as described in the Summary of Proposed Variables (Table 1). The time required to complete the survey was limited to 30 minutes to maximize response rate and ease response burden. A patterned series of responses, fatigue and disinterest can jeopardize the reliability of any survey instrument. Approaches to minimizing the risk of patterned responses was used, such as changing the order of fixed responses from question to question and using questions that vary substantially in terms of wording or length.

Instrument Pretest Selection and Data Collection. A pretest was used to determine the clarity, comprehensiveness and acceptability of the research instrument. The pretest also provided estimates of the time required to complete the instrument and the cost of data collection.

For the pre-test, The Pacific Institute for Research and Evaluation recruited a random sample of 60 of the individuals that participated in the focus groups described previously (Kelly et al., 2005). The instrument was reviewed and approved by the University of Louisville's Institutional Review Board (IRB) and the Kentucky Cabinet for Health and Family Services.

Pretest Protocol. The Pacific Institute for Research and Evaluation provided interviewers with a list of telephone numbers to contact potential study candidates. An IRB-approved preamble was read to all potential study participants that identified the researchers conducting the study and the purpose of the study, provided an estimate of the time required to complete the survey, assured confidentiality, and requested informed consent.

After obtaining informed consent, the interviewer asked a screening question to determine if the candidate met the inclusion criteria for the study. In order to be included, a child must not have been treated for dental problems nor had their teeth cleaned during the previous two years. Potential participants were asked, "Has your child been treated for any dental problems or had a tooth cleaning during the past two years?" If the answer was negative (indicating low utilization of dental care), the parent was included in the telephone survey. If the parent answered in the affirmative, which would indicate moderate to high utilization, they were thanked for their time and not included in the survey.

Telephone Instrument Refinement. Based on the pretest analysis, the survey instrument was finalized. Poorly worded questions were identified and skip patterns verified. In addition, bivariate correlation results were reviewed to ascertain potential items in specified theoretical composite variables that do not correlate with the overall cluster of items. A final Computer Assisted Telephone Interview (CATI) version of the instrument was constructed after this pilot-test analysis. 


\section{APPENDIX 2}

\section{Parental Help Seeking - Intervention Outline}

At the end of the baseline telephone survey, subjects will be 1) randomly assigned to the Treatment Group and will receive the Intervention immediately or 2) randomly assigned to the Control Group and placed on a wait list. The Control Group subjects will receive the intervention after the subjects in the Treatment Group have completed the intervention.

Subjects in the Treatment Group will be told they have been randomly selected to receive some additional services. The following information was provided to intervention subjects by the telephone interviewer to assist in answering any questions.

\section{What additional services will I receive?}

Our dental coordinator, David C., will contact you to set up a short meeting with you and your child at a time and place that is convenient for you. You can have the meeting at your home or in your neighborhood, whatever is best for you.

At the meeting, you will receive free toothbrushes and toothpaste as well as other materials. David will also provide some educational materials and information about the study.

If your child has a dentist, David will assist you in setting up an appointment and arranging transportation if needed. If your child doesn't have a dentist or you would like to try a new dentist, David will also help you set up an appointment and get there.

\section{What happens first at the dentist office?}

The first visit your child will have will not involve anything painful or scary. David will meet you at the dentist office and introduce you to the dentist and staff. Your child will receive an examination and maybe $x$-rays to see what treatment needs to be done.

After your first visit to the dentist, we will call you again for your second telephone interview. You will be mailed $\$ 20.00$ after you complete the second interview. 


\section{What do I have to do after the first visit?}

David will help you in setting up any other dental visits that may need to be made and will help you get there. He will call you to remind you about the appointments the day before and will help you if you have any problems.

After your child has all his/her dental appointments, we will call you for your third and final telephone interview. We will send you $\$ 25.00$ after you complete the third interview.

\section{How long will all this take?}

The three telephone interviews should not take more than 2 hours of your time. David's first meeting with you and your child will take about 30 minutes. Your child's first dental visit may take 1 to 2 hours. Depending on what your child needs, other dental appointments usually take around an hour or two each. 


\section{CURRICULUM VITAE \\ CATHERINE J. BINKLEY, D.D.S., MSPH \\ UNIVERSITY OF LOUISVILLE \\ SCHOOL OF DENTISTRY}

\section{PERSONAL INFORMATION}

May 2007

Place and Date of Birth: Toronto, Ontario, Canada

Citizenship:

U.S.A., Naturalized 1983

Addresses:

University Office: $\quad$ Surgical \& Hospital Dentistry

School of Dentistry

University of Louisville

Louisville, KY 40292

(502) 852-5083

FAX (502) 852-5988

e-mail: cjbink01@louisville.edu

Private Practice: $\quad$ Faculty Private Practice

School of Dentistry

Louisville, KY 40292

(502) 852-540।

\section{ACADEMIC AND ADMINISTRATIVE INFORMATION}

Initial Rank \& Appointment

Instructor

1981

Department of Community Dentistry

Present Rank \& Appointment

Associate Professor

Dept. of Surgical \& Hospital Dentistry

Tenure Status Tenured 


\section{HIGHER EDUCATION}

College/University

Columbia Union College

Takoma Park, MD

1971-1972

Montgomery College

Takoma Park, MD

Assoc. Science Degree (Honors)

1973-1975

University of Maryland

College Park, MD

Pre-Dental

1975-1976

Dental

Baltimore College of Dental Surgery

University of Maryland at Baltimore

D.D.S. (Magna Cum Laude)

1976-1980

Postgraduate

University Hospital/School of Dentistry

University of Louisville

Certificate - General Practice Residency

1980-1981

University of Louisville School of Medicine

1999-2001

Masters of Science in Public Health

University of Louisville School of Public Health

$\mathrm{PhD}$ in Epidemiology and Population Health

2001-present

\section{HONORS, AWARDS, SCHOLARSHIPS AND OTHER RECOGNITION} RECEIVED

Honors

Omicron Kappa Upsilon

National Dental Honor Society - Student Induction

1980

Woman of Achievement 1990 - nomination

Business \& Professional Women's Organization,

Louisville Chapter

American College of Dentists - Fellowship

1993

Phi Kappa Phi Member

2003

Awards

International College of Dentists 
Presidents Initiative for Research

University of Louisville

ULSD Award for Research \& Scholarship

1990

\section{DENTAL LICENSURE INFORMATION}

National Board of Dental Examiners

1980

Northeast Regional Board of Dental Examiners 1980

Southern Regional Board of Dental Examiners 1980

Maryland Board of Dentistry

1981

License \# 7478

Kentucky Board of Dentistry

1981

License \# 5208

\section{PROFESSIONALLY RELATED EMPLOYMENT}

Director, General Practice Residency

School of Dentistry \& University of Louisville Hosp. $\quad$ 1982-2001,2004

Associate Professor, Department of Surgical and

Hospital Dentistry, University of Louisville

1988-present

Director, Advanced General Dentistry

Program, Univ. of Louisville

1989-1992

Private Practice of Dentistry

Faculty Practice Plan, University of Louisville

1981-present

Assistant Professor

Department of Community Dentistry, University of Louisville 1982-1988

Instructor

Department of Community Dentistry

University of Louisville

$1981-1982$

PARTICIPATION IN LEARNED ORGANIZATIONS, PROFESSIONAL ORGANIZATIONS AND COMMITTEES

MEMBERSHIPS:

National

American Dental Association

980-Present

American Association of Dental Schools

1981-Present

American Association of Hospital Dentists

1983-Present

Academy of General Dentistry

1986-1996 


\begin{tabular}{llr}
\multicolumn{2}{l}{ Omicron Kappa Upsilon } & 1980-Present \\
State & American Association for Dental Research & 2004-Present \\
& $\begin{array}{l}\text { Kentucky Dental Association } \\
\text { Kentucky Medical Association }\end{array}$ & 1981-Present \\
Local & 1986-Present \\
& Louisville Dental Society & \\
& Jefferson County Medical Soc. & 1981-Present \\
& 1986-Present
\end{tabular}

APPOINTMENTS:

National

American Association of Dental Schools

Section Secretary, Chairman-elect \& Chairman

Oral Surgery, Anesthesia \& Hospital Dentistry

$1986-1988$

U.S. Department of Health \& Human Services

Bureau of Health Professionals

Advanced General Dentistry Grant Review Committee -

Charter Member

Statutory Provisions Committee

1987-1993

1993

American Dental Association

Commission on Dental Accreditation

Consultant

1988-1998

GPR Advisory Committee Member

1993-1996

GPR Advisory Committee Chair

1996-1998

Residency Review Committee

1998- 2000

For Postdoctoral General Dentistry

American Association of Dental Schools

Council of Hospitals

Administrative Board member

1991-1993

Chair

1993-1994

Harry Bruce Fellowship Selection Committee

1994-1996

University

University Academic Review Council

Review Subcommittee

1988

Graduate Medical Education Committee

1984-1995

Primary Care Center, Clinical Director

1994-2000

Conflict of Interest Task Force

2002-2005

Hospital Appointments

University of Louisville Hospital -Active Staff

1983-Present

Veterans Admin. Med. Center -Attending Staff

1983-Present

Kosair/Children's Hospital-Active Staff

1987-present

-Courtesy Staff

1985-1987 
Norton Hospital -Courtesy Staff

1984-Present

Jewish Hospital -Courtesy Staff

1988-Present

University Hospital -Active Staff

1982-1983

School of Dentistry Committees

Academic Achievement Comm. I 1982

Student Ethics Committee 1982

D.M.D. Admissions Committee 1982-1987

G.P.R. Advisory Committee 1982-1983

Postgraduate Academic Advisory Committee -Chair 1982-2001

Committee to Explore Advanced Dental Education 1984

Faculty Practice Plan Board of Governors 1985-1986

Faculty Senate - Social Committee 1982-1984

Ad Hoc Task Force on Part-Time Faculty 1992-1993

Search Committee - Assoc. Dean for Clinical Affairs 1992

Search Committee - Oral Surgery Faculty 1995-2004

Decanal Review Committee 1996

Quality Assurance Committee 1996

Pre-doctoral Curriculum Committee 1996- 2001

School of Dentistry Dean Search Committee 1998

Student Grievance Committee 2000-2004

TEACHING RESPONSIBILITIES - University of Louisville UNDERGRADUATE

Senior Enrichment Program-CMDY 861 - Assistant Director, supervision and organization of clinical and classroom activities for select senior students 1981-82

Practice Management II-CMDY 825 - Course Director, Classroom and clinical instruction in operative and four-handed dentistry for freshman students 1982

Practice Management V-CMDY 855 - Instruction in Family Practice (TEAM) Clinic where senior dental students developed practice management skills in a comprehensive care clinic 1981-82

Clinical Operative Dentistry I \& II-Rest 851, Rest 853 - Clinical instruction in basic operative and crown and bridge to freshmen, sophomore and senior dental students 1981-82

Practice Management IV-CMDY 843 - Seminar presentations to senior students 1981-82

Practice of Dentistry IV - Clinical instruction during initial operative dentistry procedures, Sophomore - 1982

Principles of Oral Surgery II-OSUR 832 - Lectures to Junior dental students on basic concepts and application of dental implant systems 1987-88 
Behavioral Sciences in Dentistry-IDSC 901 - Seminar presentation to graduate students on special patient care 1986

Student Advisor - Freshman, Junior and Senior dental students - four per year 1982-86, - Junior dental students 1995

Course Director - Implant Dentistry - Senior dental students 1996-2000

\section{GRADUATE}

GENERAL PRACTICE RESIDENCY PROGRAM - Program Director 1982-2001, 2004

ADVANCED GENERAL DENTISTRY PROGRAM - Program Director 1989-1992

\section{BIBLIOGRAPHY:}

\section{Book Chapters}

Binkley, C.J. \& Alpert, B.: Osteointegrated Implants in Ito \& Johnson (Eds.) "Color Atlas of Periodontal Surgery", Binkley, CJ \& Alpert, B.: Espaxs, S.A., 1994

Journals

Willis, D., Hartley, L., Scheetz, J. \& Binkley, C.: "Enhancing Dentist-Patient Communications". Quintessence International 13:1245-50, Nov. 1982

Sipes, R. \& Binkley, C.: "The Use of Formocresol in Endodontics - A Review of the Literature". Quintessence International 17:415-417, July 1986

Sipes, R. \& Binkley, C.J.: "Lumbago del Formocresolo in odontoiatria: un'analisi delle informazioni bibliografiche" Quintessence International, Edizione Italiana, 2:I29-I3I, Febbraio 1987

Binkley, T.K. \& Binkley, C.J., "A Practical Approach to Full Mouth Reconstruction". J. Pros Dent 57:26I-265, March 1987

Binkley, C.J. \& Irvin, T.: "Reinforced Heat-Processed Acrylic Resin Provisional Restorations. J. Pros Dent 57:689-693, June 1987

Mann, W.V. \& Binkley, C.J.: "A Discourse on the Sponsorship of Postdoctoral Education Programs in General Dentistry" J. Dent Ed 5l:287-292, June 1987 
Binkley, T.K. \& Binkley, C.J.: "Porcelain Fused-to-Metal Crowns as Replacements for denture teeth in removable partial denture construction." J. Pros Dent 58:53-56, July 1987

Binkley, C., Verdi, G.V. \& Alpert, B.: "Surgical-prosthetic rehabilitation of the extremely atrophic mandible". Quintessence International $19: 223-227,3,1988$

Binkley, C., Verdi, G.V. \& Alpert, B.: ARiabilitazione chirurgico-prostesica della mandibola fortemente atrofica@ Quintessence International 4:447-451, Maggio 1988

Binkley, C.J.: "Outcomes Assessment in General Practice Residency Programs." Journal of Special Care in Dentistry 17:169-174, Sept./Oct. 1997

Furr L.A., Binkley CJ, McCurren C: "Model to Explain Oral Care Practices in Intensive Care Units" - Accepted, Journal of Advanced Nursing

Binkley C.J., Furr L.A., Carrico R: "National Survey of Oral Care Practices in Intensive Care Units" - American Journal of Infection Control 2004: 32(3);161-169.

Kelly S.E., Binkley C.J., Gale B, Neace W.P. Barriers to Parental Care Seeking Behavior for Children's Oral Health Among Low Income Parents, American Journal of Public Health, August 2005, 95(8):1345-1351

Binkley C.J., Neace W.P., Kitchens D.H., Lewis K.L. Dentist and Staff Attitudes Towards Medicaid and Parents of Medicaid children. Submitted to the Journal of the American Dental Association 2006.

Kitchens D.H., Binkley C.J., Darling D., Wallace D. Helicobacter pylori infection in intellectually and developmentally disabled persons: a review. Accepted for publication in July/August 2007 Special Care in Dentistry.

Abstracts

Campbell, E. \& Binkley, C.: "Senior Enrichment Program". J. Dent Ed:35-36, Jan 1982

Kelly SE, Gale BS, Binkley CJ, Johnson KW, Neace WB. "Barriers to Parental Dental Care Seeking Behavior for Medicaid Children" Presented at International Association for Dental Research annual meeting, March 2004. Journal of Dental Research, 83, Special Issue $A$. 
Binkley CJ, Kitchens DH, Wallace DL. "Oral \& Respiratory Status of Mentally Retarded/Developmentally Disabled Persons." Presented at International Association for Dental Research annual meeting, March 2007.

\section{GRANT AND RESEARCH ACTIVITIES:}

\section{Sponsored - Funded}

U.S. Department of Health \& Human Services Grant \# D30-DHI4030 1986-89

Residency Training in the General Practice of Dentistry General Practice Residency Program $\$ 176,895$

U.S. Department of Health \& Human Services Grant \# 1 D30 DH14041-01 Residency Training in the General Practice of Dentistry Advanced Education in General Dentistry $\$ 314,491$

University of Louisville 1989 Program Enhancement $\$ 36,000$

University of Louisville, Research Incentive Grant 2002

University of Louisville School of Dentistry, Intramural Grant PI, "National Survey of Oral Care Practices in ICUs" 2002 $\$ 3,950$

National Institute for Dental \& Craniofacial Research PI, "Parental Help Seeking for Dental Care" 2002-2005 1R21DE014967-01 \$450,000

National Institute for Dental \& Craniofacial Research Co-PI, "Oral Care and Respiratory Pathogen Colonization" 1R03 DE014879-01A1 $\$ 100,000$

National Institute of Dental \& Craniofacial Research PI, "Oral \& Respiratory Status of Retarded/Disabled Persons" 1R21 DE016477 2004-2006 $\$ 275,000$

National Institute of Dental \& Craniofacial Research Co-PI, "Dental Anxiety, Pain, and Melanocortin-1 Receptors" 1R21 DE016064-01 
National Institute of Dental \& Craniofacial Research

$\mathrm{PI}$, "Chlorhexidine \& Pneumonia in Nursing Home Residents" 1K23DE015760-01 A1

2005-2009

$\$ 507,000$

\section{Pending Funding}

National Institute of Dental \& Craniofacial Research

$\mathrm{PI}$, "Effect of Chlorhexidine on VAP and Mortality in ICU Patients"

1R21DE017706-01 Clinical Trial Planning Grant 2007-2009 $\$ 275,000$

National Institute of Dental \& Craniofacial Research

Investigator, "Oral H. pylori in Intellectually Disabled Persons"

$\mathrm{PI}$, Kitchens

2007-2009

$\$ 275,000$ 